\title{
Symposium on Environmental Chemistry for Securing Water Quality
}

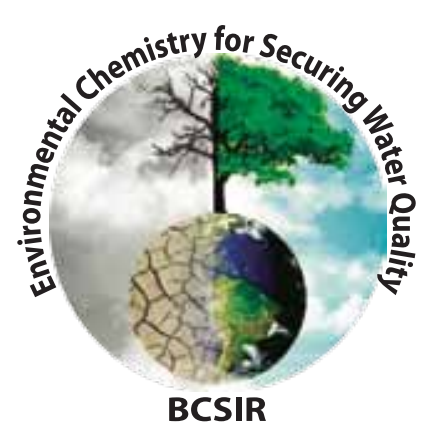

\section{Theme: Water is Life 30 July 2017}

\begin{abstract}
Venue
Bangladesh Council of Scientific and Industrial Research (BCSIR) Dr. Qudrat-I-Khuda Road, Dhanmondi, Dhaka-1205
\end{abstract}

\section{Organized by}

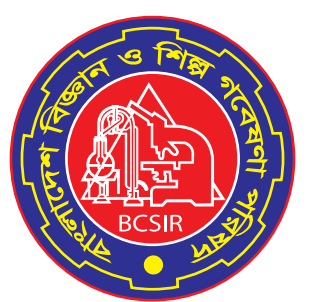

Bangladesh Journal of Scientific and Industrial Research (BJSIR) 


\section{Theme Lecture}

Water crisis: clean water scarcity in Bangladesh A. M. S. Alam 


\title{
Water crisis: clean water scarcity in Bangladesh
}

\author{
A. M. S. Alam \\ Department of Chemistry, University of Dhaka, Dhaka-1000
}

\section{Abstract}

Water issues affect us all from the women who spend hours a day fetching water to political battles over International River to melting icepack and rising sea level. We are all downstream. Worldwide just under 900 million people lack reliable access to safe water that is free from disease and industrial water. And 40 percent do not have access to adequate sanitation facility. The result is one of the world's greatest public health crises: 4,500 children die every day from waterborne diseases, more than from HIV-AIDS, malaria and tuberculosis combined. A robust economy depends on water. So does a thriving ecosystem. Enter politics, fulcrum of the water issue, weighing the fate of economics against the health of individuals and of the environment as a whole. Balance has been elusive one fifth of the world's population lives in areas where water is physically scarce and a quarter of the population faces shortages due to lack of infrastructure. Water is considered polluted when it is altered from the natural state in its physical condition and chemical and microbiological composition. So that it becomes unsuitable or less suitable for any safe and beneficial consumption. Factories, power plants and sewage treatment plants are considered point sources of water pollution. Non point sources of water pollution are scattered or diffused. Cropland, forests, urban or suburban lands, roadways and parking lots are non point sources of a variety of substances including dust, sediment, pesticide, asbestos, fertilizer, heavy metals, oil, grease, salts. Pollution takes place in all the three main sources of water i.e rain water, surface water and ground water. Surface water is more susceptible than ground water, which is naturally protected from surface activities. Rain water is polluted by acid rain which damages forest and may cause significant decrease in productivity. It also damages monuments and buildings, crops, plant and trees. Surface water occurs in oceans, rivers, lakes, ponds and flood plains. It has been the sources of water supply since the dawn of civilization. But intense human activities have been polluting these readily available sources. Surface water used to be the primary source of water supply in Bangladesh, but it is no longer the case. Surface water in Bangladesh is extensively polluted by sources such as industrial and urban wastes, agrochemical and sewage wastes and sea water intrusion. Surface water bodies are extensively used for disposal of untreated industrial wastes. The Buriganga is a typical example of serious surface water contamination. Apart from industrial sources, surface water in the country is also extensively contaminated by human faces as sanitation in general is poor. Agrochemicals are extensively used in the country causing pollution of surface water. Due to withdrawal of water turn the Ganges, sea water intrudes a long way inside the coastline which cause river water pollution by salinity. Numerous natural and anthropogenic activities cause ground water pollution. A number of physical, chemical and biochemical process cause alteration of ground water properties either by addition of new elements /ions /compounds or by increasing the existing concentrations. Before the discovery of contamination in Bangladesh, ground water used to be considered a safer source of drinking water. Arsenic contamination of ground water in Bangladesh is now considered the world's largest case of water pollution. Ground water in Bangladesh is also polluted by a number of anthropogenic and natural sources. The most widespread anthropogenic sources are the infiltration of industrial and urban wastes disposed on the ground or in surface water bodies. Polluted water of Buriganga, Sitalakha, Turag, Dhaleshwari, Balu and Narai flowing around the greater Dhaka city is posing serious threads to public life as it is unfit for human use. Like many other countries of the world, river pollution in Bangladesh is a burning issue. At the government level since the last quarter of the past century several rules, regulations, policies, and strategies have been formulated to save the river from pollution. No positive results have been achieved. Therefore a proactive, instead of reactive approach might provide a practical and sustainable solution to the problem. In this regard, provision of monetary incentives, rewards and recognitions for polluters who reduce pollution may work effectively. The local community and civil society in protecting rivers can also play a great role. Awareness campaign can effectively help the citizens of Bangladesh address unhygienic practices. The WHO understands that it is unrealistic to expect programs to repair 10 million tube wells in the country. However, targeted awareness campaign can provide community members with the knowledge they need to make local changes. Clean water is important for direct health reasons and it is fundamental to the progress of communities. With the mounting pressure on water system due to migration from rural areas, clean and safe water is more important than ever. In communities, water can be purified with boiling. Current water sanitation programs are starting to see fewer diarrhea outbreaks with increased hygiene awareness. Moving latrines further away from tube wells has proven essential. In addition with increased awareness more community members are willing to pay for technologies and practices that will keep their drinking water clean.

*Corresponding author e-mail: amsalam2010@gmail.com 
Available online at www.banglajol.info

Bangladesh J. Sci. Ind. Res. 52(Special Issue), 2017
BANGLADESH JOURNAL

OF SCIENTIFIC AND

INDUSTRIAL RESEARCH

E-mail: bjsir07@gmail.com

\section{BANGLADESH JOURNAL OF SCIENTIFIC AND INDUSTRIAL RESEARCH}

Plenary Lecture (PL) CONTENTS

Special Issue 2017

01. A decade attempt for arsenic mitigation in Bangladesh: sharing our practical experience on arsenic 02 removal technologies
A. I. Kazi

02. Pesticides and its adverse effect on health and environment

N. Nahar

03. Low cost graphite based sensor for simultaneous detection of benzenediols M. A. Yousuf

04. Sustainable water management in developing countries such as Bangladesh 


\title{
A decade attempt for arsenic mitigation in Bangladesh: sharing our practical experience on arsenic removal technologies
}

\author{
A. I. Kazi \\ Institute of National Analytical Research and Service, Bangladesh Council of Scientific and Industrial Research
}

\begin{abstract}
Arsenic mitigation is of interest due to high risk of cancer in contaminated areas in Bangladesh. Arsenic mitigation processes include rain water harvesting, uses of surface water and water treatment by arsenic removal technology (ART). Many ARTs have evolved in the last decades to produce arsenic safe water. Most of them have not been verified in the real world arsenic contaminated water. Their efficacies have been projected by relying on laboratory based experiment only. Bangladesh Council of Scientific and Industrial Research (BCSIR) has promoted arsenic mitigation effort by deploying thirteen ARTs in five hydrogeological areas in Bangladesh covering high to low arsenic contaminated areas and variable water quality. It was found that the arsenic removal efficiency of ARTs in the real world was generally less than that derived in the laboratory. Only six of them performed at a certain level, however, rest of them failed to meet the expectation level to remove arsenic due to inherent problems of ARTs and complex water matrices in Bangladesh ground water. Here, we will demonstrate that the arsenic removal media used in the technology was not responsible for deficiency of ARTs, rather the design, the cracks and crevices in the media and the operation and maintenance caused their failure. Sometimes, minor modification in the technology such as iron removal in the pre-filter, backwash of the media, optimizing the flow rate indicated improvement in arsenic removal efficiency. In this paper, we will also discuss the possible designs, and operation and maintenance of future ARTs such that they can eliminate the possible reasons of failure during the test in the real world arsenic mitigation.
\end{abstract}

*Corresponding author e-mail: aikazibcsir@gmail.com 


\title{
Pesticides and its adverse effect on health and environment
}

\author{
N. Nahar \\ Department of Chemistry, University of Dhaka, Dhaka-1000, Bangladesh
}

\begin{abstract}
The chemical compounds which are used to control or kill pests and diseases of plants, to eradicate weeds and microorganisms that spoil agricultural products, storage foods, materials and help to improve both quality and quantity of food crops, to control parasites, vectors of dangerous diseases of human and animals are called pesticides. But when the pesticides reach outside the target, and the level is high then they have short and long-term adverse effect to the environment and human health. After the Second World War, many organic compounds were synthesized like organochlorine, organophosphorus, carbamates and pyrithroids to use as pesticides. With the increase of population and reduction of cultivable agricultural land the world wide concern was to boost up crop production in order to ensure food security, to reduce hunger and poverty and to have better life for humanity. Bangladesh started to use organochlorine compounds (OCs) in mid-fifties; which possess high insecticidal property and gave better yield of agricultural products. OCs compounds persist in the environment for longer time; bioaccumulation occurs in the fatty tissues of biological species and through the food chain comes to human subjects and has adverse effect on human health and environment. Bangladesh followed worldwide concern about OCs, banned use of OCs and allowed to use organophosphorus, carbamates and pyrithroids groups of pesticides in the country. Contaminants from agricultural fields and from other sources discharged into rivers and ultimately to the sea. Fresh water fish samples; omnivores, herbivores and carnivores from different trophic levels of meghna river, sea water fish and fish samples from markets were analyzed. Level of DDTs varied in different trophic levels and higher amount was found in carnivores followed by omnivores and herbivores. DDTs in fish samples from sea water samples was less than the fresh water fish but in all the samples DDTs were far below MRL. Our study during last ten years showed level of DDTs has been decreased in the environment. Dissipation pattern of a few pesticides in the vegetable samples from the experimental fields of BARI (Bangladesh Agricultural Institute), from farmer fields of different parts Bangladesh and pesticide residues in vegetable samples from the local markets were studied. Dissipation of pesticides in different vegetables collected from farmer fields was lower than the samples from experimental of BARI and 7-10 days required to come down below MRLs. Dissipation of same pesticide differed from vegetables to vegetables. Vegetable samples analyzed from market were found to contain residues below their MRL values according to FAO/CODEX Allimentruris Commission.
\end{abstract}

*Corresponding author e-mail: naharnilufar51@gmail.com 


\title{
Low cost graphite based sensor for simultaneous detection of benzenediols
}

\author{
M. A. Yousuf \\ Department of Chemistry, Khulna University of Engineering \& Technology, Bangladesh
}

\begin{abstract}
Electrochemical sensor has been fabricated for the simultaneous detection of benzenediols (BDs); hydroquinone (HQ), catechol (CC) and resorcinol (RS) in aqueous system by using graphite based pencil electrodes. Cyclic Voltammetry (CV) and Differential Pulse Voltammetry (DPV) were adopted for the detection technique. Both bare and modified HB \& 2B pencil electrodes were employed as working electrode. In case of bare system only HB pencil showed good electroanalytical activity on the redox reaction towards BDs. HB pencil modified by aspartic acid termed as ASA-HB electrode showed catalytic behavior towards similar redox reactions. On the other hand 2B pencil showed electroanalytical activity towards similar redox reactions when it was modified by ionic liquid; namely 1-Butyl-3-Methylimidazolium hexafluorophosphate termed as BIHP-GPE. Total analyses were performed in phosphate buffer solution (PBS) at pH 6.8. The scan rate effects were found to be diffusion controlled electrode process. Concentration effects of isomers were linear with current. The limit of detection (LOD) was calculated by signal-to-noise ratio $(\mathrm{S} / \mathrm{N}=3)$. In simultaneous detection, the LOD for HQ, $\mathrm{CC}$ and $\mathrm{RS}$ at bare $\mathrm{HB}$ pencil electrodes were $12.473 \mu \mathrm{ML}^{-1}, 16.132 \mu \mathrm{ML}^{-1}$ and $25.25 \mu \mathrm{ML}^{-1}$ while sensitivities were $470.481 \mu \mathrm{A} / \mathrm{mM} / \mathrm{cm}^{2}, 363.781 \mu$ $\mathrm{A} / \mathrm{mM} / \mathrm{cm}^{2}$ and $232.416 \mu \mathrm{A} / \mathrm{mM} / \mathrm{cm}^{2}$, respectively. LOD for HQ, CC and RS at ASA-HB were $22.459 \mu \mathrm{ML}^{-1}, 25.478 \mu \mathrm{ML}^{-1}$ and $38.303 \mu \mathrm{ML}^{-1}$ respectively while sensitivities were $374.483 \mu \mathrm{A} / \mathrm{mM} / \mathrm{cm}^{2}, 330.108 \mu \mathrm{A} / \mathrm{mM} / \mathrm{cm}^{2}$ and $219.574 \mu \mathrm{A} / \mathrm{mM}^{2} \mathrm{~cm}^{2}$ respectively. LOD for $\mathrm{HQ}, \mathrm{CC}$ and $\mathrm{RS}$ were $9.09 \mu \mathrm{ML}^{-1}, 8.15 \mu \mathrm{M} \mathrm{L}^{-1}$ and $26.78 \mu \mathrm{M} \mathrm{L}^{-1}$ respectively at BIHP-GPE while sensitivities were $525.21 \mu \mathrm{A} / \mathrm{mM} / \mathrm{cm}^{2}, 585.68 \mu \mathrm{A} / \mathrm{mM} / \mathrm{cm}^{2}$ and $178.00 \mu \mathrm{A} / \mathrm{mM} / \mathrm{cm}^{2}$ respectively. All electrodes showed good selectivity, stability and strong anti-interference for detection of HQ, CC and RS simultaneously in aqueous media.
\end{abstract}

*Corresponding author e-mail: yousuf2716@yahoo.com 


\title{
Sustainable water management in developing countries such as Bangladesh
}

\author{
M. J. Ahmed \\ Department of Chemistry, University of Chittagong, Chittagong-4331, Bangladesh
}

\begin{abstract}
Definition by the Brundtland Commission, "Sustainable development is development that meets the needs of the present without compromising the ability of future generations to meet their own needs." Sound strategies for community water supply and sanitation programmes in developing countries should be based on (i) a clear understanding of the existing problems, (ii) the beneficial impacts achievable, and (iii) the factors which determine sustainability. Sustainability, in the sense of continued delivery and uptake of services, is threatened by numerous attitudinal, institutional and economic factors, and community participation approaches alone are no guarantee of success. The key to sustainability is that all stakeholders involved in consumption/use, maintenance, cost recovery, and continuing support, perceive it in their best interests to deliver high-quality services. This paper presents a global strategy for the sustainable management of water resources. It stresses the importance of water in human lives and in other species as well and addresses the problem of water scarcity, especially in developing countries. It is noted that the majority of poor people are still without safe drinking water and adequate sanitation services, that 1 billion people lack an assured supply of good quality water, and that 1.7 billion have no adequate sanitation. Providing reliable and affordable waste water treatment in rural areas is a challenge in many parts of the world, particularly in developing countries such as Bangladesh. As populations expand and make various uses of water its growing scarcity becomes a serious issue in developing countries such as Bangladesh. Water can no longer be considered a totally free resource, and plans must be developed for its efficient use through better management and rules that preserve everybody's access to it and interest in its development. Because it is a common resource, its development and management should involve all beneficiaries. The government's role in this process is to establish the ground rules for water use and conservation through a policy and legal framework and a monitoring system that ensure its continued safety of supply to and responsible use of water by every sector and the economy. The challenges posed by climate change and growing economic development require that the quantity and quality of water resources in Bangladesh be managed by sustainable development policies. Without such a plan, Bangladesh will continue to face serious challenges to achieve economic growth to support the growing population confined in a densely-populated land with declining water resources. The water resources are intertwined with most of the planetary boundaries, such as ocean acidification, loss of biodiversity, nutrient loads, land system changes, and chemical pollution, all of which either already have exceeded or are about to exceed the tolerance limits or threshold limits required for beneficial uses. The major benefits of the paper will be sustainable water supply to a growing population in service areas-including improved access, convenience, and reliability of water supply, as well as increased quantities of water and improved water quality. To initiate the establishment of pilot scale greywater recycling projects using low cost locally available materials and investigate their performance in hot climates. With proper treatment greywater can be put to good use. These uses include water for laundry and toilet flushing, and also irrigation of plants. The role of analytical chemistry in the study of aquatic chemistry is highlighted with special reference to quality control issues. Physicochemical assessment of surface and ground water quality parameters is most important to Analytical Chemists. To that end, we need significance investment in our education and research, and chemistry is central to that endeavor.
\end{abstract}

*Corresponding author e-mail: pmjahmed55@gmail.com 


\section{BANGLADESH JOURNAL \\ OF SCIENTIFIC AND INDUSTRIAL RESEARCH}

E-mail: bjsir07@gmail.com

\section{BANGLADESH JOURNAL OF SCIENTIFIC AND INDUSTRIAL RESEARCH}

\section{Keynote Speech (KS)}

CONTENTS

01. Water contamination in drinking water distribution systems: management and mitigation M. S. Rahman

02. Phytoextraction efficiency of cadmium and zinc by arum (Colocasia esculenta L.) grown in hydroponics and soil

M. S. Islam

03. Modification of water structure by different perturbations 


\title{
Water contamination in drinking water distribution systems: management and mitigation
}

\author{
M. S. Rahman \\ Atmospheric and Environmental Chemistry Laboratory, Chemistry Division, Atomic Energy Center, 4-Kazi Nazrul Islam \\ Avenue, Dhaka-1000, Bangladesh
}

\begin{abstract}
Surface and ground water have been using for different purposes (i.e. domestic, agriculture, recreation). However, due to anthropogenic activities and natural processes, the water sources are contaminated day by day. The uses of synthetic chemicals have created numerous problems in the modern society. Even a Nobel Laureate Chemist, Robert Curl, called this 'chemical addiction' a technological disaster. Some 4,000 artificial chemicals are routinely used in our society in practically all sectors. Most of these chemicals originate from different types of industries and end up with the surface and ground water systems. Subsequently, agricultural land and food chains might have contaminated for using contaminated water along with other sources. On the other hand, it has been suspected that contaminated water might have impact on the increase of ecological risk and subsequently human health risk. Therefore, it is an important field of research areas to maintain and management of water quality. Heavy metals/ metallic compounds are targeted in these days in order to remove and/or replace them from contaminated water using different types of natural additives. Because heavy metals are non biodegradable and remains in environment for years. Some heavy metals are responsible for creating different types of problems in human body including cancer. For removing these toxic heavy metals from contaminated water, different types of water treatment processes have been used. Adsorption process is found to be one of the best techniques for removing heavy metals from contaminated water. On the other hand, degradation of drinking water quality in water distribution systems is another big problem as well different types of metallic pipes were installed broadly in all over the world. Many of these metallic pipes are corroded and are continuous sources of different types of metal ions in drinking water distribution systems. Long time exposure of these toxic metals could be reason of cancer in human body. On the other hand, recent studies have reported that soluble or particulate metals decreases water quality in distribution systems. From our study, we have found that a lower content of metal suspension color, turbidity, and smaller particle size would appear to be obtained in presence of a phosphate based corrosion inhibitor at a $\mathrm{pH}$ value of 6.5 compared to a $\mathrm{pH}$ value of 8.5. Disinfection by-products (DBPs), which is toxin and liable for creating cancer is another big problem in water distribution systems. To disinfect the microorganism in drinking water, several disinfecting agents are adding in water that reduces water born death. But unfortunately disinfecting agents react with natural organic matter in water and produces DBPs. From our studies we found that different variables, i.e. iron nano particles, phosphate, $\mathrm{pH}$ and reaction time might have impact on DBPs formation in water. It should be mentioned that DBPs (THMs and HAAs) extraction from water and analysis are time consuming and complex procedure. Therefore, we have developed mathematical models considering the significant $(\alpha=0.05, \mathrm{p}<0.05)$ variables for the prediction of DBPs formation in drinking water distribution systems. This study suggested that the models' performance were found to be excellent under a wide range of studied variables for controlling DBPs formation in drinking water distribution systems. On the other hand, dissolved organic matter (DOM) has been identified as one of the important precursors for DBPs formation. Therefore, DOM removal study has been conducted using different materials; and from this study, we found that iron nano particles i.e. goethite and magnetite were significantly removed DBPs precursor (DOM), which reduced the formation of toxin BDPs in drinking water. Molecular weight (MW) distributions of DBPs precursor (DOM) revealed that the higher molecular weight fractions adsorbed preferentially onto goethite followed by magnetite surface. The change of MW distribution of DOM was found to be in reasonable agreement with the change of DBPs formation in iron-water systems.
\end{abstract}

*Corresponding author e-mail: safiur_baec@yahoo.com 


\title{
Phytoextraction efficiency of cadmium and zinc by arum (Colocasia esculenta L.) grown in hydroponics and soil
}

\author{
M. S. Islam*, M. A. Kashem and K. T. Osman \\ Department of Soil Science, University of Chittagong, Chittagong-4331, Bangladesh
}

\begin{abstract}
Cadmium (Cd) and Zinc ( $\mathrm{Zn})$ tolerance and phytoextraction efficiency of arum (Colocasia esculenta L.) were investigated in hydroponics. Plants were grown for 60 days in nutrient solution after addition of $\mathrm{Cd}$ and $\mathrm{Zn}$ at the levels of $0,15,30$ and 60 $\mu \mathrm{mol} \mathrm{L} \mathrm{L}^{-1}$ and $0,100,500$ and $1000 \mu \mathrm{mol} \mathrm{L}^{-1}$, respectively. Growth of arum was unaffected by low levels of metal concentration $\left(15 \mu \mathrm{mol} \mathrm{L}{ }^{-1} \mathrm{Cd}\right.$ and $\left.100 \mu \mathrm{mol} \mathrm{L}{ }^{-1} \mathrm{Zn}\right)$ in solution. In arum shoots, $\mathrm{Cd}$ and $\mathrm{Zn}$ concentrations were 713 and $10,120 \mathrm{mg} \mathrm{kg}^{-1}$ respectively, at their low levels in solution. These concentrations $\left(15 \mu \mathrm{mol} \mathrm{L} \mathrm{L}^{-1} \mathrm{Cd}\right.$ and $\left.100 \mu \mathrm{mol} \mathrm{L}^{-1} \mathrm{Zn}\right)$ did not cause any growth retardation indicating that arum is a metal hyperaccumulator. To investigate the comprehensive aspects of the metal tolerance and phytoextraction efficiency, arum was grown for 105 days in soil after addition of $\mathrm{Cd}$ and $\mathrm{Zn}$ at the levels of 0,10 , 30 and $90 \mathrm{mg} \mathrm{kg}^{-1}$ and 0, 100, 200 and $400 \mathrm{mg} \mathrm{kg}^{-1}$, respectively. In arum shoots, Cd and $\mathrm{Zn}$ concentrations were 1,041 and $11,186 \mathrm{mg} \mathrm{kg}^{-1}$, respectively, at their highest levels in the soil. These concentrations $\left(90 \mathrm{mg} \mathrm{kg}^{-1} \mathrm{Cd}_{\text {and }} 400 \mathrm{mg} \mathrm{kg}^{-1} \mathrm{Zn}\right) \mathrm{did}$ not cause any growth retardation indicating that arum is a metal hyperaccumulator. Transfer factor (TF) greater than one in both hydroponics and soil experiments also confirmed the hyperaccumulating behavior of arum for $\mathrm{Cd}$ and $\mathrm{Zn}$. Cadmium and $\mathrm{Zn}$ concentration in arum shoots and TF in arum in both the experiments indicates that this plant is a suitable candidate for the phytoremediation of water and soil contaminated with $\mathrm{Cd}$ and $\mathrm{Zn}$.
\end{abstract}

*Corresponding author e-mail: msislam@cu.ac.bd

\section{Modification of water structure by different perturbations}

\author{
M. A. Bin Hasan Susan
}

Department of Chemistry, University of Dhaka, Dhaka 1000, Bangladesh

\begin{abstract}
Water is a matter and matrix of all living organisms. There has been a surge of interest to unveil the mystery of this simplest but yet possibly the most critical and widely studied liquid of the universe. However, description of the structure of water beyond any doubt in the pure liquid state, at interfaces, and in solutions still remains an elusive goal. The degrees of hydrogen bonding in water can vary with pressure, temperature, and different additives. Consequently, changes in water structure can bring about changes in fundamental properties. In this work, we studied modification of water structure by different perturbations. Temperature dependencies of modification of water structure in presence of additives, such as urea, amides, sugars and ionic liquids have been studied at different concentrations by near-infrared (NIR) spectroscopy and 2D correlation spectroscopy with emphasis on concentration of additives and temperature. Deconvolution and 2D correlation studies have been used to understand the extent of perturbation. The thermodynamic parameters such as free energy change of activation, change in enthalpy and entropy of activation for viscous flow of solutions, determined from volumetric and viscometric analyses, have been used to explain the thermodynamic state of solutions with the change of temperature and concentrations and to correlate the nature of interactions i.e., the structure-making and structure-breaking properties of aqueous solutions. Finally, modifications of water structure by different perturbations have been correlated with water quality.
\end{abstract}

*Corresponding author e-mail: susan@du.ac.bd 


\section{BANGLADESH JOURNAL OF SCIENTIFIC AND INDUSTRIAL RESEARCH}

\begin{tabular}{lll}
\hline Oral Presentation (OP: A1-A9) & CONTENTS & Special Issue 2017 \\
\hline
\end{tabular}

01. Microbial fuel cell for generation of bioelectricity via treatment of biowaste

A. Al Moinee, T. Islam and N. Sanzida

02. A highly sensitve and selective spectrofluorimetric method for the determination of manganese at 08 ultratrace levels in idustrial, environmental waters, biological, soil, food and pharmaceutical samples using 2-( $\alpha$-pyridyl)-thioquinaldinamide

M. T. Islam, F. Hossain and M. J. Ahmed

03. Assessment of heavy metals in tap and ground water in and around Dhaka, Bangladesh

T. R. Choudhury, M. A. Maksud, S. R. Khan, L. N. Lutfa, B. A. Begum and S. B. Quraishi

04. Characterization of textile effluents and present status of effluent management in a selected textile 09 industry

M. A. Islam, N. Alam and M. S. Hossen

05. Heavy metal contamination in the surface water of the Cox's Bazar sea beach, Bangladesh: a 10 potential impact on environment

A. K. M. Atique Ullah, S. B. Quraishi, S. R. Khan and A. K. M. Fazle Kibria

06. Synthesis of high surface area crystalline $\mathrm{TiO}_{2}$ nanoparticle and its application on waste water 10 treatment

M. K. Hossain, U. S. Akhtar, M. Moniruzzaman and B. Saha

07. Groundwater quality potential of lower aquifer of Singair upazila in Manikganj district, 11 Bangladesh

M. Islam, K. Bashar, N. Ahmed, M. G. Rasul, S. Hossain and M. M. R. Sarker

08. Bioelectricity generation through decolorization of textile dye by chromium resistant bacteria in a 11 mediatorless microbial fuel cell $(\mathrm{mfc})$

R. M. Mazumdar

09. Making safe drinking water common place in Bangladesh

V. More 


\title{
Microbial fuel cell for generation of bioelectricity via treatment of biowaste
}

\author{
A. Al Moinee, T. Islam and N. Sanzida*
}

Department of Chemical Engineering, Bangladesh University of Engineering and Technology

\begin{abstract}
Microbial fuel cell (MFC) reflects a mechanism for simultaneous waste treatment and electricity generation biologically. MFC is a bioreactor that converts the energy stored in chemical bonds in organic compounds directly into current by catalytic reactions of microorganisms through their metabolism under anaerobic conditions. In this work wastewater from food industry are treated in laboratory scale MFC to study the extent of COD removal by generating electricity. The performance of the fuel cell was observed by using different types of electrode material, different types of electrolyte and different salt bridges with the presence and absence of aeration and nutrients, with a view to determining the most efficient combination to produce viable amount of current through the treatment of waste to descend the pollution load and determining the most efficient combination. The notable results attained in the experiments of this project are $185.8 \mu \mathrm{A}$ current with $757.4 \mathrm{mV}$ voltage gain providing $53 \%$ COD removal. The results show that microbial fuel cells are promising greener threshold of renewable energy to curb global energy crisis and environmental degradation.
\end{abstract}

*Corresponding author e-mail: nahidsanzida@che.buet.ac.bd

\section{A highly sensitve and selective spectrofluorimetric method for the determination of manganese at ultratrace levels in idustrial, environmental waters, biological, soil, food and pharmaceutical samples using 2-( $\alpha$-pyridyl)-thioquinaldinamide}

\author{
M. T. Islam, F. Hossain and M. J. Ahmed
}

Laboratory of Analytical Chemistry, Department of Chemistry, University of Chittagong, Chittagong-4331, Bangladesh

\begin{abstract}
A very simple, ultra-sensitive and highly selective non-extractive spectrofluorimetric method is presented for the determination of manganese at ultra trace levels using 2-( $\alpha$-pyridyl)-thioquinaldinamide (PTQA). PTQA has been proposed as a new analytical reagent for the direct non-extractive spectrofluorimetric determination of manganese(VII). This novel fluorimetric reagent, PTQA get oxidized in a slightly acidic (0.0125-0.05 $\left.\mathrm{M} \mathrm{H}_{2} \mathrm{SO}_{4}\right)$ solution with manganese(VII) in absolute ethanol to produce highly fluorescent oxidized product $\left(\lambda_{\mathrm{ex}}=319 \mathrm{~nm} ; \lambda_{\mathrm{em}}=373 \mathrm{~nm}\right)$. Constant and maximum fluorescence intensities were observed over a wide range of acidity $\left(0.0125-0.05 \mathrm{M} \mathrm{H}_{2} \mathrm{SO}_{4}\right)$ for the period between $5 \mathrm{~min}$ and $24 \mathrm{~h}$. Linear calibration graphs were obtained for $0.01-800 \mu \mathrm{g} \mathrm{L}^{-1}$ of Mn, having a detection limit of $1 \mathrm{ng} \mathrm{L}^{-1}$; the quantification limit of the reaction system was found to be $10 \mathrm{ng} \mathrm{L}^{-1}$ and the RSD was $0-2 \%$. A large excess of over 60 cations, anions and complexing agents (like, chloride, phosphate, azide, tartrate, oxalate, $\mathrm{SCN}^{-}$etc.) do not interfere in the determination. The developed method was successfully used in the determination of manganese in several Standard Reference Materials (alloys, steels, hair and sediments) as well as in some environmental waters (potable and polluted), biological samples (human blood, urine and hair), soil samples, food samples (vegetables, fruits, tea, rice, wheat), fertilizer samples and pharmaceutical samples (multivitamin-mineral tablet and syrup), tea samples, solution containing both manganese(II) and manganese(VII) and complex synthetic mixtures. The results of the proposed method for biological and food samples were comparable with AAS and were found to be in excellent agreement. The method has high precision and accuracy $\left(\mathrm{s}= \pm 0.01\right.$ for $\left.0.5 \mu \mathrm{g} \mathrm{L}^{-1}\right)$.
\end{abstract}

*Corresponding author e-mail: nahidsanzida@che.buet.ac.bd 


\title{
Assessment of heavy metals in tap and ground water in and around Dhaka, Bangladesh
}

\author{
T. R. Choudhury*, M. A. Maksud, S. R. Khan, L. N. Lutfa, B. A. Begum and S. B. Quraishi \\ Analytical Chemistry Laboratory, Chemistry Division, Atomic Energy Centre, Dhaka, Bangladesh
}

\begin{abstract}
Water resources in the world have been profoundly influenced over the last years by human activities, whereby the world is currently facing critical water supply and drinking water quality problems. In many parts of the world heavy metal concentrations in drinking water are higher than some international guideline values. The levels of heavy metals in ground and tap water samples collected in and around Dhaka, Bangladesh were determined using AAS techniques (Flame, Hydride and Cold Vapor AAS). The samples were analyzed for their contents of lead, cadmium, chromium, copper, cobalt, nickel, arsenic, mercury, iron, manganese, zinc, calcium, magnesium, sodium, potassium etc and were also compared with the WHO (2008) specified contaminant levels for drinking water. The results obtained showed that all the tap and ground water samples investigated contain high concentration of Lead even though in some places cadmium concentrations were found to be above the WHO maximum acceptable concentration. However, in case of other elements of the samples had concentration below the WHO guidelines value. It is a well known fact that the heavy metal ions are potentially toxic to human health and could be quite detrimental for human life. Our study suggests the preventive measures which should be adopted to control the contamination of excess $\mathrm{Pb}$ present in the ground and tap water around this region.
\end{abstract}

*Corresponding author e-mail: tasrina_rabia@yahoo.com

\section{Characterization of textile effluents and present status of effluent management in a selected textile industry}

\author{
M. A. Islam*, N. Alam and M. S. Hossen \\ Department of Environmental Science, Faculty of Agriculture, Bangladesh Agricultural University, Mymensingh-2202
}

\begin{abstract}
The study was conducted to observe the present situation of effluent management of the selected textile industry and to investigate the physiochemical parameters including color, temperature, $\mathrm{pH}, \mathrm{DO}, \mathrm{BOD}, \mathrm{EC}$, TDS, alkalinity and heavy metals $(\mathrm{Pb}, \mathrm{Ni}, \mathrm{Zn})$ content at different stages of treatment processes. Results revealed that the $\mathrm{pH}$ values of the samples were greater than 7 except one sample which was slightly alkaline. The highest $\mathrm{pH}$ value was observed at the aerobic biological reaction chamber. The EC values recorded at different sampling points ranged from 185 to $193 \mu \mathrm{s} / \mathrm{cm}$. This higher EC values indicates the greater amount of salts in the water due to dumping of solid waste and discharging of industrial effluents. The effluent of the industry was discharged into the sewerage canal which was not satisfactory for sound environment. The highest TDS value $2824 \mathrm{mg} / \mathrm{L}$ was observed at the screening pit unit that the other part of the ETP. Value of DO at different sampling points is ranged from 0.8 to $5.0 \mathrm{mg} / \mathrm{L}$. Pb concentration in all samples ranged from 0.33 to $0.97 \mathrm{ppm}$ whereas $\mathrm{Zn}$ ranged from 0.69 to $1.28 \mathrm{ppm}$. Ni content was recorded from 0.15 to $1.04 \mathrm{ppm}$. It may conclude that the effluents content water is harmful for aquatic life and unsuitable for bathing. Attention is needed to organize different types of chemical treatment to be used for removing metals, salts, harmful chemicals and properly managed by environmental experts.
\end{abstract}

*Corresponding author e-mail: maislam@bau.edu.bd 


\title{
Heavy metal contamination in the surface water of the Cox's Bazar sea beach, Bangladesh: a potential impact on environment
}

\author{
$\underline{\text { A. K. M. Atique Ullah }}^{1 *}$, S. B. Quraishi ${ }^{1}$, S. R. Khan ${ }^{1}$ and A. K. M. Fazle Kibria ${ }^{2 *}$ \\ ${ }^{1}$ Analytical Chemistry Laboratory, Chemistry Division, Atomic Energy Centre Dhaka, Bangladesh Atomic Energy \\ Commission, Dhaka-1000 \\ ${ }^{2}$ Nuclear Safety, Security and Safeguards Division, Bangladesh Atomic Energy Commission, Dhaka-1207
}

\begin{abstract}
Cox's Bazar sea beach is the longest beach in the world and over 1,000,000 tourist visit the beach each year. Subsequently, the beach water is being polluted due to the natural and anthropogenic activities. About $80 \%$ of the diseases of the world population and more than one third of the deaths in the developing countries are due to contamination of water. Heavy metal is one of the most potential pollutants among all other chemical contaminants. Consequently, continuous monitoring of the heavy metals in the beach water is required. Therefore, for the assessment of water quality, during the pre-monsoon (May 2015) fifteen surface water samples were collected randomly at different locations of three beaches, Labani, Kalatali and Sugandha beach. The collected samples were analyzed by atomic absorption spectrometry (AAS). The concentrations of heavy metals $\mathrm{Pb}$, $\mathrm{Cd}, \mathrm{Cr}, \mathrm{As}, \mathrm{Hg}, \mathrm{Mn}, \mathrm{Fe}, \mathrm{Co}, \mathrm{Ni}, \mathrm{Cu}$ and $\mathrm{Zn}$ in the beach water were found to be in the range of 674-719 $\mu \mathrm{g} \mathrm{L}^{-1}, 60-64 \mu \mathrm{g} \mathrm{L}{ }^{-1}$, $<11 \mu \mathrm{g} \mathrm{L}^{-1},<2.0 \mu \mathrm{g} \mathrm{L}^{-1}, 0.3 \mu \mathrm{g} \mathrm{L}^{-1}, 911-1220 \mu \mathrm{g} \mathrm{L}^{-1}, 25.82-35.38 \mathrm{mg} \mathrm{L}^{-1}, 299-322 \mu \mathrm{g} \mathrm{L}^{-1}, 315-340 \mu \mathrm{g} \mathrm{L}^{-1}, 46-54 \mu \mathrm{g} \mathrm{L}^{-1}$ and 121 $-135 \mu \mathrm{g} \mathrm{L}^{-1}$ respectively. The results indicated that in most of the cases the values of heavy metals exceeded the national and international guideline. Since heavy metals can have toxic effect and also the levels were considerable to those compared to the WHO drinking water guideline values, the results will serve to arouse public interest and lead to much research on a potential health hazard in the area studied.
\end{abstract}

*Corresponding author e-mail: atique.chem@gmail.com, kibriaf@yahoo.com

\section{Synthesis of high surface area crystalline $\mathrm{TiO}_{2}$ nanoparticle and its application on waste water treatment}

\author{
M. K. Hossain*, U. S. Akhtar, M. Moniruzzaman and B. Saha
}

Soil and Enviroment Research Section, Biological Research Divisison, Bangladesh Council of Scientific and Industrial Research (BCSIR) Laboratories Dhaka, Bangladesh

\begin{abstract}
Titanium di oxide $\left(\mathrm{TiO}_{2}\right)$ is one of the most important crystalline metal oxides which are currently widely used in industry and academia for various purposes including catalysts and catalysts supports. Its applications benefit most when it is prepared in the ordered highly crystalline nanoparticle form, coupled with high phase purity and high surface area. In this regard, great efforts have been directed at the development of the methods to prepare it in such a form. Considering the importance of the material and the current wide demands for the material in large quantities. This has prompted us to analyze the problems and seek for new conceptual approaches to synthesize the important material in a scalable and reproducible manner. Application for decomposition of 4-chlorophenol (4-CP) and methylene blue (MB) shows the superior over the commercial catalyst.
\end{abstract}

*Corresponding author e-mail: kamal_bcsir@hotmail.com 


\title{
Ground water quality potential of lower aquifer of Singair upazila in Manikganj district, Bangladesh
}

\author{
$\underline{\text { M. Islam }}^{1 *}$, K. Bashar ${ }^{1}$, N. Ahmed ${ }^{2}$, M. G. Rasul ${ }^{2}$, S. Hossain ${ }^{2}$ and M. M. R. Sarker ${ }^{1}$ \\ ${ }^{1}$ Dept. of Geological Sciences, Jahangirnagar University, Savar, Dhaka \\ ${ }^{2}$ Isotope Hydrology Division, Bangladesh Atomic Energy Commission, Savar, Dhaka
}

\begin{abstract}
An attempt has been taken to determine the water quality potential of lower aquifer of Singair upazila, Manikganj district, Bangladesh. Geologically, the area can be attributed to quaternary alluvial sequence. The depth range of upper aquifer waters varies from 12 to $70 \mathrm{mbgl}$ and 70 to $247 \mathrm{mbgl}$ for the lower aquifer waters. Upper aquifer waters have higher EC than lower aquifer and negative Eh waters indicate reducing condition. Both aquifer waters are mainly $\mathrm{Ca}-\mathrm{Mg}-\mathrm{HCO}_{3}$ type. Except arsenic (As), most of the ions of both aquifer waters are within the limit of drinking standard of WHO (2004) and Bangladesh (DoE, 1997). Arsenic concentrations of upper aquifer exceed both the WHO (10 $\mu \mathrm{g} / \mathrm{l})$ and Bangladesh standard (50 $\mu \mathrm{g} / \mathrm{l})$ and for lower aquifer exceed only WHO standard. Waters in both aquifers in north western and central part of the study area show high arsenic concentration due to lack of continuous impermeable layer between the aquifers as revealed from borelog data. Water quality index map also indicates that north western and central part is not suitable for ground water development because of inferior quality. The average $\delta^{18} \mathrm{O}$ values for upper and lower aquifer waters are isotopically enriched compared to river water $(-10.08 \%)$. Similar isotopic composition of upper $(-4.77 \%$ ) and lower aquifer waters $(-5.50 \%)$ indicates both waters were mixed in the past and mixing may be continued in the future. The mixing may be preferentially from the upper aquifer to lower aquifer because of high capacity water pump, lack of impermeable layer and high permeability of the upper aquifer etc. Therefore, the potentiality of the lower aquifer may not be suitable for large-scale ground water development project in the study area without any mitigation measure.
\end{abstract}

*Corresponding author e-mail: mazeda@juniv.edu

\section{Bioelectricity generation through decolorization of textile dye by chromium resistant bacteria in a mediatorless microbial fuel cell $(\mathrm{mfc})$}

\section{R. M. Mazumdar}

Institute of Food Science and Technology (IFST), Bangladesh Council of Scientific and Industrial Research (BCSIR), Dhaka, Bangladesh

\begin{abstract}
Target of Microbial Fuel Cell (MFC) technology is to generate electricity from industrial effluent and waste water. Dye in textile effluent is a major concern for the environment. Degradation of the dyes in effluent MFC can generate electricity as well as improve the scenario. A two chambered Microbial fuel Cell (MFC), $200 \mathrm{~mL}$ each, was constructed to produce electricity by degrading textile dye using a chromium resistant bacterium. Chromium(VI) resistant (1000 ppm) isolates from tannery were studied for dye decoulorization activity. Among them, a Pseudomonas spp. denoted as CrSp-11 was selected for the purpose. Fucozol Red UCX (Reactive Red 195) dye (100 ppm) containing basal medium was used as anolyte and phosphate buffer (PH-7) was as catholyte. Carbon plate was used as electrode. $3 \% \mathrm{KCL}$ agar salt bridge was used to connect the chambers. $24 \mathrm{~h}$ enriched inoculum as $1 \mathrm{ml} / 100 \mathrm{ml}$ added in the cathode. Performance of MFC was studied by determining the voltage. $170 \mathrm{mV}$ of electricity generated continuously for $120 \mathrm{hr}$ with $100 \%$ decolorization of the dye. Result showed that chromium resistant Pseudomonas spp. can be used to generate electricity along with degradation of textile dye.
\end{abstract}

*Corresponding author e-mail: reazbio@gmail.com 


\title{
Making safe drinking water common place in Bangladesh
}

\author{
V. More \\ Global Deploy Leader, Water R\&D, Hindustan Unilever Research Center, Mumbai, India
}

\begin{abstract}
Globally, an estimated 2.1 billion people lack ready access to improved source of drinking water (source: $12^{\text {th }}$ July 2017 report WHO). Bangladesh also suffers from deteriorating water quality (Joshua Nizel Halder \& M. Nazrul Islam- JOURNAL OF ENVIRONMENT AND HUMAN). As per 2011 survey, diarrhea and dysentery are two of the most prevalent ailments in Bangladesh (Source: Bangladesh Bureau \& WHO studies) which are caused by pathogenic micro-organisms. Faecal pathogens including rotavirus, adenovirus, Shigella, Vibrio cholera and enter toxigenic E. coli have also been detected in tube-well water. Recent studies in Bangladesh have demonstrated that up to $65 \%$ of tube-wells contain indicators of faecal contamination. Unilever, as part of its mission to provide 150 billion liters of safe drinking water, has launched a range of purifiers which meet one of the most stringent standards for residential purifiers of United States Environmental Protection Agency. As per the USEPA Guide Standard for Performance of Microbiological PoU Water Purifiers (1987), there are clearly defined standards for microbiological performance of PoU water purifiers. These are: $6 \log$ reduction of bacteria, $4 \log$ reduction of virus \& $3 \log$ reduction of cyst. CB\&I Federal Services (CB\&I, USA), under the contract with U.S.E.PA, in collaboration with Unilever R\&D (Mumbai) India has evaluated the performance of four of its household point-of-use (POU) devices. These four household water treatment systems are designed to treat drinking water with four different technologies that include ultra-filtration, reverse osmosis membranes, ultraviolet (UV) irradiation and halogen-based biocides. These technologies cover a majority of the water purification technologies being used by Unilever currently. A series of microbiological tests were conducted on above four types of water treatment systems-Pureit Marvella UVTM, Pureit MarvellaSleekTM, Pureit ExcellaTM and Pureit Marvella Slim ROTM water purifiers. The four systems were evaluated for removal of Cryptosporidium parvum (C. parvum) oocysts (a protozoan cyst), Escherichia coli (E. coli) (as a surrogate for bacteria) and Male Specific 2 (MS2) bacteriophage (as a surrogate for viruses). Performance was monitored throughout the life of the water treatment systems for compliance with the Guide Standard and Protocol for Testing Microbiological Water Purifiers (USEPA 1987) of $3-\log$ reduction of cyst, 6-log reduction of bacteria, and a 4-log reduction of virus. Results were also compared to the treatment guidelines published by the World Health Organization (WHO 2011a) for the performance of microbial treatment in household systems. Based on the experimental conditions in these studies, all four household water treatment systems achieved satisfactory removal of $E$. coli, MS2, and Cryptosporidium throughout their design life. Based on the experimental results, all the POU units evaluated showed excellent removal of bacteria, viruses, and cysts exceeding the recommendations of Guide Standard and Protocol for Testing Microbiological Water Purifiers (USEPA 1987) of 3-log reduction of cyst, 6-log reduction of bacteria, and a 4-log reduction of virus.
\end{abstract}

*Corresponding author e-mail: Veena.More@unilever.com 


\section{BANGLADESH JOURNAL OF SCIENTIFIC AND INDUSTRIAL RESEARCH}

\begin{tabular}{lll}
\hline Oral Presentation (OP: B1-B9) & CONTENTS & Special Issue 2017 \\
\hline
\end{tabular}

01. Preparation of amidoxime adsorbent by radiation induced grafting of acrylonitrile on 13 polyethylene film and its application in $\mathrm{Cr}$ (VI) removal

N. Rahman, N. C. Dafader, M. F. Alam

02. Simultaneous detection of $\mathrm{Pb}, \mathrm{Cu}$ and $\mathrm{Cd}$ in surface water using pencil graphite electrode

S. Rana, M. A. Yousuf and M. Jamal

03. Status of ground water quality and its health risk assessment with the special emphasis on arsenic contamination: a case study

M. S. Rahman, M. Asaduzzaman, M.E. Huda, S. Akther, M. J. Kabir, Y. N. Jolly, K. J. Fatema, $\quad$ H. Sushmita, B. A. Begum, S. B. Quaraishi

04. Risk assessment of trihalomethanes (thms) formation in the supplied water of Dhaka city, 15 Bangladesh

M. Bodrud-Doza, N. Chowdhury and M. S. Rahman

05. Monitoring the water quality over a year by characterization of microbial community \& 15 metagenomic analysis and measurement of physicochemical parameters of Hathirjheel lake water

R. Patwary, S. Shill and S. Parveen

06. Effects of pesticide pollution on the haematological parameters of a fish, Labeo rohita 16 (Hamilton, 1822)

J. Jasmin, M. M. Rahman and M. R. Islam

07. Determination of PAHs in the water and sediment of Hatirjheel lake using GC-MS and study of 16 the water quality parameter

M. A. Haque, M.Z. Sarkar, S. Ahmed and M. Mostafa

08. Spatial and temporal representation of metal pollution caused by ship breaking activities in the 17 coastal area of Chittagong using GIS and remote sensing

M. H. Haque, F. Ahmad, F. Abdullah and M. Maliha

09. The fate of selected heavy metals from industrial waste water on soil along the bank of Karnopara 18 canal at Savar, Bangladesh

R. Rani, S. Hoque, M. Moniruzzaman and S. H. Rahman 


\title{
Preparation of amidoxime adsorbent by radiation induced grafting of acrylonitrile on polyethylene film and its application in $\mathrm{Cr}(\mathrm{VI})$ removal
}

\author{
$\underline{\text { N. Rahman }}$, N. C. Dafader and M. F. Alam \\ Nuclear and Radiation Chemistry Division, Institute of Nuclear Science and Technology, Atomic Energy Research \\ Establishment, Savar, Dhaka-1349, Bangladesh
}

\begin{abstract}
Present study focuses on preparation a new adsorbent by radiation induced grafting and the application of the adsorbent as $\mathrm{Cr}(\mathrm{VI})$ recovery agent from aqueous solution. Pre-irradiation technique was applied to graft acrylonitrile (AN) onto polyethylene film. The graft yield was optimized with respect to radiation dose, monomer concentration and reaction time. Effect of $\mathrm{H}_{2} \mathrm{SO}_{4}$ as additive on graft yield was studied. Highest graft yield obtained was $120 \%$ at $70 \mathrm{kGy}$ radiation dose, $60 \%$ monomer concentration and $4 \mathrm{~h}$ reaction time using $\mathrm{H}_{2} \mathrm{SO}_{4}$ as additive. The AN grafted films were modified with hydroxyl amine hydrochloride to prepare amidoxime adsorbent. The prepared adsorbent was characterized by FTIR, TGA and DMA. The prepared amidoxime adsorbent showed high affinity towards $\mathrm{Cr}(\mathrm{VI})$ adsorption. Adsorption capacity was studied under different conditions: contact time, $\mathrm{pH}$ and initial metal ion concentration. The highest adsorption capacity obtained was 200 $\mathrm{mg} / \mathrm{g}$ after $72 \mathrm{~h}$ contact time at $\mathrm{pH} 1.5$ and initial metal ion concentration $200 \mathrm{ppm}$. Kinetics and isotherm of Cr(VI) adsorption were investigated. Desorption and reuse of the adsorbent film was studied.
\end{abstract}

*Corresponding author e-mail: naziabaec@gmail.com

\section{Simultaneous detection of $\mathrm{Pb}, \mathrm{Cu}$ and $\mathrm{Cd}$ in surface water using pencil graphite electrode}

\author{
S. Rana, M. A. Yousuf and M. Jamal* \\ Department of Chemistry, Khulna University of Engineering \& Technology, Khulna-9203, Bangladesh
}

Heavy metal pollution is one of the most serious environmental problems and regulations are becoming stricter. Many efforts have been made to develop sensors for monitoring heavy metals in surface water. Pencil graphite electrode (PGE) is one of the new technologies for fabricating simple, low cost, portable and disposable analytical device for many application areas including clinical diagnosis, food quality control and environmental monitoring. The unique properties of this sensor allow the passive liquid transport and compatibility with chemical/biochemical are the main advantage of using this sensing platform. In this work, a complete analysis of physical and electrochemical properties of PGE has been performed to detect $\mathrm{Pb}, \mathrm{Cu}$ and $\mathrm{Cd}$ simultaneously in water. After initial optimization of different PGE, it has been found that $2 \mathrm{~B}$ shows the maximum current signal in Ferricyanide solution. Afterward the PGE is dedicated on stripping voltammetry techniques, where bare PGE is used to detect $\mathrm{Pb}, \mathrm{Cu}$ and $\mathrm{Cd}$ simultaneously within the potential scanning range from -0.9 to $+0.3 \mathrm{~V}$.

*Corresponding author e-mail: mamun.jamal@chem.kuet.ac.bd 


\title{
Status of ground water quality and its health risk assessment with the special emphasis on arsenic contamination: a case study
}

\author{
M. S. Rahman ${ }^{1}$ M. Asaduzzaman ${ }^{2 *}$, M. E. Huda ${ }^{2}$, S. Akther ${ }^{1}$, M. J. Kabir ${ }^{1}$, Y. N. Jolly ${ }^{1}$, K. J. Fatema ${ }^{1}$, \\ H. Sushmita ${ }^{1}$, B. A. Begum ${ }^{1}$ and S. B. Quaraishi ${ }^{1}$ \\ ${ }^{1}$ Chemistry Division, Atomic Energy Centre, Bangladesh Atomic Energy Commission, 4-Kazi Nazrul Islam Avenue, Shahbag, \\ Dhaka 1000, Bangladesh \\ ${ }^{2}$ Department of Environmental Sciences, Jahangirnagar University, Savar, Dhaka 1342
}

\begin{abstract}
Ground water is an important resource for domestic, agriculture, industrial and other economic sectors in Bangladesh. But unfortunately, arsenic contamination of ground water has emerged as a major public health problem in Bangladesh. The ground water arsenic contamination in Bangladesh was first discovered by the Chemistry Division of the Atomic Energy Centre, Dhaka (AECD) at Village Barogharia of Chapainawabganj District under Rajshahi Division in late 1993. As a part of ongoing research works at AECD, this study has been conducted in one of the most arsenic contaminated areas in Bangladesh for the assessment of ground water quality and its health risk. Total thirty-one ground water samples have been collected from six upazilas of Comilla district in order to assess the processes controlling geochemical constituents of ground water in the aquifer system. Irrigation water quality and health risk assessment is done to evaluate the suitability of ground water for irrigation and drinking purposes. From piper diagram it is found that the major water type is $\mathrm{Ca}^{2+}-\mathrm{Mg}^{2+}-\mathrm{HCO}_{3}$ in the study area. Gibbs plot suggesting that most of the samples fall within the rock-dominance zone. Silicate weathering-carbonate dissolution and silicate weathering-evaporation dissolution have been identified as the major processes that control the ground water solute content respectively. The suitability of water for irrigation is evaluated based on sodium percent ( $\mathrm{Na} \%)$, sodium adsorption ratio (SAR), residual sodium bicarbonate (RSBC), permeability index (PI), magnesium hazard (MH) and Kelly's ratio (KR). Na\%, SAR, RSBC, PI and KR values indicate that ground water is suitable for irrigation purposes. Drinking ground water and eating vegetables/crops/fruits grown in As contaminated areas are major pathways for human exposure to arsenic. This study revealed that As conc. of $83.87 \%$ and $90.32 \%$ ground water samples are exceeding the Bangladesh National Standard (50 ppb) and WHO guideline (10 ppb) respectively in the study areas. For health risk assessment of arsenic the average daily dose, hazards quotient (HQ) and cancer risk were calculated by using USEPA Models. The values of HQ were found to be $>1$ in $90.32 \%$ samples, which employed highly potential health risk to local residents. In addition, average value for cancer risk of 8per 1000 was found in study area. Arsenic is strongly correlated with $\mathrm{HCO}_{3}^{-}, \mathrm{Mg}^{2+}$ and $\mathrm{K}^{+}$. This principal component analysis (PCA) suggests that As mobilize in the shallow aquifer through dissolution of carbonate minerals. The results show that consumption of arsenic contaminated ground water poses an emerging health threat to the populations in the study area and hence needs urgent remedial and management measures. Continued monitoring of arsenic levels is recommended for future management strategies.
\end{abstract}

*Corresponding author e-mail: safiur_baec@yahoo.com 


\title{
Risk assessment of trihalomethanes (thms) formation in the supplied water of Dhaka city, Bangladesh
}

\author{
$\underline{\text { M. Bodrud-Doza }}^{1 *}$, N. Chowdhury ${ }^{1}$ and M. S. Rahman ${ }^{2}$ \\ ${ }^{1}$ International Centre for Climate Change and Development (ICCCAD), Independent University, Bangladesh (IUB) \\ ${ }^{2}$ Atmospheric \& Environmental Chemistry Laboratory, Chemistry Division, Atomic Energy Center, Dhaka, Bangladesh
}

\begin{abstract}
The presence of trihalomethanes (THMs) in the supply water system could increase the number of cancer patients in Dhaka. To identify the potential formation of THMs in supplied water, this research uses the Specific UV Absorbance (SUVA) indicator measuring the level of dissolved organic carbon (DOC) and UV-absorbance from water samples which are sourced from the surface water, treated and supplied by the water supply authority DWASA. Among the disinfection by-products (DBPs) and their levels of presence, THMs are the most common and indexed as carcinogenic. These are potentially formed by the reaction of the commonly used chemical disinfectants (e.g. chlorine, chlorine dioxide and chloramines) with organic matter (usually measured as total organic carbon) and/or inorganic matter (bromide). If the level is beyond the threshold limit, people might be exposed to THMs through ingestion of drinking water as well as inhalation of indoor air due its volatile characteristic. The drastic decreasing level of the groundwater aquifer of Dhaka city along with the ever-growing thirst of people together are driving the water supply authority on scaling up the possible surface water sources whereas this sources contain higher levels of organic matter increasing the potential of THMs formation in the water supply system. Therefore the measurement of DBPs in the newly expanding supply water system should be cautiously monitored to avoid the upcoming threat of a slow-onset hazard from supply water.
\end{abstract}

*Corresponding author e-mail: bodruddoza.env12@gmail.com

\section{Monitoring the water quality over a year by characterization of microbial community \& metagenomic analysis and measurement of physicochemical parameters of Hathirjheel lake water}

\author{
R. Patwary, S. Shill and S. Parveen \\ Institution of Food Science and Technology (IFST), Bangladesh Council of Scientific and Industrial Research (BCSIR)
}

\begin{abstract}
The Rajdhani Unnayan Kartipakkhya (RAJUK) initiated the Integrated Development of Hatirjheel-Begunbari Project in 2007 to save the water body from encroachment and turn it into a rainwater retention pond. According to official data, an integrated drainage management connecting Begunbari canal with Gulshan and Banani lakes, a sewer network, an aesthetic public space, and waterfronts. Prokaryotes, especially bacteria, play a dominant role in nutrient recycling and decomposition of chemical compounds in eutrophic lakes. Therefore, a shift in bacterial communities may be one of the most sensitive indicators of environmental change in eutrophic lakes. Our study aims to evaluate the water quality over a year period from different points of Hathirjheel lake and will be compared with Dhanmondi's lake water which is settled as control. Main concern is that portion lake water contain high number of antibiotic resistant bacteria load (Amoxicillin, Cefixime and Ciprofluxacin currently used as prophylaxis against enteric diseases) and that antibiotic resistant determinants harboring bacteria will be disseminated throughout the lake water body inevitably. Six months data also revealed that most of the isolated E. coli and pathogenic Salmonella sp. are resistant against Amoxicillin, Cefixime and Ciprofluxacin. That resistance may be acquired in the lake water due to lake water community dynamics or harboring before in the sewage. It can be speculated that hospital sewages are connected in the Hathirjhil lake. High dissolved Oxygen (DO) and low Biological Oxygen Demand (BOD) denote acceptable quality of sewage water effluent. In the Rampura region lake water DO is declined and BOD is increased with time and that is alarming in respect to environment concern. But other locations DO and BOD remain static or DO increased and incase of BOD is vice-versa.
\end{abstract}

*Corresponding author e-mail: rubel.sh019@gmail.com 


\title{
Effects of pesticide pollution on the haematological parameters of a fish, Labeo rohita (Hamilton, 1822)
}

\author{
J. Jasmin, M. M. Rahman* and M. R. Islam \\ Department of Fisheries, University of Rajshahi, Rajshahi-6205, Bangladesh
}

\begin{abstract}
As pesticide's pollution is a common phenomenon in aquatic environment of Bangladesh, an attempt has been made to investigate the effects of two pesticides, difenoconazole and thiamethoxam on haematological parameters of a widely consumed fish, Labeo rohita for 7 days. Two experiments were conducted in glass aquariums under 3 treatments $\left(T_{1}, T_{2}\right.$ and $\mathrm{T}_{3}$ ). In Experiment-1: $\mathrm{T}_{1}$ treated as control; $\mathrm{T}_{2}$ treated with difenoconazole at $0.001 \mathrm{ml} / \mathrm{L}$ and $\mathrm{T}_{3}$ treated with difenoconazole at $0.0 .003 \mathrm{ml} / \mathrm{L}$. In Experiment-2: $\mathrm{T}_{1}$ treated as control; $\mathrm{T}_{2}$ treated with thiamethoxam at $0.05 \mathrm{mg} / \mathrm{L}$ and $\mathrm{T}_{3}$ treated with thiamethoxam at $0.10 \mathrm{mg} / \mathrm{L}$. In this study, water quality parameters (temperature, dissolved oxygen and $\mathrm{pH}$ ), behaviour of fish and haematological parameters (WBC, RBC, Hb, PCV, MCV, MCH and MCHC) were analyzed with standard methods. Statistical analysis was done by using one-way analysis of variance. During the study period, there was no significant difference in the temperature, $\mathrm{DO}$ and $\mathrm{pH}$ of test water among the treatments and were within the productive ranges. When the fishes were exposed to the pesticides, they decreased their food intake, exhibited restlessness and sluggish swimming. When the fishes treated with difenoconazole showed a significant decrease of WBC, RBC, Hb, PCV and MCV whereas $\mathrm{MCH}$ and $\mathrm{MCHC}$ increased compared to the control. On the other hand, when fishes treated with thiamethoxam, RBC, Hb, $\mathrm{PCV}, \mathrm{MCH}$ and $\mathrm{MCHC}$ increased significantly, but $\mathrm{WBC}$ and $\mathrm{MCV}$ decreased compared to the control. The study concluded that presence of difenoconazole and thiamethoxam pesticides in aquatic environment produce an adverse effect in haematological parameters of the fish.
\end{abstract}

*Corresponding author e-mail: mratan1980@gmail.com

\section{Determination of PAHs in the water and sediment of Hatirjheel lake using GC-MS and study of the water quality parameter}

\author{
M. A. Haque $^{1 *}$, M.Z. Sarkar ${ }^{1}$, S. Ahmed ${ }^{2}$ and M. Mostafa ${ }^{2}$ \\ ${ }^{I}$ Deparment of Chemistry, Jagannath University, Dhaka-1100 \\ ${ }^{2}$ Institute of National Analytical Research and Service(INARS), BCSIR, Dhaka-1205
}

\begin{abstract}
Many carcinogenic PAHs found in water and sediment samples from different locations along the Hatirjheel lake, collected in April 2015. All the PAHs were determined by using GC-MS. Four carcinogenic PAHs were determined in water sample. These are mentioned with their concentrations as Pyrene (786.952 ppb), Benzo[a]anthracene (152.900 ppb), Anthracene (107.299 $\mathrm{ppb}$ ), Phenanthrene (220.392 ppb). Three PAHs were determined in the sediment sample, Pyrene (691.815 ppb), Phenanthrene (506.332 ppb) and Crysene (655.588 ppb). The water samples were also tested for some water quality parameters namely, $\mathrm{pH}$, electrical conductivity (EC), dissolved oxygen (DO), biological oxygen demand (BOD) and total organic carbon (TOC). Samples from some sampling points exceed the standard value set for waste discharged quality standards. EC was found to be $640 \mu \mathrm{s} / \mathrm{cm}$ to $860 \mu \mathrm{s} / \mathrm{cm}$ while TOC was in the range of $26.95 \mathrm{mg} / \mathrm{L}$ to $57.06 \mathrm{mg} / \mathrm{L}$.
\end{abstract}

*Corresponding author e-mail: amin2k4@yahoo.com 


\title{
Spatial and temporal representation of metal pollution caused by ship breaking activities in the coastal area of Chittagong using GIS and remote sensing
}

\author{
M. H. Haque ${ }^{*}$, F. Ahmad, F. Abdullah and M. Maliha \\ Department of Water Resources Engineering, Bangladesh University of Engineering and Technology (BUET), Dhaka-1000, \\ Bangladesh
}

\begin{abstract}
Ship breaking or in other words ship dismantling is an industry that focuses on retrieving the metal that the ships harbor and properly recycling the metal found. Bangladesh is one of the front runners in the industry and is greatly dependent on the metal that is recycled. However, the non-regulation of the industry and the overall indifference of the people concerned are leading to the destruction of the environment around ship breaking yards. In the context of this paper, this impact has been purposefully illustrated by devising maps using GIS that show the concentric variation of metals and quality of water found in a control site and the area around the ship breaking yards. Utilizing spatial and temporal variation of metal concentration data obtained from preceding studies and those derived from Remote Sensing imagery, the extent of metal pollution in the coastal zone of Chittagong is represented through GIS illustrations. A control site has been characterized by the lesser extent of pollution observed. A comparison is going to be made among the concentrations of metals found in the control site with that of Chittagong and the standard value. Through the illustrated comparison of both these sites, it can be understood how drastically the environment around the ship breaking yards is impacted and the assessment of the negative impact of this pollution on the fish, zooplankton and other vertebrates and invertebrates living here. GIS mapping not only provides an easily understandable idea about the pollution but also expedites the decision making procedures.
\end{abstract}

*Corresponding author e-mail: hhaque6944@gmail.com, fahimahmad1993@gmail.com 


\title{
The fate of selected heavy metals from industrial waste water on soil along the bank of Karnopara canal at Savar, Bangladesh
}

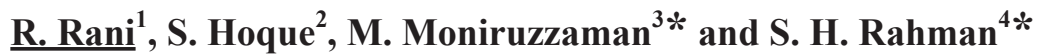 \\ ${ }^{1}$ Department of Soil Science, Dhamrai Govt. College, Dhamrai \\ ${ }^{2}$ Department of Soil, Water and Environment, University of Dhaka, Dhaka 1000 \\ ${ }^{3}$ Soil and Environment Section, Biological Research Division, BCSIR Laboratories, Dhaka 1205 \\ ${ }^{4}$ Department of Environmental Sciences, Jahangirnagar University, Dhaka 1342
}

\begin{abstract}
The impacts of selected heavy metals $(\mathrm{Cd}, \mathrm{Pb}, \mathrm{Ni}, \mathrm{Cr}$ and $\mathrm{Zn}$ ) in soils irrigated using industrial wastewater (termed as contaminated soil) and ground water (termed as controlled soil) was investigated at four different locations along the bank of Karnopara canal, Savar, Bangladesh. The soil was collected from 0-50 cm depth from the ground. Metals were determined by flame Atomic Absorptions Spectrophotometer (AAS) (Model Shimadzu AA - 7000). Total Cd, Pb, Ni, Cr and Zn in the contaminated soils ranged from $0.41-0.50,11.37-39.46,44.92-65.27,31.76-40.41$ and $350.61-357.92 \mu \mathrm{g} / \mathrm{g}$ respectively. The standard sequential extraction method was used determining the fate of metal species applied through irrigation water in the soils. The sequences of extractions were six operationally defined groups: water-soluble (F1), exchangeable (F2), carbonate bound (F3), oxide bound (F4), organic bound (F5) and residual (F6). The mobile fractions (F1+F2+F3) of contaminated and controlled soils contained $36 \%$ and $19 \%$ of total $\mathrm{Cd}, 1.61 \%$ and bdl $*$ of total $\mathrm{Pb}, 1.04 \%$ and $2.40 \%$ of total $\mathrm{Ni}, 4.74 \%$ and $6.32 \%$ of total $\mathrm{Cr}, 0.10 \%$ and $0.67 \%$ of total $\mathrm{Zn}$, respectively. The mobile fractions were higher for Cd than other metals. The relative extractability expressed as the ratio of DTPA to $\mathrm{HNO}_{3}-\mathrm{HClO}_{4}$ acid digested contents were 0.156 for $\mathrm{Cd}, 0.098 \mathrm{for} \mathrm{Pb}, 0.006$ for $\mathrm{Ni}, 0.002$ for $\mathrm{Cr}$ and 0.005 for $\mathrm{Zn}$. Of the total heavy metals, only a small portion becomes mobile and as a consequence create the less toxic effect at the present state of soil contamination.
\end{abstract}

*bdl= Below Detection Limit

*Corresponding author e-mail: monirbcsir@gmail.com, hafizsr@juniv.edu, 


\section{BANGLADESH JOURNAL OF SCIENTIFIC AND INDUSTRIAL RESEARCH}

\begin{tabular}{lll}
\hline Oral Presentation (C1-C9) & CONTENTS & Special Issue 2017 \\
\hline
\end{tabular}

01. An environmental friendly approach for reclamation of lead and cadmium contaminated soil 19 using soluble organic matter

Tamjid-Us-Sakib and Sirajul Hoque

02. $\mathrm{Cd}, \mathrm{Cr}, \mathrm{Ni}$ and $\mathrm{Cu}$ in some tannery effluents in dry and rainy season

Shahnaz Sultana, M. F. Alam, F. T. Ahmed, N. C. Dafadar, M. S. Rahman and G. Ara

03. Environmental aspects of coal ash pond water: surface and ground water contamination

A. A. Khan, Tamjid-Us-Sakib, A. N. Ahmed and S. Sultana

04. Ammonia free deliming agent based on organic acid for leather processing

A. H. Quadrey, M. T. Uddin, M. J. Chowdhury, M. A. Razzaq and Al- Mizan

05. Health risk assessment of adults and children in presense of $\mathrm{Cd}$ in groundwater in Damurhuda Union, Chuadanga.

F. T. Ahmed, S. Shahnaz, M. F. Alam, N. C. Dafadar and M. T. Hasan

06. PAHs and VOCs - A new threat to our environment in Bangladesh

S. Siraj, S. Ahmed, M. A. Akbor, M. A. Haque and M. A. Ahsan

07. Oxidation of vanadium(iii) to vanadium(iv) by thioredoxin and l-serine by biogenic oxidants: an in vitro study for the redox behavior of vanadium in the vanadocyte of ascidians

M. K. Islam, F. B. Biswas, R. I. Ripon and M. M. Hossain

08. Environmental and chemical safety management practices in knit garments industry in 22 Bangladesh

B. C. Sarker, A. K. Reza

09. Physicochemical assessment of groundwater resources in some selected parts of greater 23 Chittagong district, Bangladesh

M. D. Alam Chowdhury, M. J. Ahmed*, S. H. Begum and N. Mandal 


\title{
An environmental friendly approach for reclamation of lead and cadmium contaminated soil using soluble organic matter
}

\author{
$\underline{\text { Tamjid-Us-Sakib }}^{1 *}$ and S. Hoque ${ }^{2}$ \\ ${ }^{1}$ Institute of Mining, Mineralogy and Metallurgy, BCSIR, Joypurhat \\ ${ }^{2}$ Department of Soil, Water and Environment, University of Dhaka
}

\begin{abstract}
The presentstudy reports the feasibility of reclamation of a lead and cadmium contaminated soil using the solution containing organic carbon resulting from the decomposition of organic matter, an environmentally-friendly and cost-effective leachate. For conducting this experiment, three soil samples were used. Column leaching experiments were performed to test the efficiency of organic solution containing two rates of organic carbon $(0.25 \mathrm{~g} / \mathrm{L}$ and $0.50 \mathrm{~g} / \mathrm{L})$ for the reclamation of the lead and cadmium contaminated soil in natural conditions. Results showed that utilization of the solution containing organic carbon resulting from the decomposition of organic matter was effective for removal of lead from the contaminated soil, attaining $30.87 \%-74.97 \%$ of $\mathrm{Pb}$ in an alkaline condition. On the other hand, it was found that this concentration of carbon was not much effective for Cd removal from contaminated soil, attaining only $1.18 \%-24.14 \%$ of Cd. Clay content, $\mathrm{pH}$ and organic matter content of soil might be responsible for such differences in removal efficiency among samples. Such a reclamation procedure indicated that solution containing organic carbon released during decomposition of fresh organic matter is a promising agent for remediation of lead contaminated soils. However, further research is needed before the method can be practically used for in situ reclamation of heavy metal contaminated sites.
\end{abstract}

*Corresponding author e-mail: abir.swe@gmail.com

\section{$\mathrm{Cd}, \mathrm{Cr}$, Ni and $\mathrm{Cu}$ in some tannery effluents in dry and rainy season}

\author{
S. Sultana ${ }^{*}$, M. F. Alam, F. T. Ahmed, N. C. Dafadar, M. S. Rahman and G. Ara \\ Nuclear and Radiation Chemistry Division, Institute of Nuclear Science \& Technology, Bangladesh Atomic Energy \\ Commission, P. O. Box 3787, Dhaka, Bangladesh.
}

\begin{abstract}
Tannery effluents are considered as one of the major contributors to environment pollutions. In the present study, tannery effluents were collected from three different polluted sites of the river Buriganga, Dhaka, and ground water within half kilometer of the river in dry and rainy seasons. The elemental analysis of the samples was conducted using Flame Atomic Absorption Spectrophotometer (FAAS). The $\mathrm{pH}$ of the effluents was found to be in acidic range. The concentrations of Cd, $\mathrm{Cr}$, $\mathrm{Ni}$ and $\mathrm{Cu}$ of tannery effluents were found in the range of $0.98-1.42,0.11-9.75,0.08-0.77$ and $0.75-0.82$ ppm respectively. Concentrations of most of the elements in the water samples were higher than the DoE standard for recommended Effluent Treatment Plants especially $\mathrm{Cd}$ and $\mathrm{Cr}$ in the tannery effluents were higher. Most of the dissolved metal concentrations in the water samples were similar. However, the concentrations of different physicochemical properties varied with the seasons. The dry season had significantly higher contamination loads, which were decreased during the monsoon season. Anthropogenic activities, as well as the variation in river water flow during different seasons were the main reasons for this high degree of water pollution.
\end{abstract}

*Corresponding author e-mail: shahnazju32@gmail.com 


\title{
Environmental aspects of coal ash pond water: surface and ground water contamination
}

\author{
A. A. Khan, Tamjid-Us-Sakib, A. N. Ahmed and S. Sultana * \\ Institute of Glass \& Ceramic Research and Testing (IGCRT), BCSIR, Dhaka
}

\begin{abstract}
Coal ash pond is an engineered structure for disposal of bottom ash and fly ash. Ash is pumped to ash pond in the form of paste under high concentration slurry disposal or mixed with water in a ratio varying from 1: (8 to 20). Leachate from fly ash contains heavy metals in excess of allowable standard. Coal ash ponds are toxic sources of dangerous pollutants that pose a danger to human and environmental health if the toxins spread to adjacent surface water and drinking water. This research was done in order to determine contamination level of coal ash pond water (Barapukuria thermal power plant) between surface water and ground water. Samples were collected from different spots of coal ash pond, nearby surface water and tube-well water from surrounding area. Physiochemical parameters including Temperature, $\mathrm{pH}, \mathrm{EC}$, TDS, Turbidity, DO and BOD were measured. Different heavy metals such as arsenic (As), cadmium (Cd), chromium $(\mathrm{Cr})$, lead $(\mathrm{Pb})$, copper $(\mathrm{Cu})$, zinc $(\mathrm{Zn})$ and mercury $(\mathrm{Hg})$ were analyzed. The result reported that the surrounding area was highly contaminated with $\mathrm{Pb}, \mathrm{Cr}$, and $\mathrm{Cu}$. No tube-well of that area can pump water within 100 feet depth in soil. As a result, in future people of that area will be suffered by drinking water crisis. It can be concluded that the age of this power plant increases the contamination level will be increased.
\end{abstract}

*Corresponding author e-mail: sharminkanak@yahoo.com

\section{Ammonia free deliming agent based on organic acid for leather processing}

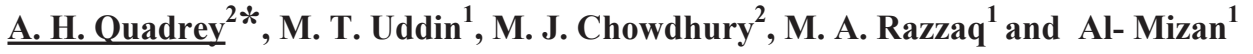 \\ ${ }^{1}$ Leather Research Institute, BCSIR, Nayarhat, Savar, Dhaka-1350, Bangladesh \\ ${ }^{2}$ BCSIR Laboratories, Dhaka, BCSIR-1205, Bangladesh
}

\begin{abstract}
Environmental pollution is a major concern for leather industries. The generation of huge amounts of affluent and their disposal into water bodies without proper treatment has lead to detrimental effects on environment. Each tannery effluent is composed of several kinds of liquid waste: soak, lime, delime \& bate, pickle \& chrome and all kind of wash water. Conventional deliming is based on ammonium salts in which significant amount of ammonia is liberated which leads to further demand for critical waste water treatment. Deliming is an important step in leather wet processing. Since liming includes the addition of excess lime inside the hide or skin being processed, the key objective of deliming is to eliminate alkalinity as well as lowering the $\mathrm{pH}$. Therefore, this research is an endeavor to develop an industrially viable deliming agent based on organic acid which evolves no ammonia. Deliming efficiency of deliming agent and physical property, other parameters are comparable with the conventional delimed leather. No remarkable change in the usual deliming process is required except introduction of the newly developed deliming agent in processing chain. Furthermore ammonia nitrogen content in delime discharge bath significantly reduced.
\end{abstract}

*Corresponding author e-mail: quadery.1ri@gmail.com 


\title{
Health risk assessment of adults and children in presense of $\mathrm{Cd}$ in ground water in Damurhuda Union, Chuadanga
}

\author{
$\underline{\text { F. T. Ahmed }}^{1 *}$, S. Shahnaz ${ }^{1}$, M. F. Alam ${ }^{1}$, N. C. Dafadar ${ }^{1}$ and M. T. Hasan ${ }^{2}$ \\ ${ }^{1}$ Nuclear and Radiation Chemistry Division, Institute of Nuclear Science and Technology, Atomic Energy Research \\ Establishment, G. P. O. box-3787, Dhaka, Bangladesh \\ ${ }^{2}$ Department of Public Health and Informatics, Jahangirnagar University, Savar, Dhaka.
}

\begin{abstract}
Ground water samples were collected from 10 different sites throughout the Damurhuda Union, Damurhuda, Chuadanga for risk assessment study. The aim of the study is to determine the level of Cd metal in drinking water of the study area and calculate the health risk (hazard quotient, HQ and carcinogenic risk) of adults and children with exposure to this element via oral ingestion and absorption through skin. The concentration of $\mathrm{Cd}$ was measured using Atomic Absorption Spectrophotometer. HQ was found greater than 1 in all sampling site. The carcinogenic risk of Cd for adult and children ranged from 0.00016 to 0.00072 and from 0.00033 to .00153 which indicates high cancer risk respectively with an overall average of 0.00043 and 0.00090 .
\end{abstract}

*Corresponding author e-mail: farahchem53@hotmail.com

\section{PAHs and VOCs-A new threat to our environment in Bangladesh}

\author{
$\underline{\text { S. Siraj }}^{1 *}$, S. Ahmed ${ }^{1}$, M. A. Akbor ${ }^{1}$, M. A. Haque ${ }^{2}$ and M. A. Ahsan ${ }^{1}$ \\ ${ }^{1}$ Institute of National Analytical Research and Service, Bangladesh Council of Scientific and Industrial Research \\ ${ }^{2}$ Department of Chemistry, Jagannath University
}

\begin{abstract}
In the last decade, the scientific community in Bangladesh often discussed the water pollution caused by heavy metals and other inorganic contaminants. However, organic pollutants may become potential hazards in future if they remain unfocused. In this paper, we will present the polyaromatic hydrocarbons (PAHs) and volatile organic compounds (VOCs) contamination level in the river water around Dhaka city in the years between 2012-2016. Some of the PAHs and VOCs are environmentally significant and known as carcinogens. This study investigated such PAHs e.g. benz[a]anthracene, benzo[a]pyrene, benzo[ghi]perylene, benzo[k]fluoranthene, chrysene, dibenz[a,h]anthracene, fluorene, indeno[1,2,3,-cd]pyrene, phenanthrene, acenapthylene, anthracene and pyrene and VOCs e.g. chlorobenzene, ethylbenzene, tetrachloroethylene, styrene, o-xylene, p-xylene and toluene in the sampling areas. In this study, water and sediments were collected from Buriganga, Turag, and Shitolokkha river. Liquid-liquid and solid-liquid extraction was employed for sample preparation for water and sediments, respectively and the prepared samples were analysed by gas chromatograph - mass spectrometer. The listed PAHs were found below detection limit in Buriganga water. However, benz[a]anthracene (119 mg/g), benzo[a]pyrene (130 mg/g), benzo[k]fluoranthene $(157 \mathrm{mg} / \mathrm{g})$, pyrene $(240 \mathrm{mg} / \mathrm{g})$ and anthracene $(2700 \mathrm{mg} / \mathrm{g})$ were detected in one of the sediment samples collected from Buringanga. In contrast, VOCs including toluene (2-90 mg/L), ethylbenzene (1-5 mg/L), p-xylene (1-14 mg/L), styrene (1-15 mg/L), and o-xylene (1-54 mg/L) were predominantly found in water samples. In sediments, tetrachloroethylene $(0.13 \mathrm{mg} / \mathrm{g})$ and chlorobenzene $(0.04 \mathrm{mg} / \mathrm{g})$ were additionally detected with other VOCs including toluene $(0.05-0.8 \mathrm{mg} / \mathrm{g})$, ethylbenzene (1-5 mg/g), p-xylene (1-14 mg/g), styrene (1-15 mg/g), and o-xylene (1-54 mg/g). Turag and Shitolokkha have also encountered similar contamination by PAHs and VOCs. In this study, we also attempted to understand the transport of the contaminants between water and sediments. We will propose possible treatment processes for both PAHs and VOCs which is crucial for supplying water in Dhaka city.
\end{abstract}

*Corresponding author e-mail: shajahan.siraj.au@gmail.com 


\title{
Oxidation of vanadium(III) to vanadium(IV) by thioredoxin and L-serine by biogenic oxidants: an in vitro study for the redox behavior of vanadium in the vanadocyte of ascidians
}

\author{
M. K. Islam ${ }^{1 *}$, F. B. Biswas ${ }^{1}, \underline{\text { R. I. Ripon }}{ }^{1}$ and M. M. Hossain ${ }^{2}$ \\ ${ }^{1}$ Department of Chemistry, Mawlana Bhashani Science and Technology University, Santosh, Tangail-1902, Bangladesh \\ ${ }^{2}$ Department of Chemistry, Jahangirnagar University, Savar, Dhaka-1342, Bangladesh
}

\begin{abstract}
Ascidians are known to accumulate high levels of vanadium from sea water, in their blood cells, called vanadocytes. To evaluate the fact that total accumulation process of vanadium by ascidians are redox or not, and to justify the subsistence of trace extent of vanadium(IV) with large extent of vanadiu(III) in the vanadocyte of ascidians, the oxidation behavior of vanadium(III) to vanadium(IV) followed by series of amino acids and thioredoxin were investigated. UV-Visible and electron spin resonance (ESR) spectroscopy revealed that thioredoxin and only L-serine assist very fast oxidation having adoption the physiological pH (4 5.5) region relevant to vanadocyte. Specially, amino acids favor the oxidation of vanadium(III) which have the low stability constant with vanadium(III) and larger stability constant with vanadium(IV), i.e., $\log \mathrm{K}_{1} \operatorname{and} \log \mathrm{K}_{2}>10$.
\end{abstract}

*Corresponding author e-mail: dr.islam.mbstu@gmail.com

\section{Environmental and chemical safety management practices in knit garments industry in Bangladesh}

\author{
B. C. Sarker $^{1 *}$ and A. K. Reza ${ }^{2}$ \\ ${ }^{1}$ Assistant Secretary (Training), Fire \& Safety Department, Bangladesh Knitwear Manufacturers \& Exporters Association \\ (BKMEA) \\ ${ }^{2}$ Senior Assistant Secretary, Research \& Development Department, Bangladesh Knitwear Manufacturers \& Exporters \\ Association (BKMEA)
}

\begin{abstract}
The knit garments industry of Bangladesh has been undergoing many different changes in the past decade, with significant advances being done in chemical safety and environmental management practices. An understanding of these advances is crucial as a comparative analysis shows a finite change that has been happening in the industry. The scope of the study is in the areas of Dhaka, Narayanganj and Gazipur with a sample size of 45 knit factories in 2016 . The study yields results that that $95 \%$ of the management practices are set due to regulations by buyers, and due to national policies. The local national policies are adopted by more than $80 \%$ of the factories, but high end brands do not take in orders if stricter policies are not adopted. This study also shows that $75 \%$ of the factories are concerned with chemical safety practices and will adopt them on need basis. In addition, this study discusses about great change of disposal methods in the form of ETP discharge (mainly biological) and other initiatives common to the environmental management practices.
\end{abstract}

*Corresponding author e-mail: biddutsarker.bau@gmail.com 


\title{
Physicochemical assessment of ground water resources in some selected parts of greater Chittagong district, Bangladesh
}

\author{
M. D. Alam Chowdhury, M. J. Ahmed*, S. H. Begum and N. Mandal \\ Laboratory of Analytical Chemistry, Department of Chemistry, University of Chittagong, Chittagong-4311, Bangladesh
}

\begin{abstract}
Chittagong is one of the major developing cities in Bangladesh; its area is rapidly increasing as neighboring districts like Rangamati, Khagrachori, Bandorban and Cox's Bazar are demarcated as separate the Chittagong Municipal Corporation $(\mathrm{CMC})$. Majority of the people are using the ground water as a prime source for their domestic needs, besides the CMC is supplying them with an allocation of treated water. Assessing the quality of ground water is an important issue in the modern times. So our research work has been focused on various essential physical and chemical parameters including color, odor, transparency, $\mathrm{pH}$, conductivity, salinity, total dissolved solids (TDS), dissolved oxygen (DO), Chemical oxygen demand (COD), silica, sulfate, nitrate, ammonia, orthophosphate, total acid hydrolysable phosphate, chloride, fluoride, M. alkalinity, P. alkalinity, hardness, sodium, calcium, magnesium, arsenic, iron, potassium, manganese, chromium, nickel, cadmium, lead silver, mercury and zinc of water samples from various districts of Chittagong region. An attempt has been made in this study to evaluate the ground water quality in different districts greater Chittagong region. Ground water samples were collected from shallow wells, deep wells and hand pumps of different heavily industrialized and domestic blocks. The work has been confined to greater Chittagong region and districts of Rangamati, Khagracchari, Bandarban and Cox's Bazar. Since the water quality is expected to vary with season, multiple samples have been collected from 100 sites at an interval of 2 to 3 weeks in each district before and after monsoon for hydrological year 2014-2015. The perennial natural water resources and located at different geological sites will be sampled only once or twice. The work will be conceded by traveling to the sampling site, collection of required water samples, and estimation of water discharge and determination of basic parameters of the site. The water samples have been analyzed for physicochemical parameters as prescribed by APHA, using standard techniques and compared with WHO (2014-2015) drinking water quality standards. The laboratory findings of water quality parameters were also compared with the recommended values set by DoE and BSTI. From Pearson Correlation program, significant positive and negative correlations were found for different parameters. The results revealed that the ground water in the two districts is unfit for drinking as per WHO/BSTI guidelines. The presence of elements like $\mathrm{As}, \mathrm{Se}$, and $\mathrm{Pb}$ in toxic amounts is a matter of serious concern. Need for water quality information is to provide a basis on which regional and national level policy decisions can be based. Wise decisions must be based on sound information.
\end{abstract}

*Corresponding author e-mail: pmjahmed55@gmail.com 


\section{BANGLADESH JOURNAL OF SCIENTIFIC AND INDUSTRIAL RESEARCH}

\section{Poster Presentation (PP)} CONTENTS Special Issue 2017

01. Water quality of the Karnafuli river and its impact on the environment of Chittagong, Bangladesh 24 M. E. Ali, M. A. Islam and M. J. Ahmed

02. Drinking water quality in MBSTU campus

A. C. Bhowmick, F. B. Biswas and M. Ashrafuzzaman

03. A simple spectrofluorimetric method for the determination of cadmium at ultra-trace level in some 25 environmental water, biological, food, and soil samples using 2', 3, 4', 5, 7-pentahydroxyflavone M. J. Ahmed, I. Jahan and M. A. Hakim

04. Assessment of water quality parameters and treatment of the meghna river water of Bhairab Bazar, 26 Kishoreganj, Bangladesh

R. Rahman, A. Al Ryhan, T. S. B. Monir, A. Mia, M. R. Islam, M. R. Islam and R. A. Khan

05. Photocatalytic decomposition of textile dyeing effluent on $\mathrm{TiO}_{2}$ catalyst M. H. Tareque, M. G. Mostafa and M. A. Islam

06. Air Pollution tolerance index on Mangifera indica plant species in the greater Dhaka region, Bangladesh 27 Halima-E-Sadia, F. Jeba, M. D. Hossain and A. Salam

07. Fishery status of Tangail sadar area in Bangladesh A. Al Mamun Siddiqui and M. Rashed-Un-Nabi

08. Organochlorine compounds and toxic metals in marine fish samples of Bangladesh M. M. Islam, R. Islam, M. Shoeb and N. Nahar

09. Hydro-environmental imbalance due to the minerals and ionic pollution of Turag river in Bangladesh

J. B. Islam, S. Akter, M. N. Uddin and M. Sarkar

10. Antibacterial activity of soil-bound oxytetracycline

S. Chowdhury, P. Chakma and S. Hoque

11. Transformation of malathion by phosphate solubilizing bacteria

P. Chakma, S. Chowdhury and S. Hoque

12. Analysis and treatment of Shitalakshya river water in Bangladesh

M. N. Islam, N. A. Kona, S. Shahida, M. M. Haque, M. R. Islam, M. S. Manir and R. A. Khan

13. Harvested potable rainwater quality of Mongla and Sarankhola upazila in Bagerhat district, Bangladesh

M. A. Rahman, M. A. Hashem and M. H. R. Sheikh

14. Heavy metal contents in the surface water of Chittagong sea beach in Bangladesh

A. K. M. Atique Ullah, S. B. Quraishi, S. R. Khan, A. R. M. Tareq and A. K. M. Fazle Kibria

15. Trace metal concentration in some branded teas in Bangladesh 


\section{BANGLADESH JOURNAL OF SCIENTIFIC AND INDUSTRIAL RESEARCH}

\section{Poster Presentation (PP)}

\section{CONTENTS}

Special Issue 2017

16. Hybrid hydrogel for removal of heavy metals from waste effluents

S. Afroz, F. Afrose, M. A. Alam, A. K. M. M. Alam and R. A. khan

17. Phytoremediation of cadmium and zinc from water using water hyacinth (Eichhornia crassipes)

T. Yeasmin and M. S. Islam

18. Impacts of tidal river management on biodiversity: a case study in Beel Vayena

M. M. Al Masud

19. Impacts of tidal river management on food security and household income in Jessore district of 34 Bangladesh

M. M. Al Masud and A. K. Azad

20. Microbiological quality of drinking water in Khulna City Corporation slum area in Bangladesh A. Kundu, M. A. Rahman and M. A. Yousuf

21. Ozone wash in waste water treatment

S. Bhattacharjee and F. Taylor

22. Treatment of waste water from leather industry in Dhaka, Bangladesh

Z. R. Usha, A. Mia, M. R. Islam, M. S. Manir and R. A. Khan

23. Water quality of Hatirjheel lake in Dhaka, Bangladesh M. Akther and M. R. Rakib

24. Water quality assessment and ground water modelling of rapidly industrialized Konabari district of Bangladesh

S. Bhattacharjee, M. Bermund, H. Ahmed and P. Das

25. Quality of surface water of different river sources

P. Laboni, M. Islam and A. F. M. M. Rahman

26. Ground and surface water quality of Noakhali Science and Technology University (NSTU) 38 campus, Noakhali, Bangladesh

T. S. B. Monir, R. R. Rima, A. A. Rayhan, A. Mia, M. R. Islam, M. A. Alam and R. A. Khan

27. Selected mango varieties and correlation with the shelf-life of their developed products 


\section{BANGLADESH JOURNAL OF SCIENTIFIC AND INDUSTRIAL RESEARCH}

Poster Presentation (PP) CONTENTS Special Issue 2017

28. Analysis and treatment of the Meghna river water, Ramgoti, Laxmipur, Bangladesh 39 A. Al Ryhan, R. Rahman, T. S. B. Monir, A. Mia, M. R. Islam, M. R. Islam and R. A. Khan

29. Phenols and a few phenolic derivatives: a comprehensive study in Shitalakshya river water K. M. Rahman and R. Islam

30. Effects of biochar on plant growth

U. Salma, S. M. I. Huq, M. H. Rashid and T. F. Khan

31. Waste water of Hazaribagh tannery areas in Dhaka, Bangladesh F. Ahmed, A. N. M. Fakhruddin and M. M. Kabir

32. Pollution status of heavy metals in water of Halda river using pollution evaluation indices B. Das, M. A. Islam, S. B. Quraishi and B. Hossain

33. Physio-chemical status of water and distribution of Chlorophyll $a$ in Jamuna river S. Anwar, U. H. Mitu, A. S. M. Saifullah, S. Sheikh and M. J. Uddin

34. Analysis and treatment of Madhumati river water of Bangladesh A. Mia, M. N. Salam, Z. R. Usha, M. R. Islam, M. S. Manir, M. Z. I. Mollah and R. A. Khan

35. Coastal fisheries and socio-economic status of Maheshkhali upazila, Cox's Bazar, Bangladesh M. A. Kashem and A. A. M. Siddiqui

36. Hydro geochemical characterization of groundwater in Gazipur district of Bangladesh F. Yeasmin, A. H. M. Saddat, M. A. T. M. Tanvir Rahman and B. Saha

37. Environmental awareness among urban residents in Bangladesh: a case study of Sylhet City 43 Corporation

S. D. Shuvo

38. Proximate composition and quality of freshwater dried fish products M. B. Alam, M. A. B. Siddique, M. M. Alam, M. A. Hussain and F. A. Flowra

39. Health risk assessment of leachate in the surrounding areas of waste landfill site at Khulna in 44 Bangladesh

P. K. Mahanta and M. R. Isalm

40. Environmental parameters (temperature, humidity, noise and illumination) in ready-made 45 garment industries, Gazipur, Bangladesh

J. Ferdouse, R. Sultana, M. B. Latif, S. K. Mondol and B. C. Sarker

41. Biochemical quality assessment of fish powder

S. N. Jahan, M. B. Alam, B. Islam, P. K. Karmakar and F. A. Flowra

42. Clay composites to prevent the growth of pathogenic microorganism 


\section{BANGLADESH JOURNAL OF SCIENTIFIC AND INDUSTRIAL RESEARCH}

\section{Poster Presentation (PP)}

\section{CONTENTS}

Special Issue 2017

43. Removal of chromium from aqueous system using adsorbents synthesized from bio-waste M. Saha, S. Mostofa, S. A. Jahan, N. Sharmin and S. Ahmed

44. Conductive microemulsion used as template for electrodeposition of cobalt

F. Begum, M. Y. A. Mollah, M. M. Rahman and M. A. B. H. Susan

45. Volumetric and viscometric properties of $\mathbf{n}$-acetylcysteine in aqueous dimethylsulfoxide solution at different temperatures

M. H. Khan, P. Ahamed and M. A. Yousuf

46. Cost effective graphite pencil based sensor for simultaneous detection of dihydroxybenzene isomers M. I. Khan, N. T. Tonu, P. Ahamed, M. Jamal and M. A. Yousuf

47. Physico-chemical properties of rain water samples from Dhaka, Bangladesh N. A. Kona, A. Mia, S. Shahida, M. N. Islam, T. S. B. Monir, R. Rahman and R. A. Khan

48. Quality parameters and treatment of Meghna river water of Bangladesh M. M. Khanam, M. N. Salam, A. Mia, M. R. Islam, M. S. Manir and R. A. Khan

49. Physico-chemical parameters of water in flood affected area at Gazipur, Bangladesh F. T. Ahmed, S. Shahnaz, M. F. Alam and N. C. Dafadar

50. Detoxification of hexavalent chromium by Bacillus pumilus and assessment of multiple antibiotic resistance index for biosafety measure

M. E. Karim, M. Akhter, M. Moniruzzaman, M. U. Hossain, Z. Fardous, K. C. Das, M. Salimullah and M. A. Z. Chowdhury

51. Hydro-chemistry and pollution of Dhaleshwari river due to recently shifted tannery industry K. S. Ahmed, M. Sarkar and B. Saha

52. Fish species diversity of Halti beel fish sanctuary and income status of fishermen M. A. B. Siddique M. B. Alam, M. A. Hussain, M. M. Alam and F. A. Flowra

53. Climate change and sea water intrusion in selected coastal areas of Bangladesh: impacts on water quality

M. F. Sarder, M. S. Isalm and M. G. Mostafa

54. Physicochemical and microbial characterization of green and red chili: a comparative study M. Rahman, M. Razzak, M. Z. I. Mollah, A. Z. M. Salahuddin, A. H. M Kamal and R. A. Khan 


\title{
Water quality of the Karnafuli river and its impact on the environment of Chittagong, Bangladesh
}

\author{
M. E. Ali, M. A. Islam and M. J. Ahmed* \\ Laboratory of Analytical Chemistry, Department of Chemistry, University of Chittagong, Chittagong-4331, Bangladesh
}

\begin{abstract}
The present study was conducted to assess the physicochemical characteristics of water quality parameters and heavy metals concentrations in water at different locations of the Karnafuli River. The assessment was carried out for various physicochemical parameters in three seasons during pre-monsoon, monsoon and post-monsoon seasons for continuous monitoring during the hydrological year 2014-2015. The statistical methods of sampling were used for collecting samples from different points of Karnafuli River. The samples were collected in low and high tide conditions. Since the water quality is expected to vary with season, multiple samples were collected at an interval of 2 to 3 weeks. The work has been carried out by traveling to the sampling sites for collection of required water samples and estimation of water discharge and determination of basic parameters of the sites. Samples were preserved using suitable preservation methods and transported to the laboratory. Standard methods were followed to determine the physicochemical water quality parameters as well as heavy metals concentrations. In the present study, seasonal variation in hydro-chemical character of Karnafuli River water has been evaluated and assessed the suitability of water for human \& animal's consumption, irrigation and industrial purposes. The study stress to assess various essential physical and chemical parameters including color, odor, transparency, $\mathrm{pH}$, conductivity, salinity, total hardness, total dissolved solids(TDS), total suspended solid(TSS), turbidity, alkalinity, acidity, dissolved oxygen(DO), chemical oxygen demand(COD), biological oxygen demand(BOD), sulfate, nitrite, nitrate, phosphate, ammonia, carbon dioxide, chloride, arsenic, cadmium, cobalt, copper, chromium, iron, lead, manganese, nickel and zinc. The average values of maximum parameters studied both physical and chemical were found higher than those of the World Health Organization(WHO), Department of Environment(DoE) and BSTI drinking water guidelines. The laboratory findings of water quality parameters were also compared with the recommended values set by DoE and BSTI. From Pearson Correlation program, significant positive and negative correlations were found for different parameters. These assessment data indicated that the water quality of Karnaphuli river are highly polluted which are continuously polluting the coastal zone, sea and the Halda river of Chittagong. The environmental impact of water quality of Karnafuli river has been discussed.
\end{abstract}

*Corresponding author e-mail: pmjahmed55@gmail.com 


\title{
Drinking water quality in MBSTU campus
}

\author{
A. C. Bhowmick*, F. B. Biswas and M. Ashrafuzzaman
}

Department of chemistry, Mawlana Bhashani Science and Technology University, Tangail-1902, Bangladesh

\begin{abstract}
The study was carried out to assess the drinking water quality of Mawlana Bhashani Science and Technology University (MBSTU) campus area and thus to provide the current status of ground water for its suitability for drinking purposes. Water samples were collected from five deep aquifer based tube wells from different parts of MBSTU campus in summer season (April-May). Three samples were collected from each station. In order to investigating the ground water quality, the water samples were analyzed for different physiochemical properties such as temperature, $\mathrm{pH}$, electrical conductivity (EC), total dissolved solids (TDS), dissolved oxygen (DO), turbidity, total hardness (TH), total alkalinity (TA) and chloride ( $\left.\mathrm{Cl}^{-}\right)$ concentration. The temperature, $\mathrm{pH}$ and $\mathrm{EC}$ values in analyzed water samples varied from 29.2-29.6 ${ }^{\circ} \mathrm{C}, 7.2-7.4$ and $248-505 \mu$ $\mathrm{s} / \mathrm{cm}$ respectively. Average value of the TDS, DO, turbidity, total hardness, total alkalinity and chloride concentration were 299 $\mathrm{mg} / \mathrm{L}, 6.5 \mathrm{mg} / \mathrm{L}, 8.28 \mathrm{ntu}, 143 \mathrm{mg} / \mathrm{L}$ and $14.4 \mathrm{mg} / \mathrm{L}$ respectively. The results were compared with the standards prescribed by World Health Organization and Environmental Conservation Rules. All the parameters were found to be in the prescribed permissible limit and so it was not polluted. The water quality index (WQI) result also indicates that the water of the study area was fair and can be used for drinking or other purposes.
\end{abstract}

*Corresponding author e-mail: ashrafchem905@gmail.com

\section{A simple spectrofluorimetric method for the determination of cadmium at ultra-trace level in some environmental water, biological, food, and soil samples using 2', 3, 4', 5, 7-pentahydroxyflavone}

\author{
M. J. Ahmed*, I. Jahan and M. A. Hakim \\ Laboratory of Analytical Chemistry, Department of Chemistry, University of Chittagong, Chittagong-4331, Bangladesh
}

\begin{abstract}
A very simple, ultra-sensitive and highly selective non-extractive spectrofluorimetric method for the determination of cadmium at ultra-trace levels using 2',3,4',5,7-pentahydroxyflavone (Morin) has been developed. Morin reacts in a slightly acidic (0.0005-0.002 $\mathrm{M} \mathrm{H}_{2} \mathrm{SO}_{4}$ ) aqueous solution with cadmium and to form intensely fluorescent chelate, which has high fluorescence intensity $\left(1_{\mathrm{ex}}=424 \mathrm{~nm} ; 1_{\mathrm{em}}=485 \mathrm{~nm}\right)$. The reaction is instantaneous and the fluorescent intensely remain stable for the period between $5 \mathrm{~min}$ and $24 \mathrm{~h}$. Linear calibration graphs were obtained for $0.01-600 \mu \mathrm{g} \mathrm{L}^{-1} \mathrm{of} \mathrm{Cd}$, with a $\mathrm{R}^{2}=0.99987$, having a detection limit of $1 \mathrm{ng} \mathrm{L}^{-1}$; the quantification limit of the reaction system was found to be $10 \mathrm{ngL}^{-1}$ and the RSD was $0-3 \%$. The stoichiometric composition of the chelate is 1:2 (Cd:Morin). A large excess of over 60 captions, anions and complexing agents (like, chloride, phosphate, azide, tartrate, oxalate, $\mathrm{SCN}^{-}$etc.) do not interfere in the determination. The developed method was successfully used in the determination of cadmium in several Standard Reference Materials (alloys, steels, sediments, human hair, bovine liver, fresh water, and rice flour) as well as in some environmental waters (potable and polluted), biological samples (human blood, urine and hair), tobacco samples, food samples (rice, wheat, cake, tea, cookies and shellfish), vegetables samples (radish, carrot, ginger, potato, tomato and cabbage), fertilizer samples, soil samples, solution containing cadmium. The results of the biological, food and vegetable analyses by spectrofluorimetric method were found to be in excellent agreement with those obtained by AAS. The method has high precision and accuracy (s \pm 0.01 for $\left.0.5 \mu \mathrm{gL}^{-1}\right)$.
\end{abstract}

*Corresponding author e-mail: pmjahmed55@gmail.com 


\title{
Assessment of water quality parameters and treatment of the Meghna river water of Bhairab Bazar, Kishoreganj, Bangladesh
}

\author{
$\underline{\text { R. Rahman }}^{1,2}$, A. Al Ryhan ${ }^{1,2}$, T. S. B. Monir ${ }^{1,2}$, A. Mia ${ }^{1}$, M. R. Islam ${ }^{2}$, M. R. Islam ${ }^{1}$ and R. A. Khan ${ }^{1 *}$ \\ ${ }^{1}$ Environmental Science and Engineering Laboratory, Institute of Radiation and Polymer Technology, Bangladesh Atomic \\ Energy Commission, Savar, Dhaka, Bangladesh \\ ${ }^{2}$ Department of Applied Chemistry And Chemical Engineering, Noakhali Science And Technology University, Noakhali, \\ Bangladesh
}

\begin{abstract}
Water is a vital resource for human survival. The availability of good quality water is an indispensable feature for preventing diseases and improving quality of life. The Meghna River is one of the most important rivers in Bangladesh, one of the three that forms the Ganges Delta, the largest delta on earth fanning out to the Bay of Bengal. A part of the Surma-Meghna River System, Meghna is formed inside Bangladesh in Kishoreganj District above the town of Bhairab Bazar by the joining of the Surma and the Kushiyara, both of which originate in the hilly regions of eastern India as the Barak River. Meghna river is used for bathing, drinking, irrigation and industrial purposes and is considered to be a major water resource. The water quality of Meghna has become a matter of concern due to serious levels of pollution. The objective of the study was to determine the water quality of five different point of Meghna river which passes through Bhairab and to determine the economical treatment of wastewater. Water quality assessment of different point of the Meghna river was conducted. Physical parameters of the supplied samples like $\mathrm{pH}$, Conductivity, Total dissolved solid (TDS), Chloride were measured to understand the physicochemical parameters, salinity and the presence of toxic metal ions in water. Electrical Conductivity (EC) of water were found $67 \pm 0.7 \mu \mathrm{S} / \mathrm{cm}, 76 \pm 0.9 \mu \mathrm{S} / \mathrm{cm}, 76 \pm 0.2 \mu \mathrm{S} / \mathrm{cm}, 83 \pm 0.5 \mu \mathrm{S} / \mathrm{cm}, 78 \pm 0.8 \mu \mathrm{S} / \mathrm{cm}$ respectively. The pH Value of all water samples is $6 \pm 0.7$ and Salinity, Total Dissolved Solid (TDS), Chloride were found $0.1 \%$ and $0.2 \% ; 34 \pm 0.02 \mathrm{ppm}, 38 \pm 0.5 \mathrm{ppm}$, $38 \pm 0.1 \mathrm{ppm}, 41 \pm 0.8 \mathrm{ppm}, 39 \pm 0.3 \mathrm{ppm} ; 4 \pm 0.7 \mathrm{ppm}, 6 \pm 0.03 \mathrm{ppm}, 4 \pm 0.6 \mathrm{ppm}, 8 \pm 0.2 \mathrm{ppm}, 6 \pm 0.3$ ppm respectively. Also Alkalinity and Hardness of Meghna river water were found 15 $\pm 0.01,18 \pm 0.05,18 \pm 0.02,23 \pm 0.5,18 \pm 0.5$ ppm; 32, 24, 34 \pm 0.6 , $33 \pm 0.3,36 \mathrm{ppm}$. The Meghna river water of Bhairab Bazar cannot be used for drinking purpose without any treatment.
\end{abstract}

*Corresponding author e-mail: dr.ruhul_khan@yahoo.com

\section{Photocatalytic decomposition of textile dyeing effluent on $\mathrm{TiO}_{2}$ catalyst}

\author{
M. H. Tareque, M. G. Mostafa* and M. A. Islam
}

Institute of Environmental Science, University of Rajshahi, Rajshahi 6205

\begin{abstract}
The textile industries discharge huge amounts of colored effluents through an open drain to a nearby surface water body causing enormous environmental degradation that poses threats to agriculture production, human and aquatic life. The study has considered advanced oxidation processes (AOPs) as an effective technology for decomposition of textile dyeing effluents. The study focused on the degradation of a real textile industrial effluent collected from a textile dying industry located at BICI area in Rajshahi. The effluent was subjected to photocatalytic decomposition using three different photocatalysts such as Degussa P-25 $\mathrm{TiO}_{2}$, Merck $\mathrm{ZnO}$, and $\mathrm{Fe}_{2} \mathrm{O}_{3}$. Various operational parameters such as initial effluent concentration, catalyst concentration, catalyst type, $\mathrm{pH}$, UV light intensity and reaction time were investigated in order to find out the optimum conditions. Results indicate that about $62 \%$ decomposition was achieved for an effluent sample within 3 hours at pH 6 with 400 ppm of TiO as a catalyst. A higher degradation rate was achieved when an oxidizing agent $\mathrm{H}_{2} \mathrm{O}_{2}$ was added in addition to $\mathrm{TiO}_{2}$ catalyst. The study results illustrated that photocatalytic degradation with $\mathrm{TiO}_{2}$ using $\mathrm{H}_{2} \mathrm{O}_{2}$ as an oxidizing agent would be a potential option for decomposition of textile dyeing effluents.
\end{abstract}

*Corresponding author e-mail: mostafa_ies@yahoo.com 


\title{
Air pollution tolerance index on Mangifera indica plant species in the greater Dhaka region, Bangladesh
}

\author{
Halima-E-Sadia, F. Jeba, M. D. Hossain and A. Salam* \\ Department of Chemistry, Faculty of Science, University of Dhaka, Dhaka-1000, Bangladesh
}

\begin{abstract}
Air pollution tolerance index (APTI) of the mango leaves (Mangifera Indica) growing in the greater Dhaka city, Bangladesh was studied. Leaf samples were collected in winter season from both roadsides and residential sites of different zillas of greater Dhaka division such as Dhaka, Narayangonj, Norsingdi, Gazipur, Savar. APTI values of the leaves were calculated from the total chlorophyll content (TCC), ascorbic acid concentration, relative water content (RWC), and $\mathrm{pH}$ of the leaf extract. Determined APTI values were compared with $\mathrm{PM}_{2.5}$ values in each sampling location. TCC and ascorbic acid concentration were determined with a UV-Visible spectrophotometer. TCC varied between 0.25 to $1.10 \mathrm{mg} / \mathrm{g}$ with an average of $0.66 \mathrm{mg} / \mathrm{g}$. The average concentration of ascorbic acid was $2.21 \mathrm{mg} / \mathrm{g}$ and ranging from 0.33 to $3.24 \mathrm{mg} / \mathrm{g}$ and the RWC varied from $81.5 \%$ to $97.4 \%$. Moreover, $\mathrm{pH}$ of the leaf extracts was found acidic (4.48 - 5.78). The average APTI values varied depending on the locations with a total average of 10.1. However, the average APTI value in the residential area (10.5) was slightly higher compared to roadsides (9.70) indicating the existence of high-level pollutions at the roadsides. The highest APTI value was observed in Dhaka city sampling location (10.6) where the lowest was found in Narayangonj (9.70). APTI values showed a strong correlation with particulate matters concentrations $\left(\mathrm{PM}_{2.5}\right)$. Our results suggest that Mangifera indica is very sensitive to the air pollutants. Government should take measures for saving mango tree from air pollution and be concerned about choosing the tree species for reforestation.
\end{abstract}

*Corresponding author e-mail: asalam@gmail.com

\section{Fishery status of Tangail sadar area in Bangladesh}

\section{$\underline{\text { A. Al Mamun Siddiqui }}{ }^{1}$ and M. Rashed-Un-Nabi ${ }^{2}$}

${ }^{1}$ Pragmatic Foundation, West Lane of Singer Show room (1 ${ }^{\text {st }}$ Floor), Victoria Road, Tangail-1900.

${ }^{2}$ Institute of Marine Sciences \& Fisheries, University of Chittagong. Chittagong-4331, Bangladesh.

\begin{abstract}
This research work was conducted at the fishery markets of Park Bazaar, Karatia Hut, Bajitpur Hut, Baillah Hut, Juggini Hut, Gharinda Hut, Tarutia Hut of Tangail Sadar Upazilla in Tangail District. There were 280 fish sellers in 7 fish markets in Tangail Sadar area. The main occupation of there retailing of fish all the year round and they became engaged in agricultural labour, fish trading, seasonal business, day laboring etc during off time. Total number of fish texa were recorded of which were exotic species. Variation in number of fish taxa were observed between the period 1990-1999 and 2000-2009. All the fish markets are situated near the good drainage system of the hut. The fishes are supplies mainly from the near by rivers and flood plains of Tangail Sadar area Bangladesh. Fisheries sector plays a crucial role in the national economy of Bangladesh through employment generation, poverty alleviation, supply of animal protein and foreign exchange earnings.
\end{abstract}

*Corresponding author e-mail: siddiquiimsfcu@yahoo.com 


\title{
Organochlorine compounds and toxic metals in marine fish samples of Bangladesh
}

\author{
M. M. Islam, R. Islam, M. Shoeb and N. Nahar*
}

Department of Chemistry, University of Dhaka, Dhaka-1000, Bangladeshs

\begin{abstract}
Fish is one of the important sources of animal based protein in Bangladesh. The Bay of Bengal is an important source of marine fishes which is situated at the Southern part of the country and large numbers of sea fishes are available for export and for local consumption. A huge amount of organochlorine compounds and heavy metals from industrial waste and agricultural sectors are discharged into the river and finally reached into sea water which are bioaccumulated into the sea fish. The objective of the present study is to analyze marine fish samples for organo chlorine compounds (such as 4,4-DDE, 4,4-DDD, 2,4'-DDT, 4,4-DDT) and toxic metals (such as $\mathrm{As}, \mathrm{Cd}, \mathrm{Pb}, \mathrm{Cr}$ and $\mathrm{Hg}$ ) since those contaminants in excess level cause harm to the organisms and human beings. The samples such as Eleutheronema tetradactylum, Metapenaeus monoceros, Lates calcarifer, Harpodon nehereus, Pampus argenteus, Setipinna phasa, Leiognathus equulus, Tenualosa ilisha, Megalapsis cordyla, Parastromateus niger, Coilia ramcarati, Otolithoides pama, Arius maculatus, Paraplagusia bilineata, Strongylura leiura, Platycephalus indicus and Gudusia chapra were collected fromthree different local markets i.e., Fishery Ghat, Riazuddin Bazar and Kazir Dauri of Chittagong, Bangladesh. The fish samples were extracted by Solid Phase Dispersion (SPD) and QuEChERS (Quick, Easy, Cheap, Effective, Rugged and Safe) methods and cleaned-up by concentrated $\mathrm{H}_{2} \mathrm{SO}_{4}$ and n-Hexane and analysed by GC-ECD. For the analysis of toxic metals, tissues of fish samples were freeze dried, digested by Microwave and analyzed by Atomic Absorption Spectrophotometer (AAS). The ranges of 4,4'-DDE, 4,4'-DDD, 2,4'-DDT, 4,4'-DDT were 0.225-7.936, $1.028-8.151,1.028-8.151$ and $1.109-6.601 \mathrm{ng} / \mathrm{g}$, respectively were found by SPD method and 0.395-3.210, 0.134-1.773, 1.082-6.481 and 1.873-12.078 ng/g, respectively were found by QuEChERS method. All these values are below the MRL values set by Codex Alimentarius, 1993. The levels of toxic metals varied significantly among fish species and showed that the range of $\mathrm{As}, \mathrm{Cd}, \mathrm{Pb}, \mathrm{Cr}$ and $\mathrm{Hg}$ in samples were $<0.10$ to $0.18,<0.10$ to $0.97,0.25$ to $1.68,1.75$ to 5.41 and $<0.10$ to $3.17 \mathrm{mg} / \mathrm{kg}$ respectively. The values were below the toxic limit set by FAO/WHO 2004, except mercury (Hg) and cadmium (Cd) those are present in little higher amount in few samples.
\end{abstract}

*Corresponding author e-mail: naharnilufar51@gmail.com 


\title{
Hydro-environmental imbalance due to the minerals and ionic pollution of Turag river in Bangladesh
}

\author{
J. B. Islam ${ }^{1 *}$, S. Akter ${ }^{1}$, M. N. Uddin ${ }^{2}$ and M. Sarkar ${ }^{2 *}$ \\ ${ }^{I}$ Analytical Research Division, BCSIR Laboratories, Dhaka-1205, Bangladesh \\ ${ }^{2}$ Pulp and Paper Research Division, BCSIR Laboratories, Dhaka, Dhaka-1205, Bangladesh
}

\begin{abstract}
Green environment is one of the prime concerns for safe future generation. Surface water pollution, from the last couple of decades, is drawing more attention as it is vulnerable for pollution with world development. In the present study the hydro-environmental impact due to minerals and ionic species of Turag river was observed in the dry as well as in wet seasons. Heavy existence of minerals and ions in river water and similar deposition in sediment has been observed. The average concentration of $\mathrm{Na}, \mathrm{Mg}, \mathrm{K}, \mathrm{Ca}, \mathrm{F}^{-}, \mathrm{Cl}^{-}, \mathrm{Br}^{-}, \mathrm{NO}_{2}^{-}, \mathrm{NO}_{3}^{-}, \mathrm{SO}_{4}^{2-}, \mathrm{PO}_{4}^{3-}$ in surface water and surface sediment was $22.1,3.86,13.2,18.25,0.28,108.5,0.8,0.7,2.6,128.5,17.8 \mathrm{mg} / 1$ and $1359.07,694.25,2526.1,1073.97,3.23,37.5$, $0.78,1.9,92.06,979.37,31.76 \mathrm{mg} / \mathrm{kg}$, respectively. This high concentration of minerals and ions in surface water and sediment indicates that the river is worst for ecosystem and harmful for using drinking purpose as well as for irrigation and household use. Amount of these minerals and ions are strongly correlated $(r=0.99)$ implies that they are coming from similar sources and forcefully added in regular basis. Principal component analysis reveals that only one principal component is covering more than $99 \%$ of cumulative variance. There is very few variation of parameters in the samples indicates that the pollution level is very high. Dendrogram analysis reflects the similar results.
\end{abstract}

*Corresponding author e-mail: akash.mamon@gmail.com

\section{Antibacterial activity of soil-bound oxytetracycline}

\author{
S. Chowdhury, P. Chakma and S. Hoque*
}

Department of Soil, Water and Environment, University of Dhaka, Dhaka - 1000, Bangladesh

\begin{abstract}
Soil contamination of antimicrobials has become an increasing concern because of the potential risks to the soil microbial ecosystem and human health. The goal of this study was to determine whether ornot soil bound antibiotics are still active against bacteria. The procedure involved sorbing various concentrations $(0.1,1,10,100$, and $1000 \mu \mathrm{g} / \mathrm{g})$ of oxytetracycline on three different textured soils (Silty clay loam, loam and clay), incubating these soils with five bacterial cultures (Escherichia coli, Azotobacter vinelandii, Rhizobium tropici, Pseudomonas putida and Bacillus cereus) and then enumerating the number of colony forming units relative to the control. Incubation was done for 24 hours under both static and dynamic conditions. The results showed that adsorption behavior of oxytetracycline in the three soils were mainly influenced by soil organic matter content and cation exchange capacity (CEC) as well as $\mathrm{pH}$ value. Strong adsorption was found in soil 1 (silty clay loam textured with organic matter content, 1.14\%) and in soil 3 (clay textured with high CEC, $21.85 \mathrm{cmole}_{\mathrm{c}} / \mathrm{kg}$ ). The results also demonstrated that no striking differences was found in the abilities of adsorbed antibiotic to suppress growth of the bacterial species under both static and dynamic conditions. This finding suggests that soil-bound oxytetracycline do not necessarily exert a selective pressure on soil bacteria.
\end{abstract}

*Corresponding author e-mail: sirajswed@du.ac.bd 


\title{
Transformation of malathion by phosphate solubilizing bacteria
}

\author{
P. Chakma, S. Chowdhury and S. Hoque*
}

Department of Soil, Water and Environment, University of Dhaka, Dhaka-1000, Bangladesh

\begin{abstract}
An experiment was carried out for isolation, identification and determination of malathion degrading phosphate solubilizing bacteria isolated from agricultural field. In this study, malathion degrading phosphate solubilizing bacteria were identified using NBRIP media. A total of 12 bacterial colonies were screened from agricultural field of Tangail, Sirajganj and Gazipur. From primarily screened 12 colonies, 6 discrete colonies were selected for identification by observing the morphological and biochemical characteristics. Of the 6 isolates, 4 were identified as phosphate solubilizing bacteria through qualitative and quantitative analysis. These isolates were Pseudomonas aeruginosa, Bacillus cereus, Bacillus subtilis and Raoultella ornithinolytica. The isolated 4 bacterial colonies were inoculated in National Botanical Research Institute's phosphate growth medium (NBRIP) broth media enriched with malathion pesticides to observe degradation of malathion pesticide under incubation study at three different temperature $\left(25^{\circ} \mathrm{C}, 30^{\circ} \mathrm{C}\right.$ and $\left.37^{\circ} \mathrm{C}\right)$. However, all the five isolates showed capability in degrading malathion pesticide. The study clearly revealed that phosphate solubilizing bacteria were capable of degrading organophosphate malathion pesticide. The degradation capacity of these bacteria decreased with increasing temperature and incubation days. The best temperature for malathion degradation was $30^{\circ} \mathrm{C}$. Pseudomas aeruginosa was the most efficient malathion degrading bacteria at $25^{\circ} \mathrm{C}$ and $37^{\circ} \mathrm{C}$ out of the five isolates. However, at $30^{\circ} \mathrm{C}$ Bacillus cereus showed the highest efficiency in degrading malathion pesticide. This study suggested that phosphate solubilizing bacteria can be used in bioremediation of environmental pollution caused by malathion pesticide.
\end{abstract}

*Corresponding author e-mail: sirajswed@du.ac.bd

\section{Analysis and treatment of Shitalakshya river water in Bangladesh}

\author{
$\underline{\text { M. N. Islam }}^{1,2}$, N. A. Kona ${ }^{1}$, S. Shahida ${ }^{1}$, M. M. Haque ${ }^{1}$, M. R. Islam, M. S. Manir, R. A. Khan ${ }^{1 *}$ \\ ${ }^{1}$ Institute of Radiation and Polymer Technology, Bangladesh Atomic Energy Commission, Savar, Dhaka, Bangladesh \\ ${ }^{2}$ Department of Computer Science and Engineering, Daffodil International University, Dhaka, Bangladesh
}

\begin{abstract}
Bangladesh is called the land of rivers because in Bangladesh about 700 rivers are flowing across the country. Rivers have a great influence on the life style of the people of Bangladesh. But at present, many river water are polluting by several ways. Textile sector is one of the polluting sources. A river named Shitalakshya was selected in this investigation because it flows near Dhaka city, capital of Bangladesh. Shitalakshya is comparatively a small river which flows in the central part of Bangladesh. The river is about $110 \mathrm{~km}$ long. The river's maximum depth is $21 \mathrm{~m}$ and average depth is $10 \mathrm{~m}$. It remains navigable year round. The water of the river was collected from the surface of the river at different points in the month of April 2017. The $\mathrm{pH}$, electrical conductivity (EC), salinity and total dissolved solid (TDS) of the river water was found to be 7.24 to $7.64,483$ to 4220 $\mu \mathrm{s} / \mathrm{cm}, 0.9$ to $8.20 \%$, and $241-2110 \mathrm{ppm}$, respectively. At the upstream of the river, the salinity and TDS were observed $0.9 \%$ and $241 \mathrm{ppm}$. On the other hand, higher salinity (8.20\%) and TDS (2110 ppm) was noticed. The reason for the huge variation of the parameters of river water is due to the presence of some textile and dyeing industries in the downstream of the river. Gamma radiation was exposed for the purification of the river water and it was found that gamma radiation have the potential for the treatment of textile waste effluents.
\end{abstract}

*Corresponding author e-mail: dr.ruhul_khan@yahoo.com 


\title{
Harvested potable rainwater quality of Mongla and Sarankhola upazila in Bagerhat district, Bangladesh
}

\author{
M. A. Rahman ${ }^{1}$, M. A. Hashem ${ }^{1,2 *}$ and M. H. R. Sheikh ${ }^{2}$ \\ ${ }^{1}$ Department of Public Health Engineering (DPHE), Zonal Laboratory, Khulna-9100, Bangladesh \\ ${ }^{2}$ Department of Leather Engineering, Khulna University of Engineering \& Technology (KUET), Khulna-9203, Bangladesh
}

\begin{abstract}
Safe potable water is indispensable for good health. Potable water is contaminated with toxic metals especially arsenic is a big issue in Bangladesh. Getting arsenic free water, rainwater harvesting is becoming popular especially in the coastal areas. The objective of the study was to assess the quality of harvested rainwater on the basis of roofing material e.g., galvanized steel. Forty eight (48) harvested potable rainwater were examined in terms of lead $(\mathrm{Pb})$, zinc $(\mathrm{Zn}), \mathrm{pH}$, turbidity, fecal coliform and total coliform of Mongla and Sarankhola upazila, Bagerhat district. All examinations were conducted according to standard methods of APHA. The metal contents, especially $\mathrm{Pb}$ and $\mathrm{Zn}$ in the water samples were analyzed by atomic absorption spectroscopy.
\end{abstract}

Comparison parameters with Bangladesh drinking standard (BDS)

\begin{tabular}{lccc}
\hline \multirow{2}{*}{ Parameters } & \multicolumn{2}{c}{ This study } & \\
\cline { 2 - 3 } & Range & Mean & \multirow{2}{*}{ BDS } \\
\hline Lead (mg/L) & $0.001-0.13$ & 0.01 & 0.05 \\
Zinc (mg/L) & $0.109-0.95$ & 0.81 & 5.0 \\
Turbidity (NTU) & $1-22$ & 4.58 & 15 \\
pH & $6.12-8.63$ & 7.24 & $6.5-8.5$ \\
Fecal Coliform $(\mathrm{CFU} / 100 \mathrm{~mL})$ & $0-96$ & 7.69 & 0 \\
Total Coliform $(\mathrm{CFU} / 100 \mathrm{~mL})$ & $0-100$ & 16.72 & 0 \\
\hline
\end{tabular}

The above table indicates that metal contents were $\mathrm{Pb} 0.001-0.13 \mathrm{mg} / \mathrm{L}$ and $\mathrm{Zn} 0.109-0.95 \mathrm{mg} / \mathrm{L}$. The $\mathrm{Pb}$ was below $(<0.05$ $\mathrm{mg} / \mathrm{L})$ the permissible level except one point $(0.13 \mathrm{mg} / \mathrm{L})$ and $\mathrm{Zn}$ was below the permissible level $(<5.0 \mathrm{mg} / \mathrm{L})$. The turbidity was below permissible level ( $<15$ NTU) except tree points; $\mathrm{pH}$ was between BDS level. In the most of the water samples fecal and total coliform were beyond permissible level. However, metal contents were below BDS level but Pb is toxic for human, especially for children. Authority should monitor to reduce metal contents, fecal and total coliform in the harvested potable rainwater.

*Corresponding author e-mail: hashem_518@yahoo.com, mahashem@le.kuet.ac.bd 


\title{
Heavy metal contents in the surface water of the Chittagong sea beach in Bangladesh
}

\author{
$\underline{\text { A. K. M. Atique Ullah }}^{1 *}$, S. B. Quraishi ${ }^{1}$, S. R. Khan $^{1}$, A. R. M. Tareq ${ }^{1}$ and A. K. M. Fazle Kibria ${ }^{2 *}$ \\ ${ }^{1}$ Analytical Chemistry Laboratory, Chemistry Division, Atomic Energy Centre Dhaka, Bangladesh Atomic Energy \\ Commission, Dhaka-1000 \\ ${ }^{2}$ Nuclear Safety, Security and Safeguards Division, Bangladesh Atomic Energy Commission, Dhaka-1207
}

\begin{abstract}
Chittagong sea beach is the second longest beach in Bangladesh. The largest ship breaking station is situated in that area and from that a huge amount of chemical contaminants are entered into the environment. Moreover, due to the industrialization and urbanization, the beach water is being polluted. About $80 \%$ of the diseases of the world population and more than one third of the deaths in the developing countries are due to contamination of water. Heavy metal is one of the most potential pollutants among all other chemical contaminants. Consequently, continuous monitoring of the heavy metals in the beach water is required. Therefore, for the assessment of water quality, twenty surface water samples were collected randomly at different locations of the beach. The collected samples were analyzed by atomic absorption spectrometry (AAS). The concentrations of heavy metals $\mathrm{Pb}, \mathrm{Cd}, \mathrm{Cr}, \mathrm{As}, \mathrm{Hg}, \mathrm{Mn}, \mathrm{Fe}, \mathrm{Co}, \mathrm{Ni}, \mathrm{Cu}$ and $\mathrm{Zn}$ in the beach water were found to be in the range of 334-353 $\mu \mathrm{g}$ $\mathrm{L}^{-1}, 17-21 \mu \mathrm{g} \mathrm{L}{ }^{-1},<11 \mu \mathrm{g} \mathrm{L}{ }^{-1},<2.0 \mu \mathrm{g} \mathrm{L}^{-1},<0.3 \mu \mathrm{g} \mathrm{L}{ }^{-1}, 289-425 \mu \mathrm{g} \mathrm{L}^{-1}, 12-18 \mathrm{mg} \mathrm{L}^{-1}, 103-123 \mu \mathrm{g} \mathrm{L}^{-1}, 86-99 \mu \mathrm{g} \mathrm{L}{ }^{-1}, 23-31 \mu \mathrm{g}$ $\mathrm{L}^{-1}$ and 69-97 $\mu \mathrm{g} \mathrm{L}^{-1}$ respectively. The values of the targeted heavy metals in the samples revealed that they exceeded the acceptable level as set up by the national and international body. The results will serve the people for awareness and lead to do much research on a potential health hazard in the beach area.
\end{abstract}

*Corresponding author e-mail: atique.chem@gmail.com, kibriaf@yahoo.com

\section{Trace metal concentration in some branded teas in Bangladesh}

\author{
S. Sultana* ${ }^{*}$ M. F. Alam, F. T. Ahmed, N. C. Dafadar, M. S. Rahman and G. Ara \\ Nuclear and Radiation Chemistry Division, Institute of Nuclear Science \& Technology, Bangladesh Atomic Energy \\ Commission, P. O. Box 3787, Dhaka, Bangladesh.
}

\begin{abstract}
Tea is a regular refreshment which fights fatigue and provides essential nutrients. Due to anthropogenic activities, undesirable trace elements are found in teas. In the present study, six black teas and two green teas were collected from local market of Bangladesh and metal concentrations were measured by Flame Atomic Absorption Spectrophotometer (AAS). Results revealed that the mean concentrations of $\mathrm{Cd}$ in tea leaves, 5 minutes boiled infusions and 10 minutes boiled infusions were $2.04 \pm 0.1$ $\mu \mathrm{g} / \mathrm{g}, 0.54525 \pm .07 \mu \mathrm{g} / \mathrm{g}$ and $0.70 \pm 0.1 \mu \mathrm{g} / \mathrm{g}$ respectively. Cu concentrations were $16.06 \pm 0.2 \mu \mathrm{g} / \mathrm{g}, 21.56 \pm 0.5 \mu \mathrm{g} / \mathrm{g}, 20.89 \pm$ $0.2 \mu \mathrm{g} / \mathrm{g}$. The concentrations of Ni were $27.66 \pm 0.8 \mu \mathrm{g} / \mathrm{g}, 21.56 \pm 0.2 \mu \mathrm{g} / \mathrm{g}, 20.89 \pm 0.4 \mu \mathrm{g} / \mathrm{g}$ and Zn were $0.17 \pm .05 \mu \mathrm{g} / \mathrm{g}, 0.14$ $\pm .02 \mu \mathrm{g} / \mathrm{g}, 0.12 \pm .03 \mu \mathrm{g} / \mathrm{g}$. The difference in metal concentrations of the tea brands might be attributed to geographical and seasonal changes as well as chemical characteristics of the cultivation areas.
\end{abstract}

*Corresponding author e-mail: shahnazju32@gmail.com 


\title{
Hybrid hydrogel for removal of heavy metals from waste effluents
}

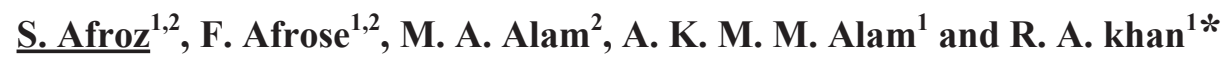 \\ ${ }^{1}$ Hydrogel Laboratory, Institute of Radiation and Polymer Technology, Bangladesh Atomic Energy Commission, Savar, \\ Dhaka, Bangladesh \\ ${ }^{2}$ Department of Applied Chemistry and Chemical Engineering, Noakhali Science and Technology University, Noakhali, \\ Bangladesh
}

\begin{abstract}
Hydrogels are three dimensional crosslinked networks with proven multifaceted applications that can absorb and retain large amounts of water. Some hydrogels undergo substantial volume changes in response to environmental stimuli, such as temperature, $\mathrm{pH}$, electric field and ionic strength. Special attention is developing a novel hydrogels with unique cross-linked structures as cross-linked structure in polymer network hydrogels affects their mechanical and swelling properties. Adsorption by hydrogel offers many potential advantages for removal of toxic heavy metals over other methods. A novel hydrogel were prepared from aqueous solution of Polyethylene oxide (PEO) (5\%) and N,N-Dimethylacrylamide (DMAAm) $(2.5 \%)$ at a ratio $2: 1$ by Gamma radiation at doses $10-30 \mathrm{kGy}$. The influence of doses, concentration of monomer and polymer on the properties of prepared hydrogel was evaluated in terms of gel content and swelling behavior, mechanical properties (Tensile strength) and Fourier Transform Infrared Spectroscopy. Hydrogel with highest swelling ratio has been obtained at dose $10 \mathrm{kGy}$; swelling behavior is prior consideration for adsorption purpose. In order to use the hydrogel for removal of heavy metal the effects of $\mathrm{pH}$, temperature on the adsorption properties has been analyzed. The optimized hydrogel adsorbed heavy metal $\left(\mathrm{Cr}^{3+}\right)$ from waste water.
\end{abstract}

*Corresponding author e-mail: dr.ruhul_khan@yahoo.com

\section{Phytoremediation of cadmium and zinc from water using water hyacinth (Eichhornia crassipes)}

\author{
T. Yeasmin and M. S. Islam*
}

Department of Soil Science, University of Chittagong, Chittagong-4331, Bangladesh

\begin{abstract}
Cadmium (Cd) and zinc ( $\mathrm{Zn}$ ) phytoremediation potential of water hyacinth (Eichhornia crassipes) were investigated in water. Plants were grown for 10 and 20 days in tap water after addition of $\mathrm{Cd}$ and $\mathrm{Zn}$ at the levels of $0,1,2$ and $4 \mathrm{mg} \mathrm{L}^{-1}$ and $0,10,20$ and $40 \mathrm{mg} \mathrm{L}^{-1}$, respectively. Each level of $\mathrm{Cd}$ will be combined with each level of $\mathrm{Zn}$ for a total of 16 treatments. The experiment showed that both $\mathrm{Cd}$ and $\mathrm{Zn}$ and $\mathrm{Cd}-\mathrm{Zn}$ interactions had effects on plant relative growth. The plant at all the concentrations used in the experiment removed approximately more than $90 \%$ of $\mathrm{Cd}$ and $\mathrm{Zn}$. Removal of metals from water was fast especially in the first ten days. The accumulation of $\mathrm{Cd}$ and $\mathrm{Zn}$ in roots and shoots increased with the initial concentration. At all levels, the plants accumulated the highest concentration of $\mathrm{Cd}$ in roots, while the highest concentration of $\mathrm{Zn}$ was accumulated in shoots. The bioconcentration factor (BCF) of $\mathrm{Zn}$ was higher than that of $\mathrm{Cd}$ at the same duration, suggesting that the accumulation potential of E. crassipes for $\mathrm{Zn}$ was higher than that for $\mathrm{Cd}$ and could be used to treat waste-water contaminated with low $\mathrm{Cd}$ and $\mathrm{Zn}$ accumulations.
\end{abstract}

*Corresponding author e-mail: msislam@cu.ac.bd 


\title{
Impacts of tidal river management on biodiversity: a case study in Beel Vayena
}

\begin{abstract}
M. M. Al Masud*
Environmental Science Discipline, Khulna University, Khulna- 9208

Abstract

Tidal River Management (TRM) is one of the important methods for water resources management which based on local people's indigenous knowledge and practices in the Southwest coastal region. TRM is a socially acceptable and eco-technical process for water-related disaster management basically removal of water-logging and sediment management. Local people introduced TRM in Beel Vayena from 1997 to 2001. It was an open TRM and no protection dam was installed alongside the villages. The objectives of the study are to find out the impacts of TRM on biodiversity at during TRM and after TRM regarding before TRM and its significance on livelihood assets. The study focuses on three scenarios of TRM and selects 4 villages randomly in Beel Vayena from which two villages Dahuri and Sarutia were affected by tidal water during TRM and another two villages Agerhati and Sholgatia were not affected. It collects primary data through questionnaire survey, Key Informant Interview (KII) and Focus Group Discussion (FGD). The study shows that the number of livestock, timber trees and fruit trees more reduced at Dahuri and Sarutia villages than Agerhati and Sholgatia villages affected by salinity at during TRM. Besides, species of birds and wetland fisheries were reduced at during TRM and after TRM. But in most cases the number of livestock, culture fisheries, timber trees and fruit trees were increased at after TRM regarding before TRM. Therefore, it uplifts the income of households and people enjoy more food at after TRM than before TRM.
\end{abstract}

*Corresponding author e-mail: md.mahedi.am@gmail.com

\section{Impacts of tidal river management on food security and household income in Jessore district of Bangladesh}

\author{
M. M. Al Masud $*$ and A. K. Azad
}

Environmental Science Discipline, Khulna University, Khulna- 9208

\begin{abstract}
Tidal River Management (TRM) in Beel Vayena and East Beel Khukshia elevated the low land of TRM Beel from 0.5 to 2 meter by deposited silt and converted the wetland into agriculture. TRM is an economically viable and agriculturally favorable and comparatively environmentally sound option for solving water-logging problem in the Southwest polder areas of Bangladesh. The objectives of the study are to measure the agricultural production and household's income and its contribution to the food security in different scenarios of TRM. The study is based on primary data and conducted at surrounding villages of Beel Vayenaand East Beel Khukshiaunder Keshabpur and Manirampurupazila of Jessore district. The study presents that paddy, vegetables and fish production increase by more than $50 \%$ as well as the number of livestock raises by TRM implementation. At during TRM, drainage capacity of the river was increased and surrounding 10 to 12 Beels had no water-logged since those Beels were gone under agriculture and good production. Although during TRM implementation, the TRM Beel was not usable for agriculture, a huge number of fish entered into the Beel from tidal river. On the basis of the findings, present study concludes that TRM both rotational and fixed may appear as a sustainable solution of water-logging in the Southwest, which ensures food security with increased food production, new employment opportunity and more livelihood options for the local people.
\end{abstract}

*Corresponding author e-mail: md.mahedi.am@gmail.com 


\title{
Microbiological quality of drinking water in Khulna City Corporation slum area in Bangladesh
}

\author{
$\underline{\text { A. Kundu }}^{1}$, M. A. Rahman ${ }^{2}$ and M. A. Yousuf ${ }^{1 \%}$ \\ ${ }^{1}$ Department of Chemistry, Khulna University of Engineering \& Technology (KUET), Khulna-9203, Bangladesh \\ ${ }^{2}$ Department of Public Health Engineering (DPHE), Zonal Laboratory, Khulna-9100, Bangladesh
}

\begin{abstract}
With the rapid growing of urban population, a large number of slums is growing up in Khulna city where basic living expediencies like, water supply, hale and hearty housing, adequate sewerage system etc. are absent. So a comparative study of bacteriological status of deep tube-well and householdstored drinking water of Khulna City Corporation slum area has been explored. Study was conducted from July 22, to August 28, 2016. A total of 100 samples; 50 from sources and other 50 from household storage vessels were collected covering 31 wards of city. Result revels that total coliform (TC) and feacal coliform (FC) counts did not meet the recommended limit of WHO (0 CFU/100mL TC, $0 \mathrm{CFU} / 100 \mathrm{~mL}$ FC) for drinking water quality.14\% Tube-Well and 16\% of household samples contained FC range 1-10 CFU/100mL, $32 \%$ Tube-Well and $2 \%$ Household samples contained TC within this range. 11-50 CFU/100mL FC contained in 10\% Tube-Well and 50\% household samples, TC contained in 26\% Tube-Well and 28\% household samples. 2\% Tube-Well and 18\% household samples contained FC range 51-100 CFU/100mL and 4\% Tube-Well sample and 40\% household samples contained TC within this range. $6 \% \mathrm{FC}$ of total household and 30\% TC of total household samples contained coliform bacteria more than $100 \mathrm{CFU} / 100 \mathrm{~mL}$. A field study was also performed to be understood the sources of contamination. Water can be contaminated before and after collection through a number of ways for example unprotected tube-well, broken and cracked fence, improper water handling, dirty containers, dirty housing condition, bad sanitation system, unclaimed living entities etc.
\end{abstract}

*Corresponding author e-mail: yousuf2716@yahoo.com

\section{Ozone wash in waste water treatment}

\author{
S. Bhattacharjee and F. Taylor*
}

Property Delight F-6, 85/A R K Mission Road, Gopibag, Dhaka-1203

\begin{abstract}
The finishing of denim is considered as highly complex procedure, uses a number of chemicals including chlorinated compound and considerable amount of water. Waste water of denim washing facility contains large number of chemical compound and intense colour which requires significant amount of chemicals. Ozone based denim shading is an innovative technique for producing bleaching effect for denims in a closed, batch-wise operation to lighten and soften garments. In addition, ozone can also be used to replicate other denim finishing processes beyond shading, such as stone washing, and also carries advantages in minimising impacts on fibre strength. The present paper was an attempt to address the environmental benefits of ozone washing for denim finishing. Both conventional and ozone based washing machine were used to light wash $60 \mathrm{~kg}$ of denim pants through standard recipe. Compare to conventional machine, ozone based machine required $68.3 \%$ and $46 \%$ less water and electricity respectively and generated $70 \%$ less waste water for effluent treatment plant. Overall mean of BOD, COD, TDS and TSS effluent of ozone based machine were $64 \mathrm{mg} / \mathrm{L}, 287 \mathrm{mg} / \mathrm{L}, 914 \mathrm{mg} / \mathrm{L}$ and $196 \mathrm{mg} / \mathrm{L}$ respectively but same effluent characteristics of conventional machine were $108 \mathrm{mg} / \mathrm{L}, 402 \mathrm{mg} / \mathrm{L}, 2081 \mathrm{mg} / \mathrm{L}$ and $388 \mathrm{mg} / \mathrm{L} \mathrm{respectively.}$ The environmental benefit of ozone based machine was found higher than conventional machine.
\end{abstract}

*Corresponding author e-mail: djzsb@yahoo.com 


\title{
Treatment of waste water from leather industry in Dhaka, Bangladesh
}

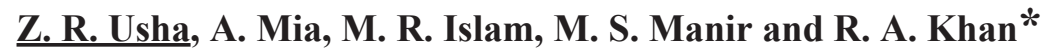 \\ Environmental Science and Engineering Laboratory, Institute of Radiation and Polymer Technology, Bangladesh Atomic \\ Energy Commission, Savar, Dhaka, Bangladesh
}

\begin{abstract}
Leather industry is a major industry in Bangladesh and the Government of Bangladesh has declared it as a priority sector. The industry is the second largest export sector of Bangladesh. The industry also plays a vital role in creating employment. Increasing interest of buyers has opened up an opportunity for footwear and leather industries of Bangladesh. Unfortunately, leather industries are creating a huge number of effluents and causing water pollution. Samples from one leather industry located in Hazaribagh, Dhaka, Bangladesh were collected April 2017. The pH, electrical conductivity (EC), salinity and total dissolved solid (TDS) of the used water of the leather industry was found to be $3.76,5160 \mu \mathrm{s} / \mathrm{cm}, 10.10 \%$, and $2580 \mathrm{ppm}$ respectively. Chloride, total alkalinity and total hardness of the river water were observed as follows: $876 \pm 5 \mathrm{ppm}, 26 \pm 2 \mathrm{ppm}$, $625 \pm 10 \mathrm{ppm}$, respectively. Water samples were exposed to $15 \mathrm{kGy}$ doses of Gamma radiation and found that gamma radiation is a powerful technique for the treatment of leather effluents. In conclusion, the effluents from leather industries are harmful for environment. Gamma radiation can be used for the treatment of the effluents of leather industries.
\end{abstract}

*Corresponding author e-mail: dr.ruhul_khan@yahoo.com

\section{Water quality of Hatirjheel lake in Dhaka, Bangladesh}

\author{
M. Akther and M. R. Rakib*
}

Department of Geography and Environment, Jahangirnagar University, Savar, Dhaka-1342, Bangladesh

\begin{abstract}
Lake always plays an important function in water retention storage and has a multi-facet contribution to urban development. In Dhaka City, due to unplanned and excessive growth of urbanization and industrialization, lake water utilization and quality deterioration has been increased fast with the contribution to serious environmental degradation. Hatirjheel has turned into one of the most favorite recreational places in Dhaka. Numerous tourists and pedestrians visit the site every evening to enjoy the reflection of light and to feel the fresh air. But now a days Hatirjheel losses its water quality. This research is based on primary and secondary data sources. As primary data, water was collected from five different sample points based on sources of pollution representing the whole water body. Secondary data were collected by journals, books, thesis and internet. Further laboratory test were perform for determining the water quality parameter. From the data analysis it is revealed that $\mathrm{pH}$ varied from 6.35 to 7.16 . Temperature is varied from $30^{\circ} \mathrm{C}$ to $31^{\circ} \mathrm{C}$. The matter weight of sample water varied from $2.01 \mathrm{mg}$ to 5.53 mg per liter water. Six types of water color are also found and very strongly bad and slightly smell odor are most noticeable. so Considering all of these, wide public awareness, government participation and government regulations can save the water of Hatirjheel lake and thus a safe and sound water environment can be made for future generations.
\end{abstract}

*Corresponding author e-mail: marziaonu@gmail.com,mrrakib@juniv.edu 


\title{
Water quality assessment and groundwater modelling of rapidly industrialized Konabari district of Bangladesh
}

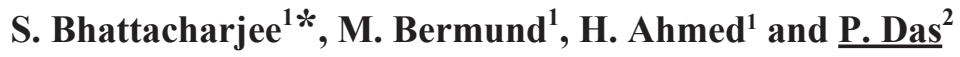 \\ ${ }^{1}$ Solidaridad Network Asia, Bangladesh \\ ${ }^{2}$ Shahjalal University of Science and Technology, Bangladesh
}

\begin{abstract}
To feed its 156.6 million of population, Bangladesh is already facing a great challenge of water scarcity. Rapid industrialization with no ground water protection policy and legislation has worsened the ground water depletion rate. Besides river water pollution rises remarkably due to waste water drainage and frequently waste disposal into river. The water quality assessment and ground water modelling were carried out in the rapidly industrialized Konabari district of Bangladesh. Here, an analysis on shallow ground water resource was carried out based on available water resource data supplied by factory of Konabari districts. Based on ground water modelling, it was proven that shallow ground water is depleting significantly in recent days. By the current rate of industrialization and ground water withdrawal, the deep ground water level of study area will decrease into 80 meters by next 20 years. Additionally, water samples from nearest river were collected in pre-monsoon (month of February), post-monsoon (month of November) and monsoon (month of July) session of 2015. Results of water quality monitoring and assessment showed that $\mathrm{DO}, \mathrm{BOD}, \mathrm{COD}, \mathrm{Zn}, \mathrm{Pb}, \mathrm{Cu}, \mathrm{Mn}, \mathrm{Cr}$ and As were found at alarming rate in nearest river. Arsenic will contaminate the shallow aquifer due to excessive amount of ground water extraction and river water pollution. This may prevalence the Arsenicosis disease among the denizens. However, Bangladesh has not been introduced any stricken policy and rules to improve its water resource management.
\end{abstract}

*Corresponding author e-mail: shubhra.bh@gmail.com

\section{Quality of surface water of different river sources}

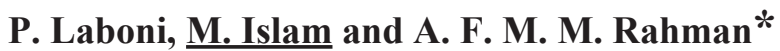

Department of Applied Chemistry and Chemical Engineering, University of Dhaka, Bangladesh.

\begin{abstract}
This study based on some physiochemical parameters of surface water at various points of Buriganga, Turag, Shitalakhya and Norshunda river. Analyses revealed that most of the water quality parameters exceeded the recommended levels set by the Department of Environment (DoE). The total dissolved solids (TDS) values fluctuate rhythmically due to have some external influences on the river water. The TDS value of Buriganga river is higher than that of Turag and Shitalakhya rivers in dry season. This study analyses that the total dissolved solids (TDS) values of all the stations were much higher than 1000 $\mathrm{mg} / \mathrm{L}$ which exceed the Environmental Conservation Rules, 1997. Present study also satisfies the findings of the World Bank as this paper showed higher TDS in dry season. The Shitalakhya river have significantly high levels of turbidity and TDS concentrations compared to Buriganga and Turag river in most cases. But the turbidity values of Buriganga, Shitalakhya and Turag river are higher than DOE standard value which is due to addition of suspended silt and clay particles along with organic matter near sampling point. The source of organic and microbial pollutants present in the water was also responsible for higher turbidity. Dissolved oxygen (DO) level has experienced a little bit fluctuation and has decreased much over the last five years. Most alarming is that the DO level was $6 \mathrm{mg} / \mathrm{L}$ in 2006 but now it is $0-4 \mathrm{mg} / \mathrm{L}$ which supports no life in water. Water of all the rivers showed alkalinity measurements that were not more than the maximum permissible limit of DoE. Sometimes alkalinity values were below the lower limit of DoE standard. Throughout the study, we observed that the experimental stations did not exceed the permissible limit of hardness of drinking water which is $200-500 \mathrm{ppm}$. All these four rivers the value of heavy metals $(\mathrm{Cr}, \mathrm{Hg}, \mathrm{As}, \mathrm{Fe}, \mathrm{Zn})$ concentration is below the DoE standard value. These study also revealed that the chloride, fluoride, nitrate and sulphate concentration are not in satisfactory level. We see that the water of Buriganga and Turag is now in a very critical condition. But the water of Shitalakhya and Norshunda rivers is still much better than those. However, it is getting worse day by day.
\end{abstract}

*Corresponding author e-mail: mustafizacce@du.ac.bd 


\title{
Ground and surface water quality of Noakhali Science and Technology University (NSTU) campus, Noakhali, Bangladesh
}

\author{
T. S. B. Monir ${ }^{1,2}$, R. R. Rima ${ }^{1,2}$, A. A. Rayhan $^{1,2}$, A. Mia ${ }^{1}$, M. R. Islam ${ }^{1}$, M. A. Alam ${ }^{2}$ and R. A. Khan ${ }^{1 *}$ \\ ${ }^{1}$ Environmental Science and Engineering Laboratory, Institute of Radiation and Polymer Technology, Bangladesh Atomic \\ Energy Commission, Savar, Dhaka, Bangladesh \\ ${ }^{2}$ Department of Applied Chemistry \& Chemical Engineering,Noakhali Science\& Technology University, Noakhali, Bangladesh
}

\begin{abstract}
Water is essential to life and human health, economic development, food security, poverty reduction and sustainable ecological function. Surface and ground water are the main water resources for drinking, bathing, irrigation and household purposes for the coastal population of Bangladesh. Noakhali is a district in South-eastern coastal zone of Bangladesh. Ground water is contaminated by salinity and other metal ions because of saltwater intrusion from the Bay of Bengal. Water quality assessment of different point of ground water and surface water from NSTU campus and sadar of Noakhali was conducted. Physical parameters of the supplied samples like $\mathrm{pH}$, conductivity, total dissolved solid (TDS), chloride were measured to understand the physicochemical parameters, salinity and the presence of toxic metal ions in water. Electrical conductivity (EC) of the ground water, surface water of NSTU campus and the ground water of residential area of Maijdee, Sadar were found to be $3500 \pm 500$ $\mu \mathrm{s} / \mathrm{cm}, 180 \pm 10 \mu \mathrm{s} / \mathrm{cm}$ and $1200 \pm 50 \mu \mathrm{s} / \mathrm{cm}$ respectively. The $\mathrm{pH}$ value of all water samples is $7.50 \pm 0.5$ and salinity, total dissolved solid (TDS), chloride were found to be $6.5 \pm 0.5 \%, 0.4 \pm 0.5 \%$ and $2.0 \pm 1 \% ; 1500 \pm 500 \mathrm{ppm}, 91 \pm 1 \mathrm{ppm}$ and $620 \pm 20 \mathrm{ppm}$; $35000 \pm 5000 \mathrm{ppm}, 580 \pm 20 \mathrm{ppm}$ and $4080 \pm 20 \mathrm{ppm}$ respectively. Also alkalinity and hardness of the ground water, surface water of NSTU campus and the ground water of residential area of Maijdee, Sadar were found to be $20 \pm 10,5 \pm 2,15 \pm 5 ; 700 \pm 100 \mathrm{ppm}$ $60 \pm 10,50 \pm 5$. The ground water of NSTU campus is so saline that it cannot be used for drinking purpose without any treatment.
\end{abstract}

*Corresponding author e-mail: dr.ruhul_khan@yahoo.com

\section{Selected mango varieties and the correlation with the shelf-life of their developed products}

\author{
$\underline{\text { S. M. M. Kabir }}{ }^{1 *}$, A. Alam $^{2}$ and B. Uddin ${ }^{3}$ \\ ${ }^{1}$ Department of Chemistry, Rajshahi University of Engineering and Technology, Rajshahi, Bangladesh \\ ${ }^{2}$ Department of Chemistry, Rajshahi University of Engineering and Technology, Rajshahi, Bangladesh \\ ${ }^{3}$ Department of Food Technology and Rural Industries, Bangladesh Agricultural University, Mymensingh-2202
}

\begin{abstract}
The study is concentrated with the role of inherent antioxidants content of selected mango varieties on the quality and shelf-life of developed mango products. Three mango varieties as gutti, ashina, and langda and two mango products; mango bar and mango fruit drinks were used as factors of this study. The samples of ripe mangoes are collected from several places of Bangladesh. Antioxidant contents of three varieties of mango pulp and microbial loads as influenced by the inherent antioxidant of mango bar and mango fruit drinks with time were assessed. All three varieties contained vitamin A, beta carotene, and vitamin $\mathrm{C}$ as antioxidant and their contents were higher in gutti variety than other two varieties; Asina and Langda. These inherent antioxidants were made an effective role to resist microbial load in the mango products like mango bar and mango fruit drink. No microbial growth was observed within three months in the products (mango bar and mango fruit drink) of gutti mango variety except TPC, which showed slight growth after four months of storage. In the product of other two varieties Asina and Langda were affected by microbial growth (TPC) within one and two months consecutively. The study discloses that the inherent antioxidant content of mango varieties had significant effect on the quality and shelf life in mango products.
\end{abstract}

*Corresponding author e-mail: marufqc@gmail.com 


\title{
Analysis and treatment of the Meghna river water, Ramgoti, Laxmipur, Bangladesh
}

\author{
$\underline{\text { A. Al Ryhan }}^{1,2}$, R. Rahman ${ }^{1,2}$, T. S. B. Monir ${ }^{1,2}$, A. Mia ${ }^{1}$, M. R. Islam ${ }^{2}$, M. R. Islam ${ }^{1}$ and R. A. Khan ${ }^{1 *}$ \\ ${ }^{I}$ Environmental Science and Engineering Laboratory, Institute of Radiation and Polymer Technology, Bangladesh Atomic \\ Energy Commission, Savar, Dhaka, Bangladesh \\ ${ }^{2}$ Department of Applied Chemistry and Chemical Engineering, Noakhali Science and Technology University, Noakhali, \\ Bangladesh
}

\begin{abstract}
People on globe are under tremendous threat due to undesired changes in the physical, chemical and biological characteristics of air, water and soil. Due to increased human population, industrialization, use of fertilizers and man-made activity water is highly polluted with different harmful contaminants. Meghna river is one of the most important rivers in Bangladesh. Meghna is formed inside Bangladesh by the joining of Surma and Kushiyara rivers originating from the hilly regions of Eastern India. It is the widest river among those that flow completely inside the boundaries of Bangladesh. The river receives partially treated and untreated sewage effluent, sewage polluted surface run-off and untreated industrial effluent from nearby residence and industrial areas. The river is further polluted by indiscriminate throwing of household, clinical, pathological \& commercial wastes and discharge of spent fuel and human excreta. The objective of the study was to determine the water quality of five different point of Meghna river which passes through Ramgoti, Laxmipur and to determine the economical treatment of wastewater. Water quality assessment of different point of the Meghna river was conducted. Physical parameters of the supplied samples like $\mathrm{pH}$, conductivity, total dissolved solid (TDS), chloride were measured to understand the physicochemical parameters, salinity and the presence of toxic metal ions in water. Electrical conductivity (EC) of water were found to be $300 \pm 0.2 \mu \mathrm{S} / \mathrm{cm}, 220 \pm 0.01 \mu \mathrm{S} / \mathrm{cm}, 240 \pm 0.1 \mu \mathrm{S} / \mathrm{cm}, 212 \pm 0.5 \mu \mathrm{S} / \mathrm{cm}, 225 \pm 0.5$ $\mu \mathrm{S} / \mathrm{cm}$ respectively. The $\mathrm{pH}$ value of all water samples is $7 \pm 0.7$ and salinity, total dissolved solid (TDS), chloride were found to be $0.4 \%$ and $0.5 \% ; 130 \pm 0.2 \mathrm{ppm}, 110 \pm 0.7 \mathrm{ppm}, 120 \pm 0.5 \mathrm{ppm}, 106 \pm 0.2 \mathrm{ppm}, 110 \pm 0.5 \mathrm{ppm} ; 34 \pm 0.3 \mathrm{ppm}, 22 \pm 0.4 \mathrm{ppm}$, $26 \pm 0.02 \mathrm{ppm}, 24 \pm 0.8 \mathrm{ppm}, 28 \pm 0.4 \mathrm{ppm}$ respectively. Also alkalinity and hardness of Meghna river water were found to be $13 \pm 0.3,13 \pm 0.3,16 \pm 0.5,15,20 \pm 0.01 \mathrm{ppm} ; 70 \pm 0.4,62 \pm 0.4,74 \pm 0.46,77 \pm 6 \mathrm{ppm}$. The Meghna river water of Ramgoti, Laxmipur cannot be used for industrial and drinking purpose without any treatment.
\end{abstract}

*Corresponding author e-mail: dr.ruhul_khan@yahoo.com

\section{Phenols and a few phenolic derivatives: a comprehensive study in Shitalakshya river water}

\author{
K. M. Rahman * and R. Islam
}

Department of Applied Chemistry and Chemical Engineering, University of Dhaka, Dhaka-1000, Bangladesh

The pollution of the water bodies with industrial effluents has become a worldwide problem in recent years because of their indestructibility and most of them have toxic effects on living organism. The level of the concentration of carcinogenic phenols and phenolic derivatives in the surface water and $40 \mathrm{~cm}$ depth water in the Shitalakshya river water of Bangladesh have been studied. Twenty four water samples had been collected from twelve different places of Shitalakshya river. According to the analytical results obtained phenol, 2-methyl phenol, 3-methyl phenol and 2-methoxy phenol were found in the ranges of1.14-43.1 $\mu \mathrm{g} / \mathrm{L}, 0.20-1.32 \mu \mathrm{g} / \mathrm{L}, 0.42-17 \mu \mathrm{g} / \mathrm{L}$ and $0.55-2.21 \mu \mathrm{g} / \mathrm{L}$, respectively. Phenolic compounds had been analyzed qualitatively and quantitatively by Gas Liquid Chromatography (GLC) using Mass Spectrometer (MS) detector. The method showed a good recovery percentage for the investigated phenolic compounds. The recovery results found as follows: phenol -74.7\%, 2-methyl phenol -79.12\%, 3-methyl phenol -99.54\%, 2-methoxy phenol -43.408\%.

*Corresponding author e-mail: kazimoriom14@gmail.com 


\title{
Effects of biochar on plant growth
}

\author{
U. Salma, S. M. I. Huq, M. H. Rashid and T. F. Khan * \\ Department of Soil, Water and Environment, University of Dhaka, Dhaka, Bangladesh
}

\begin{abstract}
A pot experiment was conducted to observe the comparative effects of biomass and its corresponding biochar on plant growth. For this, an upland leafy vegetable namely kalmi (Ipomoea aquatica) was cultured in net house to observe the growth in response to the applications of biomass and biochar. Three different types of biomasses viz., cow dung, poultry manure and sludge were selected and three types of biochars were produced from these. The present study included seven different treatments including a control arranged in completely randomized design. All biomasses and biochars were applied to the soil at a rate of $5 \mathrm{t} / \mathrm{ha}$. Chemical and physico-chemical parameters of both biomass and biochar of different sources were determined. Visual observations including growth parameters of kalmi were also determined. Different parameters of biomass and its biochar differed significantly. The results showed that both biomass and biochar had significant effects on growth of kalmi. Among the overall treatments, cow dung biomass showed the best growth and nutrient uptake by kalmi. However, the kalmi did not respond well with cow dung biochar. Both growth and nutrient uptake by kalmi with cow dung biochar was the worst. In case of poultry manure and sludge, growth of kalmi in both biomass and biochar treated soil were almost similar but worse than control. The uptake of nutrients was higher with poultry manure and sludge biochar compared to that of the biomass ones. In all cases, biochar treated plant was more susceptible to disease and pest attack. The comparative study on biomass and biochar vis-à-vis plant growth indicates that the biochar does not exert any significant difference on growth of plants. The study also suggests that the source of biochar plays a vital role to determine its behavior and bioavailability towards plant growth.
\end{abstract}

*Corresponding author e-mail: tazeenkhan18@du.ac.bd

\section{Waste water of Hazaribagh tannery areas in Dhaka, Bangladesh}

\author{
F. Ahmed, A. N. M. Fakhruddin* and M. M. Kabir \\ Department of Environmental Sciences, Jahangirnagar University, Savar, Dhaka-1342, Bangladesh
}

\begin{abstract}
Tannery has dreadful effects on environment although it is one of the profitable industries of Bangladesh. Waste water from tannery industries has permanent toxic effects to humans and environment. Heavy metal pollution also represents a serious environmental as well as health problem. The present study was conducted to determine some water quality parameters and trace metallic constituents of Hazaribagh tannery effluents located in Hazaribagh, Dhaka. Waste water samples were collected from Hazaribagh tannery areas and water quality parameters of Hazaribagh tannery effluent like temperature, pH, TDS, EC, DO, turbidity, BOD and TOC were determined. Heavy metal concentrations were also analyzed by Atomic Absorption Spectroscopy (AAS). The pH values of tannery effluent were found in this present study ranges from 4 to 10 . The mean value of TDS, DO, BOD and TOC were 4349 $\mathrm{mg} / \mathrm{L}, 2.55 \mathrm{mg} / \mathrm{L}, 707.4 \mathrm{mg} / \mathrm{L}$ and $4254.03 \mathrm{mg} / \mathrm{L}$, respectively. The Mean value of EC and turbidity were $9490 \mu \mathrm{S} / \mathrm{cm}$ and 368.30 FTU, respectively. All the parameters exceeded the waste discharge quality standards for industrial unit. The order of trace metallic constituents in the effluent samples were: $\mathrm{Cr}>\mathrm{Pb}>\mathrm{Fe}>\mathrm{Zn}>\mathrm{Cd}>\mathrm{Mn}>\mathrm{Cu}$. The concentrations of all the metallic constituents were higher than the standard values set by DoE. The average concentration of total chromium (Cr) in the effluent samples was $374.402 \mathrm{mg} / \mathrm{L}$ which was approximately 750 times higher than the reference value. Hazaribagh tannery effluents contain a high concentration of heavy metals, so it cannot be applied in agricultural land without proper pretreatment.
\end{abstract}

*Corresponding author e-mail: fakhruddin@juniv.edu 


\title{
Pollution status of heavy metals in water of Halda river using pollution evaluation indices
}

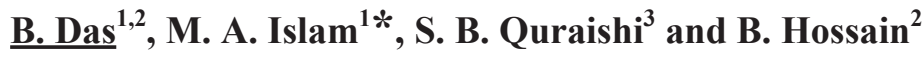 \\ ${ }^{1}$ Institute of Nuclear Science \& Technology, Atomic Energy Research Establishment, Ganakbari, Ashulia, Dhaka-1349, \\ Bangladesh \\ ${ }^{2}$ Department of Physics, Chittagong University of Engineering \& Technology, Chittagong-4349, Bangladesh \\ ${ }^{3}$ Chemistry Division, Atomic Energy Centre Dhaka, 4 KaziNazrul Islam Avenue, Dhaka, Bangladesh
}

The pollution status of heavy metals in water of the Halda River, Chittagong was investigated based on the spatial variations. To identify variation and pathways of heavy metals, water samples were collected from five stations of the river. Heavy metal concentrations of $\mathrm{Cr}, \mathrm{Mn}, \mathrm{Fe}, \mathrm{Co}, \mathrm{Ni}, \mathrm{Cu}, \mathrm{Zn}, \mathrm{As}, \mathrm{Cd}, \mathrm{Hg}$ and $\mathrm{Pb}$ were determined by using atomic absorption spectrometry (AAS) whereas Al was determined by inductively coupled plasma mass spectrometry (ICP-MS). The mean values of heavy metal pollution index (HPI) and pollution index (PI) were calculated. Comparison of the heavy metal concentrations in the water samples with different regulatory standard and background values revealed that $\mathrm{Al}, \mathrm{Co}, \mathrm{Cu}$ and $\mathrm{Pb}$ concentrations are higher than the regulatory standard values whereas concentrations for rest of the studied metals are below the regulatory standard values.

*Corresponding author e-mail: liton80m@yahoo.com

\section{Physio-chemical status of water and distribution of Chlorophyll $a$ in Jamuna river}

\author{
S. Anwar, U. H. Mitu, A. S. M. Saifullah, S. Sheikh and M. J. Uddin
}

Department of Environmental Science and Resource Management, Mawlana Bhashani Science and Technology University, Santosh, Tangail-1902, Bangladesh

\begin{abstract}
The physico-chemical and biological characteristic of a river ecosystem depicts its health and status of sustenance of life. Towards appraisal of water quality, physico-chemical parameters (i.e. water temperature, pH, DO, TSS), water nutrients(nitrate, phosphate and ammonium) and biological status (Chlorophyll-a) were determined. Samples were collected from five stations of different locations with their special feature. The study revealed a slight spatial variation in physico-chemical parameters. The water of the river was found slightly alkaline $(7.75 \pm 0.14)$. The transparency was found to be $(14.86 \pm 1.54 \mathrm{~cm})$ followed by temperature $\left(31.04 \pm 0.5^{\circ} \mathrm{C}\right)$, TSS $(0.03 \pm 0.038 \mathrm{mg} / \mathrm{L}), \quad$ DO $\quad(2.59 \pm 0.22 \mathrm{mg} / \mathrm{L}), \quad$ nitrate $(0.16 \pm 0.35 \mathrm{mg} / \mathrm{L})$, phosphate $(0.32 \pm 0.37 \mathrm{mg} / \mathrm{L})$ and ammonium $(0.32 \pm 0.25 \mathrm{mg} / \mathrm{L})$. Chlorophyll a, which represents the biomass of phytoplankton, was estimated $(0.009 \pm 0.004 \mathrm{mg} / \mathrm{L})$. Some physico-chemical parameters showed interaction with each-other where there was negative correlation between DO and ammonium ( $\mathrm{r}=-0.911$, at 0.05$)$. The present water quality of the Jamuna river seems suitable for all aquatic lives, domestic and agricultural uses. Although the overall status of the river water quality is good but degradation was detected in few points which might be due to anthropogenic activities, especially the direct discharge of domestic effluents into river.
\end{abstract}

*Corresponding author e-mail: saifullahasm@yahoo.com 


\title{
Analysis and treatment of Madhumati river water of Bangladesh
}

\author{
A. Mia, M. N. Salam, Z. R. Usha, M. R. Islam, M. S. Manir, M. Z. I. Mollah and R. A. Khan* \\ Environmental Science and Engineering Laboratory, Institute of Radiation and Polymer Technology, Bangladesh Atomic \\ Energy Commission, Saver, Dhaka, Bangladesh
}

\begin{abstract}
Bangladesh is renowned for its beautiful geomorphic features, including the massive rivers flowing throughout the country. So, Bangladesh is called a riverine country. The Bangladesh rivers drive various economic activities such as agriculture, waterway communication, drinking water, and energy source among others. Since these rivers play a significant role in the economic growth, it is therefore deemed important to study important rivers in Bangladesh. Madhumati river is flowing through south-western part of Bangladesh. The river came from the Padma (Ganges) river and then falls into the Bay of Bengal. The water of the river was collected from the surface of the river at different points in the month of March 2017. The pH, electrical conductivity (EC), salinity and total dissolved solid (TDS) of the river water was found to be 7.5 to $8.4,392 \pm 2 \mu \mathrm{s} / \mathrm{cm}$, $0.80 \pm 0.10 \%$, and $192 \pm 6 \mathrm{ppm}$ respectively. Chloride, total alkalinity and total hardness $(\mathrm{TH})$ of the river water were observed as follows: $12 \pm 5 \mathrm{ppm}, 46 \pm 8 \mathrm{ppm}, 142 \pm 1 \mathrm{ppm}$, respectively. Two different techniques were used for the treatment of Madhumati river water to be used as safe drinking water and irrigation purposes. Potash alum (10 to $1000 \mathrm{ppm}$ ) was added to the water and different parameters were checked. Water was also exposed to different doses ( 5 to $25 \mathrm{kGy}$ ) of Gamma radiation. Both techniques showed good results. Finally, the quality of the Madhumati river water showed in the good range because the south-western part of Bangladesh has only a few industries.
\end{abstract}

*Corresponding author e-mail: dr.ruhul_khan@yahoo.com

\section{Coastal fisheries and socio-economic status of Maheshkhali upazila, Cox's Bazar, Bangladesh}

\author{
M. A. Kashem $^{1 *}$ and A. A. M. Siddiqui ${ }^{2}$
}

National Land Zoning Project, Ministry of Land

Pragmatic Foundation, West Lane of Singer Show room (1 ${ }^{\text {st }}$ Floor), Victoria Road, Tangail-1900

\begin{abstract}
Bangladesh has vast coastal and marine resources along its south edge. Due to the geographical position and climatic condition, the coastal area of the country is known as one of the highly productive areas of the world. Bangladesh is rich not only in terms of its vast water areas but also in terms of the biological diversity. Maheshkhali Upazila is the western most part of Cox's Bazar district and situated on the Bay of Bengal (BoB). The Kohalia and Bakkhali River and the Maheshkhali channel are main water bodies of the upazila. The eastern part of the upazila is separated from the mainland by the Maheshkhali channel. The upazila is a part of the exposed coast of the country having direct interaction with the Bay of Bengal (BoB). The river and Estuary plays a vital role in the ecology and economy of the livelihood of the people of the upazila. The upazila occupies an area of 362.18sq. $\mathrm{km}$. (36218 hectares). There are 08 unions, 25 mouza and 151 villages (BBS, 2011). The conventional standard of living and resourceful, exceptional land use pattern and cultural heritage have an incredible impact on the economic, social and cultural life of the society. Land use in coastal Bangladesh is diverse, competitive and conflicting. Agriculture, shrimp farming, salt production, forestry, ship-breaking yards, ports, industry, settlements and wetlands are some of the uses. This work tries to explore the condition of present fisheries status, livelihood of fish farmers, socio-economic condition of fish farmers and fishermen, coastal resources of this Upazila, involvement of women during disaster, their special vulnerabilities and coping mechanism during disastrous situation. Both secondary and primary data have been used and analyzed to identify their overall condition during hazardous situation.
\end{abstract}

*Corresponding author e-mail: md.kashem@gmail.com 


\title{
Hydro geochemical characterization of ground water in Gazipur district of Bangladesh
}

\author{
$\underline{\text { F. Yeasmin }}^{1 *}$, A. H. M. Saddat ${ }^{1}$, M. A. T. M. Tanvir Rahman ${ }^{1}$ and B. Saha ${ }^{2}$ \\ ${ }^{1}$ Department of Environmental Sciences, Jahangirnagar University, Savar, Dhaka-1342, Bangladesh \\ ${ }^{2}$ Soil, Agronomy and Environment Section, Biological Research Division, Bangladesh Council of Scientific and Industrial \\ Research (BCSIR) Dr. Qudrat-i-Khuda Road Dhanmondi, Dhaka- 1205, Bangladesh
}

\begin{abstract}
Assessment of hydro geochemistry of groundwater in Gazipur districts has been carried out to determine the processes controlling the ground water chemistry. Concentrations of trace metals and major ionic constituents were determined to assess the suitability of waters for drinking and irrigational/agricultural use. 35 ground water samples were collected from Kapasia and Sreepur upazila in Gazipur district. The $\mathrm{pH}$, temperature, EH, electrical conductivity (EC), salinity, total dissolved solids (TDS) had been determined by field equipment. $\mathrm{Na}^{+}, \mathrm{K}^{+}, \mathrm{Ca}^{2+}, \mathrm{Mg}^{2+}, \mathrm{Fe}^{2+}, \mathrm{Mn}^{2+}, \mathrm{Zn}^{2+}, \mathrm{F}^{-}, \mathrm{Cl}^{-}, \mathrm{Br}^{-}, \mathrm{NO}_{3}^{-}, \mathrm{PO}_{4}^{3}-, \mathrm{SO}_{4}^{2-}$ and $\mathrm{HCO}_{3}^{-}$had been measured by Flame Photometer, AAS, Ion Chromatography and titration method. The calculated parameters e.g., alkalinity, total hardness, saturation index, water type were estimated by the Aquachem software. Sodium absorption ratio, soluble sodium percentage, permeability index and Kelley's ratio were calculated to determine the irrigation water quality in the study area. Piper diagram showed that the predominant hydrochemicalfacies for the ground water were $\mathrm{Mg}-\mathrm{Ca}-\mathrm{Na}-\mathrm{HCO}$ types. The trend of major cationic concentration of the ground water was $\mathrm{Ca}^{2+}>\mathrm{Mg}^{2+}>\mathrm{Na}^{+}>\mathrm{K}^{+}$and the trend of major anion was $\mathrm{HCO}_{3}>>\mathrm{Cl}^{-}>\mathrm{SO}_{4}{ }^{2-}>\mathrm{NO}_{3}{ }^{2-}>\mathrm{F}^{-}$. All the samples water are considered as freshwater on the basis of TDS. The concentration of the most chemicals are within the permissible limit of the drinking and irrigation purposes. Aqueous speciation modeling reveals that the ground water samples are undersaturated with respect to carbonate minerals (calcite, aragonite and dolomite). The Gibb's diagram illustrated that chemical weathering of rock-forming minerals is influencing the ground water quality. Ground water chemistry in the study area is mainly governed by rock dissolution. The dissolved minerals in ground water mainly come from silicate weathering.
\end{abstract}

*Corresponding author e-mail: farhana.jue13@gmail.com

\section{Environmental awareness among urban residents in Bangladesh: a case study of Sylhet City Corporation}

\begin{abstract}
S. D. Shuvo
Department of Geography and Environment, University of Dhaka

Abstract

Bangladesh is a developing country in the world. But the country regularly faces serious environmental problems. Due to this fact, it is mandatory to have a sense of awareness among the people of the country regarding the environmental quality. Being the hub of economic growth, urban areas are the center of all kinds of development activities and these activities bring about different environmental problems. A study on 440 inhabitants of Sylhet City Corporation was conducted to show the level of awareness among the urban people. The results of this study shows that $76.86 \%$ respondents are directly or indirectly affected by environmental problems. Main areas of concern for the citizens evolve around the scarcity of water bodies for their daily uses, high amount of dust particles in the air, absence of proper waste management system and noise pollution in some areas of the city. Interesting finding of the study is that $82.64 \%$ of the respondents think that the environmental condition of Sylhet City Corporation is better than Dhaka City Corporation. The findings of this study can not only be used for the betterment of urban environment quality in Sylhet but also in Bangladesh as well.
\end{abstract}

*Corresponding author e-mail: sauravshuvo@yahoo.com 


\title{
Proximate composition and quality of freshwater dried fish products
}

\author{
M. B. Alam*, M. A. B. Siddique, M. M. Alam, M. A. Hussain and F. A. Flowra \\ Department of Fisheries, University of Rajshahi, Rajshahi-6205, Bangladesh
}

\begin{abstract}
The present study was carried out from March to December 2016 with a view to making an assessment regarding proximate composition and quality issues in five freshwater dried fishes (Channa punctatus, Channa striatus, Wallago attu, Mystus vittatus and Puntius sp.) of Chalan beel. With respect to proximate composition, protein level was found as (from $50.32 \%$ in Puntius sp. to $78.83 \%$ in C. punctatus); fat (from $3.72 \%$ in C. punctatus to $15.3 \%$ in Puntius sp.); ash (from $14.97 \%$ in C. punctatus to $29.91 \%$ in Puntius sp.); and moisture (from $12.4 \%$ in C. punctatus to $20.90 \%$ in C. striatus). Screening of pesticide residue revealed that Chlorpyrifos, a broad-spectrum chlorinated organophosphate, was detected in C. punctatus, C. striatus and $W$. attu. In bacterial assessment E. coli count was $10 \mathrm{cfu} / \mathrm{g} M$. vittatus (within acceptable limit) and $2.6 \mathrm{X} 10^{2} \mathrm{cfu} / \mathrm{g}$ in $W$. attu (above permissible limit). These findings are a matter of grave concern for consumers in food safety aspects.
\end{abstract}

*Corresponding author e-mail: alambayezid@gmail.com

\section{Health risk assessment of leachate in the surrounding areas of waste landfill site at Khulna in Bangladesh}

\author{
P. K. Mahanta and M. R. Isalm* \\ Department of Civil Engineering, Khulna University of Engineering \& Technology (KUET), Khulna-9203, Bangladesh
}

\begin{abstract}
The most popularly used method to dispose municipal waste is Landfill in all over the world. The waste landfill sites are a major source of land, air, surface and ground water pollution. It possesses serious harm to the people especially who resides near landfill sites. The present study aims at assessing the characteristics of leachate and its probable risks to human health through surface and ground water in and around the waste landfill site located at Rajbandh, Khulna, Bangladesh.This study was carried out both in dry and rainy season. The leachate samples as well as ground and surface water samples were compiled from the five selected locations, respectively and their corresponding GPS reading was entered. The relevant parameters required for assessing health hazard were assessed through the standard methods in the laboratory. Diverse variation of parameters in dry and rainy seasons were observed. The surface and ground water during the rainy season around the landfill site appears to be polluted, most probably, through the overflow of leachate. In this study, non-carcinogenic risk assessment of selected metals in surface and ground water was evaluated using the Hazard Quotient $\left(\mathrm{HQ}_{\text {ing/Derm }}\right)$ and Hazard Index $\left(\mathrm{HI}_{\text {ing/Derm }}\right)$ following USEPA methodology. The result reveals that the child's were more vulnerable to adverse health hazards than adults around the landfill site. Hopefully, this study will assist in establishing pollutant loading reduction goal and total maximum daily load in landfill, and thus leads to preserve public health and develop water conservation strategy in the landfill site.
\end{abstract}

*Corresponding author e-mail: imrafizul@yahoo.com, pangkaj1001058@gmail.com 


\title{
Environmental parameters (temperature, humidity, noise and illumination) in ready-made garment industries, Gazipur, Bangladesh
}

\author{
$\underline{\text { J. Ferdouse }}^{1 *}$, R. Sultana ${ }^{1}$, M. B. Latif ${ }^{1}$, S. K. Mondol ${ }^{1}$ and B. C. Sarker ${ }^{2}$ \\ ${ }^{1}$ Department of Environmental Science and Resource Management, Mawlana Bhashani Science and Technology University, \\ Bangladesh \\ ${ }^{2}$ Fire \& Safety Department, Bangladesh Knitwear Manufacturers \& Exporters Association (BKMEA)
}

\begin{abstract}
The study was conducted to assess the environmental parameters (temperature, humidity, noise and illumination) to know the status of working environment in 3 industries on September, 2016 to February, 2017. In the selected industries the highest temperatures were observed in boiler room $\left(28.6^{\circ} \mathrm{C}\right)$ and generator room $\left(30.4{ }^{\circ} \mathrm{C}\right.$ and $\left.34.1^{\circ} \mathrm{C}\right)$ where the generator room was also found as the mostly noisy $(113.3 \mathrm{~dB}, 111.8 \mathrm{~dB}$ and $111.9 \mathrm{~dB}$ ) and gloomy (64 lux, 67 lux and 112 lux) area. The illumination levels in the cutting section (524 lux, 466 lux and 450 lux), sewing section (493 lux, 565 lux and 490 lux) and finishing section (474 lux and $515 \mathrm{lux}$ ) where maximum number of workforce is employed were found unfavorable. The unpleasant illumination levels were also found in the cad section (310 lux), power control and distribution room (73 lux), office and store room (142 lux), boiler room (72 lux and $217 \mathrm{lux}$ ), accessories store (205 lux), sub-station room (160 lux), generator room (112 lux), compressor room (196 lux). The temperature level of almost all the sections of three readymade garment industries were optimum to moderately high, humidity level was around optimum level but the noise levels were highly exceeded the national standard, and the illumination level was insufficient especially in the cutting and sewing section. The study revealed that congested work area, improper ventilation, building design, excessive noise, poor illumination, dust and no use of personal protective equipment were the major problem faced by the workers in these industries.
\end{abstract}

*Corresponding author e-mail: jannat159357@gmail.com

\section{Biochemical quality assessment of fish powder}

\author{
$\underline{\text { S. N. Jahan }}^{1 *}$, M. B. Alam ${ }^{1}$, B. Islam ${ }^{2}$, P. K. Karmakar ${ }^{3}$ and F. A. Flowra ${ }^{1}$
}

${ }^{1}$ Department of Fisheries, University of Rajshahi, Rajshahi, Bangladesh

${ }^{2}$ Bangladesh Council for Scientific and Industrial Research Laboratories, Rajshahi, Bangladesh

${ }^{3}$ Department of Statistics, University of Rajshahi, Rajshahi, Bangladesh

\begin{abstract}
The study carried out with a view to determining proximate and mineral composition of fish powder of five freshwater fish samples (Hypophthalmicthys molitrix, Labeo rohita, Cirrnina mrigala and Puntius sophore and small prawns). The samples collected from five local fish markets of Rajshahi city corporation were subjected to washing, gutting drying and grinding in order to make powder and homogenized sample which were preserved into plastic container for chemical analyses. All the activities were conducted in the laboratory of Department of Fisheries, University of Rajshahi, Bangladesh. Major nutrient compositions of powder products such as protein, lipid, moisture, ash, carbohydrate, phosphorus, iron and calcium were estimated. Chemical compositions were found to vary among the species. The protein, lipid, moisture and ash content of five samples ranged from 54.31 (P. sophore) to 68.90\% (small prawns), 13.33 (P. sophore) to 19.33\% (L. rohita), 11.55 (L. rohita) to $13.95 \%$ (H. molitrix) and 0.16 (small prawns) to $0.44 \%$ (C. mrigala), respectively. The highest value of carbohydrate was $19.23 \%$ (P. sophore) and the lowest was $1.75 \%$ (C. mrigala). The calcium, iron and phosphorus content of the selected species varied from 2.49 (L. rohita) to $2.55 \mathrm{~g} / \mathrm{kg}$ (small prawns), 0.43 (H. molitrix and P. sophore) to $1.89 \mathrm{~g} / \mathrm{kg}$ (C. mrigala) and 0.95 (L. rohita) to $1.91 \mathrm{~g} / \mathrm{kg}$ (P. sophore), respectively.
\end{abstract}

*Corresponding author e-mail: nusratru@yahoo.com 


\title{
Clay composites to prevent the growth of pathogenic microorganism
}

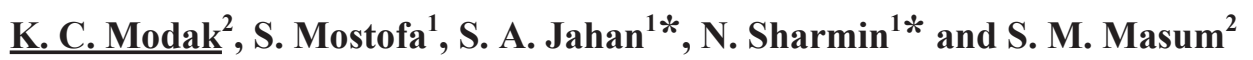

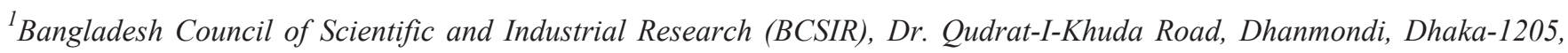 \\ Bangladesh \\ ${ }^{2}$ Department of applied chemistry and Chemical Engineering,University of Dhaka, Dhaka, Bangladesh
}

\begin{abstract}
Silver clay composites (Ag-MMT) were successfully synthesized using the wet chemical reduction method into the lamellar space layer of montmorillonite (MMT) in the absence of any heat treatment. The experimental steps consisted of purification of clay with hydrogen peroxide to remove organic matter and modification with cetyl trimethyl ammonium bromide (CTAB) to increase basal spacing in the clay. $\mathrm{AgNO}_{3}$ and $\mathrm{NaBH}_{4}$ were used as a silver precursor and reducing agent, respectively. Characterizations were done using different methods, i.e, ultraviolet-visible spectroscopy, powder X-ray diffraction, scanning electron microscopy, and Fourier transform infrared spectroscopy. The antibacterial activity of silver-clay composites was investigated against Gram-positive bacteria, i.e, Bacillus subtilis, Bacillus megaterius and Bacillus cereus by the disc diffusion method using Mueller Hinton agar at different composites of silver. All of the synthesized composites were found to have high antibacterial activity.
\end{abstract}

*Corresponding author e-mail: shirin_akterbcsir@yahoo.com,nahid_pppdc@yahoo.com

\section{Removal of chromium from aqueous system using adsorbents synthesized from bio-waste}

\author{
M. Saha, S. Mostofa, S. A. Jahan*, N. Sharmin and S. Ahmed* \\ Bangladesh Council of Scientific and industrial Research (BCSIR), Dr. Qudrat-I-Khuda Road, Dhanmondi, Dhaka-1205, \\ Bangladesh
}

\begin{abstract}
Considering the adverse effects of chromium as toxic pollutant, we have attempted to develop a cost effective but highly efficient adsorbent which will be beneficial for rapid removal of $\mathrm{Cr}$ (VI) from aqueous system. Our approach used hydroxyapatite in pure and doped format which was synthesized using egg shell as the prime source of calcium. However to examine the efficiency of HAP as adsorbent, it was subjected to thermal treatment at different temperatures $\left(110^{\circ}, 300^{\circ}\right.$ and 600 ${ }^{\circ} \mathrm{C}$ ). The adsorption profile was monitored as a function of contact time (5 to $25 \mathrm{~min}$ ), $\mathrm{pH}$ (3 to 9) and initial concentration of $\mathrm{Cr}(\mathrm{VI})$. Observed results revealed that the adsorption equilibrium was attained at 20 min while the optimum $\mathrm{pH}$ was 6 . On the other hand a significant adsorption was achieved at lower initial concentration of $\mathrm{Cr}(\mathrm{VI})$. Particularly the effect of initial chromium concentration on chromium removal efficiency using doped HAP was found to be three times higher than that of pure HAP. Adsorption data were fitted to Langmuir and Freundlich isotherm model.
\end{abstract}

*Corresponding author e-mail: shirin_akterbcsir@yahoo.com, shanta_samina@yahoo.com 


\title{
Conductive microemulsion used as template for electrodeposition of cobalt
}

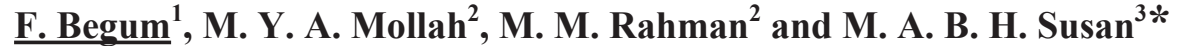 \\ ${ }^{1}$ Institute of Glass \& Ceramic Research and Testing, Bangladesh Council of Scientific and Industrial Research, Dhaka, Bangladesh \\ ${ }^{2}$ University Grants Commission of Bangladesh, 29/1 Agargaon, Dhaka-1207, Bangladesh \\ ${ }^{3}$ Department of Chemistry, University of Dhaka, Dhaka-1000, Bangladesh
}

\begin{abstract}
Reverse microemulsions comprising nanometer-sized water droplets in an apolar solvent (with the aid of surfactant or surfactant with co-surfactant) have been used as feasible templates for electrodeposition of metals. In this work, the electrochemical reduction of cobalt ion to metallic cobalt on a copper electrode $(\mathrm{CuE})$ in reverse microemulsions of sodium dodecyl sulfate (SDS) and cetyltrimethylammonium bromide (CTAB) with different water to surfactant ratios $\left(\mathrm{w}_{\mathrm{o}}\right.$ ) have been studied by cyclic voltammetry. Electrodeposition of cobalt on a $\mathrm{CuE}$ was performed from reverse microemulsions of SDS with fixed $\mathrm{w}_{\mathrm{o}}(=20.3)$ at different reduction potentials using constant potential electrolysis method. From reverse microemulsions of CTAB, electrodeposition of cobalt was carried out with increasing $\mathrm{w}_{\mathrm{o}}$ at below reduction potentials. Morphology and microstructures of deposited cobalt were examined by scanning electron microscopy while elemental characterization was carried out by energy dispersive X-ray spectroscopy. A systematic study of these conductive reverse microemulsions on different morphology with increasing $\mathrm{w}_{\mathrm{o}}$ also has been performed. At a fixed $\mathrm{w}_{\mathrm{o}}$ in microemulsion of SDS, only thickness of deposited cobalt changed with change in applied potentials while in reverse microemulsions of CTAB, morphology and structure of electrodeposited cobalt changes with increasing $\mathrm{w}_{\mathrm{o}}$ at a fixed reduction potential. Additionally, the electrochemical behavior and different morphologies of deposited cobalt have been correlated with conductivity of these reverse microemulsions with increasing $\mathrm{w}_{\mathrm{o}}$. Thus, reverse microemulsions of SDS and CTAB have been established as suitable media for electrodeposition of metals with tunable size and special morphologies depending on their entire compositions of different components.
\end{abstract}

*Corresponding author e-mail: susan@du.ac.bd

\section{Volumetric and viscometric properties of n-acetylcysteine in aqueous dimethylsulfoxide solution at different temperatures}

\author{
M. H. Khan, P. Ahamed and M. A. Yousuf* \\ Department of Chemistry, Khulna University of Engineering \& Technology (KUET), Khulna-9203, Bangladesh
}

\begin{abstract}
The density and viscosity of N-Acetyl-L-Cysteine(NAC) $(\sim 0.10$ to $\sim 1.00)$ mol. $\mathrm{L}^{-1}$ in $\mathrm{H}_{2} \mathrm{O}$, dimethylsulfoxide (DMSO) and DMSO- $\mathrm{H}_{2} \mathrm{O}$ mixed solutions were measured and studied over the entire molarity range at $(298.15,303.15,308.15,313.15$ and 318.15) $\mathrm{K}$ temperatures with a view to determining the molecular interactions among $\mathrm{NAC}_{2} \mathrm{H}_{2} \mathrm{O}$ and DMSO. The apparent molar volumes were obtained from the experimental density data. In the NAC- $\mathrm{H}_{2} \mathrm{O}$ system the apparent molar volume of NAC increases, whereas in the NAC-DMSO system it decreases smoothly. In addition, apparent molar volume at infinite dilution, apparent molar expansivity, transfer apparent molar volume and $\mathrm{S}_{\mathrm{v}}$ values were also calculated according to the experimental density data. Hepler constant which is used to determine the capacity of solute as a structure maker or structure breaker in mixed solvent system has also been determined. It is seen that NAC has good structure making property in ternary solutions than the binary systems. The viscosity data were employed to determine the viscosity (A, B) coefficients, change of free energy, $\mathrm{DG}^{*}$, change of enthalpy, $\mathrm{DH}^{*}$ and change of entropy, $\mathrm{DS} *$ for viscous flow. $[\mathrm{dB} / \mathrm{dT}]$ supports the structure making property of NAC as determined by Hepler constant. The results suggest that there is a significant effect of NAC on water and DMSO.
\end{abstract}

*Corresponding author e-mail: yousuf2716@yahoo.com 


\title{
Cost effective graphite pencil based sensor for simultaneous detection of dihydroxybenzene isomers
}

\author{
M. I. Khan, N. T. Tonu, P. Ahamed, M. Jamal and M. A. Yousuf* \\ Department of Chemistry, Khulna University of Engineering \& Technology (KUET), Khulna-9203, Bangladesh
}

\begin{abstract}
Dihydroxybenzene Isomers are used in many industries but they are considered as toxic pollutants for the environment. Simultaneous detection of these isomers in trace level is still challenging. So in this study, low cost electrochemical sensor was constructed for their low level sensing. Graphite pencil electrode was modified with electropolymerized films of glycine by cyclic voltammetric technique. The modified electrode exhibited excellent catalyticactivity, high selectivity and sensitivity toward isomers.Analyses and detection processes showed optimum results in phosphate buffer solution (PBS) at pH 6.8. Differential pulse voltammetry was employed for the detection technique. The scan rate effect was found to be diffusion controlled electrode process. Concentration effect of isomers was linear with current. The detection limit for Hydroquinone (HQ), Catechol (CC) and Resorsinol (RS) were determined as $8.366 \mu \mathrm{ML}^{-1}, 8.158 \mu \mathrm{ML}^{-1}$ and $11.054 \mu \mathrm{ML}^{-1}(\mathrm{~S} / \mathrm{N})=3$, respectively. The sensitivity for $\mathrm{HQ}, \mathrm{CC}$ and $\mathrm{RS}$ is $364.785 \mu \mathrm{A} / \mathrm{mM} / \mathrm{cm}^{2}, 282.712 \mu \mathrm{A} / \mathrm{mM} / \mathrm{cm}^{2}$ and $135.560 \mu \mathrm{A} / \mathrm{mM} / \mathrm{cm}^{2}$ respectively in simultaneous detection. Glycine modified graphite pencil electrode showed stable and reproducible response without any influence of interference commonly exist in aqueous system. The proposed method is simple and quick.
\end{abstract}

*Corresponding author e-mail: yousuf2716@yahoo.com

\section{Physico-chemical properties of rain water samples from Dhaka, Bangladesh}

\author{
N. A. Kona, A. Mia, S. Shahida, M. N. Islam, T. S. B. Monir, R. Rahman and R. A. Khan*
}

Environmental Science and Engineering Laboratory, Institute of Radiation and Polymer Technology, Bangladesh Atomic Energy Commission, Savar, Dhaka, Bangladesh

\begin{abstract}
Water covers $71 \%$ of the earth's surface but deficiency of pure water. Generally, a greater quantity of water is found in the earth's interior for several purposes. The demand for pure water is continuously increasing with the passing decades as a direct effect of population explosion. To equilibrium this imbalance of pure water,natural sources of water can be considered. Rain is the most convenient source of water available in nature. In this investigation, rain water has been collected from two locations of Dhaka named Mirpur and Tongi. Different parameters of rain water was evaluated. Physical parameters such as pH, electrical conductivity (EC), total dissolved solid (TDS), chloride were measured. EC of the rain water were found to be $75 \pm 2 \mu \mathrm{s} / \mathrm{cm}$ and $44 \pm 2 \mu \mathrm{s} / \mathrm{cm}$ respectively for Mirpur and Tongi samples. The $\mathrm{pH}$ of all water samples were in the range of 6 to 7. Salinity, TDS, chloride, total alkalinity (TA) and total hardness (TH) were found to be $0.1 \%$, and $0.1 \% ; 35 \pm 3 \mathrm{ppm}$ and $22 \pm 2 \mathrm{ppm}$ respectively for Mirpur samples and $10 \pm 2 \mathrm{ppm}$ and $7 \pm 1 \mathrm{ppm}$; $10 \pm 1$ and $5 \pm 1 ; 25 \pm 1$ and $20 \pm 1$ respectively for Tongi samples.
\end{abstract}

*Corresponding author e-mail: dr.ruhul_khan@yahoo.com 


\title{
Quality parameters and treatment of Meghna river water of Bangladesh
}

\author{
M. M. Khanam, M. N. Salam, A. Mia, M. R. Islam, M. S. Manir and R. A. Khan* \\ Environmental Science and Engineering Laboratory, Institute of Radiation and Polymer Technology, Bangladesh Atomic \\ Energy Commission, Savar, Dhaka, Bangladesh
}

\begin{abstract}
Bangladesh has 700 rivers including tributaries which flow through the country constituting a waterway of a total length of around 24, 140 kilometers. Meghna river is one of the most important rivers in Bangladesh, one of the three that forms the Ganges Delta, the largest delta on earth fanning out to the Bay of Bengal. A larger number of settlements, towns, ports and industries have sprung up on both the banks of Meghna. But at present, Meghna river water are polluting by several ways. Industrialization is one of the polluting sources. The water of the river was collected from the surface of the river in the month of April 2017. The pH, electrical conductivity (EC), salinity and total dissolved solid (TDS) of the river water was found to be $7.71,245 \mu \mathrm{s} / \mathrm{cm}, 0.5 \%$ and $122 \mathrm{ppm}$, respectively. Chloride, total alkalinity and total hardness (TH) of the river water were observed as follows: $21.3 \mathrm{ppm}, 10 \mathrm{ppm}, 60 \mathrm{ppm}$, respectively. Two different techniques were used for the treatment of Meghna river water to be used as safe drinking water, industrial uses and irrigation purposes. Potassium permanganate (10 to $1000 \mathrm{ppm})$ was added to the water and different parameters were checked. Gamma radiation was exposed for the purification of the river water and it was found that gamma radiation have the potential for the treatment of collected water.
\end{abstract}

*Corresponding author e-mail: dr.ruhul_khan@yahoo.com

\section{Physico-chemical parameters of water in flood affected area at Gazipur, Bangladesh}

\author{
F. T. Ahmed ${ }^{*}$, S. Shahnaz, M. F. Alam and N. C. Dafadar
}

Nuclear and Radiation Chemistry Division, Institute of Nuclear Science and Technology, Atomic Energy Research Establishment, G. P. O. box-3787, Dhaka, Bangladesh

\begin{abstract}
Water is a transparent and nearly colorless chemical substance that is the main constituent of Earth's streams, lakes, oceans and the fluids of most living organisms. In the current investigation, some physico-chemical parameters of water (i.e., pH, EC, total hardness, total alkalinity and concentration of different anions like $\mathrm{Cl}^{-}, \mathrm{NO}_{3}^{-}, \mathrm{SO}_{4}{ }^{2-}$ ) of five different flood affected areas from Zirani, Gazipur was studied. The result revealed that the average of $\mathrm{pH}, \mathrm{EC}, \mathrm{TH}, \mathrm{TA}, \mathrm{Cl}^{-}, \mathrm{NO}_{3}^{-}$and $\mathrm{SO}_{4}{ }^{2-}$ of five different locations were found to be $6.46,114.80 \mu \mathrm{S} / \mathrm{cm}, 86.40 \mathrm{ppm}, 3640 \mathrm{ppm}, 30.40 \mathrm{ppm}, 49.55 \mathrm{ppm}$ and $1.70 \mathrm{ppm}$ respectively. Most of the values of these parameters were found in safety levels prescribed by World Health Organization (WHO) and DoE of Bangladesh except $\mathrm{NO}_{3}^{-}$. It can be concluded that the water parameters which were taken for the present study are almost below the pollution level for surface water which suits their requirement for the use of various purposes.
\end{abstract}

*Corresponding author e-mail: farahchem53@hotmail.com 


\title{
Detoxification of hexavalent chromium by Bacillus pumilus and assessment of multiple antibiotic resistance index for biosafety measure
}

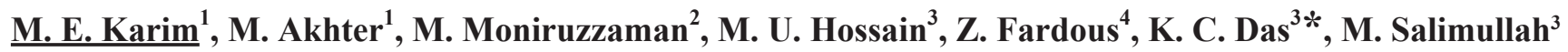 \\ and M. A. Z. Chowdhury ${ }^{4}$ \\ ${ }^{I}$ Environmental Biotechnology Division, National Institute of Biotechnology, Dhaka-1349, Bangladesh \\ ${ }^{2}$ Molecular Biotechnology Division, National Institute of Biotechnology, Dhaka-1349, Bangladesh \\ ${ }^{3}$ Bioinformatics Division, National Institute of Biotechnology, Dhaka-1349, Bangladesh \\ ${ }^{4}$ Agrochemical and Environmental Research Division, Institute of Food and Radiation Biology, Atomic Energy Research \\ Establishment, Dhaka-1349, Bangladesh
}

\begin{abstract}
Pollution of the environment with toxic heavy metals such as hexavalent chromium [Cr (VI)] is of great concern now-a-days due to its genotoxic carcinogenic effect. Microbial detoxification of $\mathrm{Cr}$ (VI) provides a viable means for environmental bioremediation of $\mathrm{Cr}$ (VI) pollution as they have the ability to reduce $\mathrm{Cr}$ (VI) to a stable speciation state of trivalent chromium [Cr (III)], which is insoluble and comparatively less toxic. In the present study, a bacterial strain DHS-12(7) was isolated from tannery waste dump sites and identified as Bacillus pumilus based on cultural, morphological, biochemical and 16S rRNA gene sequencing. Toxicity studies showed the Minimum Inhibitory Concentration (MIC) value of $250 \mathrm{ppm}$ on Luria-Bertani (LB) agar medium supplemented with $\mathrm{K}_{2} \mathrm{Cr}_{2} \mathrm{O}_{7}$ as source of $\mathrm{Cr}$ (VI). The strain was able to completely reduce $10 \mathrm{ppm}$ and $30 \mathrm{ppm} \mathrm{Cr}(\mathrm{VI})$ at $37^{\circ} \mathrm{C}$ under agitation $(150 \mathrm{rpm})$ within 20 $\mathrm{hr}$ and $42 \mathrm{hr}$, respectively. Since the concentration of total $\mathrm{Cr}$ was invariable after complete reduction as detected through AAS analysis, this experiment proposed that responsible mechanism was associated with extracellular $\mathrm{Cr}$ (VI) reduction process rather than intracellular uptake mechanism. Antibiogram studies revealed Multiple Antibiotic Resistance (MAR) index of 0.1 for this bacterium which was low as compared to standard risk assessment value of 0.20. Conclusively, Bacillus pumilus can be a potent bioremediation agent for detoxification of $\mathrm{Cr}$ (VI) from the contaminated sites from a view of public health issue for both human and animal health as well as the environment.
\end{abstract}

*Corresponding author e-mail: keshob@gmail.com 


\title{
Hydro-chemistry and pollution of Dhaleshwari river due to recently shifted tannery industry
}

\author{
$\underline{\text { K. S. Ahmed }}^{1 *}$, M. Sarkar ${ }^{2}$ and B. Saha ${ }^{3}$ \\ ${ }^{1}$ IGCRT, Bangladesh Council of Scientific and Industrial Research, Dhaka-1205, Bangladesh \\ ${ }^{2}$ Pulp and Paper Research Division, Bangladesh Council of Scientific and Industrial Research, Dhaka-1205, Bangladesh \\ ${ }^{3}$ Soil, Agronomy and Environment Section, Biological Research Division, Bangladesh Council of Scientific and Industrial \\ Research (BCSIR) Dr. Qudrat-i-Khuda Road Dhanmondi, Dhaka-1205, Bangladesh
}

\begin{abstract}
Bangladesh is a South Asian developing country. The constant GDP growth of last few years makes it a lower middle income country. In the recent years, government is focusing on the industrial development in place of agricultural based economy. Therefore, surface water is affecting more in the industrial zone due to unplanned industrial development and lack of environmental safety program. In this study, surface water pollution and hydro-chemical affect of Dhaleshwari river was observed. Some water quality parameters like $\mathrm{pH}$, DO, TDS, salinity, conductivity was observed. According to the $\mathrm{pH}$ data, all the four observed stations are slightly alkaline (7.43-7.70), DO level was near the lower permissible limit (3.45-4.68 mg/l), TDS was in the permissible limit according to the FAO (472-501 mg/l), salinity also in the permissible limit (0.04-0.05\%) and conductivity value was prone to the danger level $(944-1001 \mu \mathrm{s} / \mathrm{cm})$. Pearson correlation showed that all parameters are positively correlated at $1 \%$ level. These data indicate that, Dhaleshwari river is vulnerable to pollution. Therefore, the authority should take strict environmental safety program for recently shifted tannery industries.
\end{abstract}

*Corresponding author e-mail: shahinjnu005@gmail.com

\section{Fish species diversity of Halti beel fish sanctuary and income status of fishermen}

\author{
M. A. B. Siddique ${ }^{*}$ M. B. Alam, M. A. Hussain, M. M. Alam and F. A. Flowra \\ Department of Fisheries, University of Rajshahi, Rajshahi-6205, Bangladesh
}

\begin{abstract}
The study was conducted from July 2015 to May 2017 in Halti Beel fish sanctuary of Natore district. The sanctuary was established by the Noldanga Upazila Fisheries Office, Department of Fisheries (DoF) and managed by the Community Based Fisheries Management approach where 190 fishers were involved. The management status of the sanctuary was found satisfactory in all aspects. It was recorded that only 29 fish species were available in Halti Beel before establishment of fish sanctuary whereas a total of 67 fish species (58 native fish species and 09 exotic fish species) were recorded at present belonging 10 orders and 24 families which indicating a good impact of the sanctuary. The most dominant orders were recorded as Cypriniformes (34.34\%) having 18 species of 03 families, Siluriformes (30.54\%) having 16 species of 07 families and Perciformes (11.47\%) having 13 species of 07 families. Out of total catch, native fish species were found to account for $91.08 \%$ while exotic fish species for $8.92 \%$. Before introducing fish sanctuary, monthly income of $89.47 \%$ fishers was within Tk. 3000/- which increased up to Tk. 8000/- and Tk. 10000/- among 39.47\% and 28.98\% fishers respectively now a days.
\end{abstract}

*Corresponding author e-mail: absiddique.dof@gmail.com 


\title{
Climate change and sea water intrusion in selected coastal areas of Bangladesh: impacts on water quality
}

\author{
M. F. Sarder, M. S. Isalm and M. G. Mostafa* \\ Institute of Environmental Science, University of Rajshahi, Rajshahi 6205, Bangladesh
}

\begin{abstract}
The water quality in the coastal region is affecting by various climatic (i.e. temperature, humidity, precipitation) as well as some anthropogenic factors. The study was conducted to investigate the impacts of climate change and sea water intrusion on water quality at Kalapara in Patuakhali district, a central coastal area of Bangladesh. The study has collected some meteorological (e.g. temperature, humidity, rainfall) and physical data (e.g. water level, salinity) from 1975 to 2015 from BMD (Bangladesh Meteorological Department), BWDB (Bangladesh Water Development Board) and BIWTA (Bangladesh Inland Water Transport Authority), respectively. The surface and ground water samples of the pre-monsoon, monsoon, and post-monsoon seasons were collected from the selected locations in the study areas in 2016. Major physicochemical parameters of the water samples were analyzed in the laboratory using various standard methods of analysis. The study also determined the Arithmetic Quality Index (AQI) to assess the existing water quality of the area. The metrological data analysis results from 1975 to 2015 illustrate that maximum average temperature has increased about $1.3^{\circ} \mathrm{C}$. The results illustrated that an increasing trend in the average temperature, rainfall and relative humidity have shown, which were about $0.7^{\circ} \mathrm{C}, 50 \mathrm{~cm}$ and $5 \%$, respectively. The water level increasing trend of the same area was about $0.1 \mathrm{~m}$ from 1991 to 2009 and salinity was also found increases in the area. The water samples analysis results exemplify that most of the tube wells are suitable for all purpose uses and the surface water even estuarine seawater are suitable for domestic or agricultural purposes. However, in the pre-monsoon, all the waters were unfit for any purpose uses due to higher amount salt water intrusion. Further studies on this issue should have to be done to create a sustainable and eco-friendly coastal water resource.
\end{abstract}

*Corresponding author e-mail: mostafa_ies@yahoo.com

\section{Physicochemical and microbial characterization of green and red chili: a comparative study}

\author{
$\underline{\text { M. Rahman }}^{1,2 *}$, M. $\operatorname{Razzak}^{1}$, M. Z. I. Mollah ${ }^{1}$, A. Z. M. Salahuddin ${ }^{2}$, A. H. M Kamal ${ }^{1}$ and R. A. Khan $^{1}$ \\ ${ }^{1}$ Institute of Radiation and Polymer Technology Bangladesh Atomic Energy Commission, Dhaka 1000, Bangladesh \\ ${ }^{2}$ Department of Nuclear Science \& Engineering, Military Institute of Science and Technology, Dhaka 1216, Bangladesh
}

\begin{abstract}
Chili is famous for medicinal properties and health benefits. This investigation involved a comparative study between green and red chili powder based on heavy metals, nutritional value and microbial facts. Red chili powder was collected from local market of Dhaka, Bangladesh. Fresh green chili was collected from local market and then, cleaned, blanched and treated with 500 ppm potassium metabisulphite (KMS), $1 \% \mathrm{CaCl}_{2}$ solution and dried by mechanical drying process for better result. Flame Atomic Absorption Spectrometry (FAAS) was employed for heavy metal detections. Green chili powder showed $4.69 \mathrm{pH}, 7.19 \%$ moisture, $9.78 \%$ ash, $3.15 \%$ fat, $8.6 \%$ protein. The maximum levels of $\mathrm{Cr}$ and $\mathrm{Cd}$ found in green chili powder $0.2526 \& 0.0403$ $\mathrm{mg} / \mathrm{kg}$ respectively whereas, $\mathrm{Zn}$ and Fe were found to be 0.0852 and $25.36 \mathrm{mg} / \mathrm{kg}$. Red chili powder showed $7.86 \% \mathrm{moisture}$, $10.76 \%$ ash, $2.01 \%$ fat, $7.64 \%$ protein and $5.95 \mathrm{pH}$. The maximum levels of $\mathrm{Cr}$ and $\mathrm{Cd}$ found in red chili powder 0.0506 and $0.0474 \mathrm{mg} / \mathrm{kg}$ respectively whereas, $\mathrm{Zn}$ and Fe were found to be 0.3840 and $18.361 \mathrm{mg} / \mathrm{kg}$. Both powder contained concentration of $\mathrm{Pb}$ as below to the detection limit. In red chili, total bacterial count ranged from $6.710^{5}$ to $7.7610^{6} \mathrm{CFU} / \mathrm{gm}$ and total mold count was found from $1.0 \times 10^{3}$ to $3.1 \times 10^{3}$ which were higher in value than those found in green chili powder. The studied values from both red and green chili powder were below the maximum limit of WHO and FAO recommended values.
\end{abstract}

*Corresponding author e-mail: titu.fpe@gmail.com 